Florida International University FIU Digital Commons

\title{
Time Orientation in Organizations: Polychronicity and Multitasking
}

Kristin R. Sanderson

Florida International University, ksand004@fiu.edu

DOI: $10.25148 /$ etd.FI12112701

Follow this and additional works at: https://digitalcommons.fiu.edu/etd

\section{Recommended Citation}

Sanderson, Kristin R., "Time Orientation in Organizations: Polychronicity and Multitasking" (2012). FIU Electronic Theses and Dissertations. 738.

https://digitalcommons.fiu.edu/etd/738 


\section{FLORIDA INTERNATIONAL UNIVERSITY}

Miami, Florida

TIME ORIENTATION IN ORGANIZATIONS:

POLYCHRONICITY AND MULTITASKING

A dissertation submitted in partial fulfillment of the

requirements of the degree of

DOCTOR OF PHILOSOPHY

in

PSYCHOLOGY

by

Kristin Ruth Sanderson

2012 
To: Dean Kenneth G. Furton

College of Arts and Sciences

This dissertation, written by Kristin Ruth Sanderson, and entitled Time Orientation in Organizations: Polychronicity and Multitasking, having been approved in respect to style and intellectual content, is referred to you for judgment.

We have read this dissertation and recommend that it be approved.

$\begin{array}{r}\hline \text { Karl Galen Kroeck } \\ \hline \text { Victoria Pace } \\ \hline \text { Valentina Bruk-Lee } \\ \hline \text { Chockalingam Viswesvaran, Major Professor }\end{array}$

Date of Defense: August 31, 2012

The dissertation of Kristin Ruth Sanderson is approved.

\begin{tabular}{r} 
Dean Kenneth G. Furton \\
College of Arts and Sciences \\
\hline Dean Lakshmi N. Reddi \\
University Graduate School
\end{tabular}

Florida International University, 2012 


\section{DEDICATION}

This dissertation is dedicated to my parents, Ruth E. Sanderson and Leonard G. Sanderson, Jr. Thank you for always encouraging me and for teaching me that with enough hard work and persistence anything is possible. 


\title{
ABSTRACT OF THE DISSERTATION \\ TIME ORIENTATION IN ORGANIZATIONS: POLYCHRONICITY AND \\ MULTITASKING
}

by

\author{
Kristin Ruth Sanderson
}

Florida International University, 2012

Miami, Florida

\section{Professor Chockalingam Viswesvaran, Major Professor}

This dissertation consists of four studies examining two constructs related to time orientation in organizations: polychronicity and multitasking. The first study investigates the internal structure of polychronicity and its external correlates in a sample of undergraduate students $(\mathrm{N}=732)$. Results converge to support a one-factor model and finds measures of polychronicity to be significantly related to extraversion, agreeableness, and openness to experience. The second study quantitatively reviews the existing research examining the relationship between polychronicity and the Big Five factors of personality. Results reveal a significant relationship between extraversion and openness to experience across studies. Studies three and four examine the usefulness of multitasking ability in the prediction of work related criteria using two organizational samples $(\mathrm{N}=175$ and 119 , respectively). Multitasking ability demonstrated predictive validity, however the incremental validity over that of traditional predictors (i.e., cognitive ability and the Big Five factors of personality) was minimal. The relationships between multitasking ability, polychronicity, and other individual differences were also investigated. Polychronicity and multitasking ability proved to be distinct constructs 
demonstrating differential relationships with cognitive ability, personality, and performance. Results provided support for multitasking performance as a mediator in the relationship between multitasking ability and overall job performance. Additionally, polychronicity moderated the relationship between multitasking ability and both ratings of multitasking performance and overall job performance in Study four. Clarification of the factor structure of polychronicity and its correlates will facilitate future research in the time orientation literature. Results from two organizational samples point to work related measures of multitasking ability as a worthwhile tool for predicting the performance of job applicants. 


\section{TABLE OF CONTENTS}

CHAPTER

PAGE

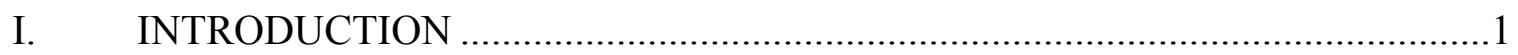

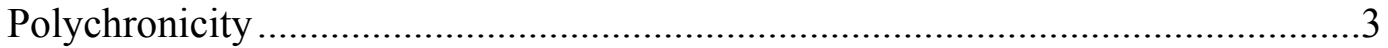

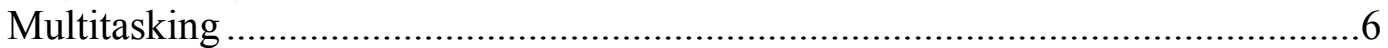

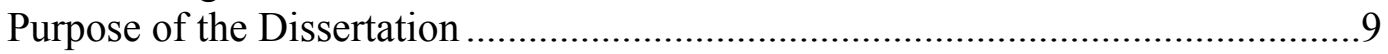

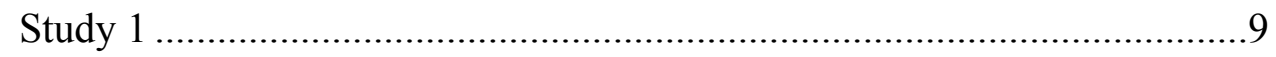

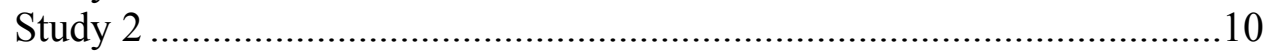

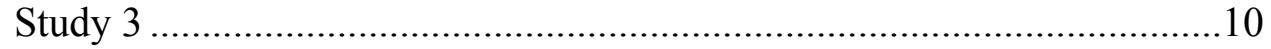

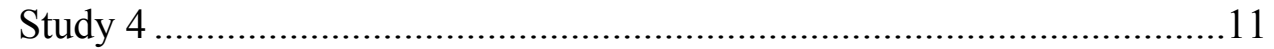

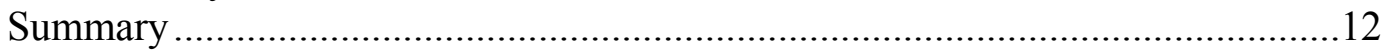

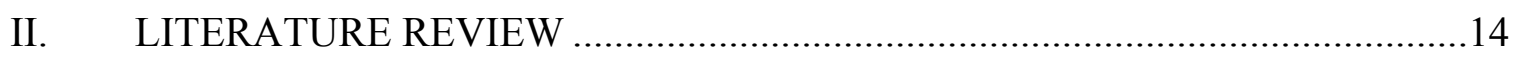

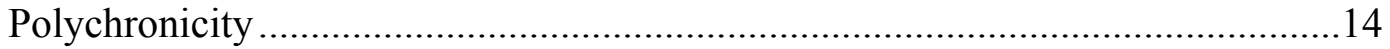

Polychronicity as a Cultural Difference.............................................................14

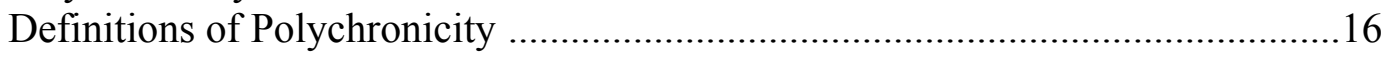

Polychronicity as an Individual Difference .....................................................18

Measures of Polychronicity ........................................................................19

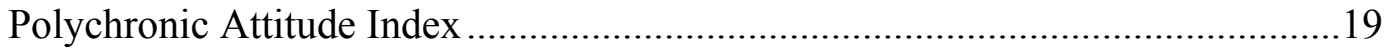

Inventory of Polychronicity Values ..............................................................19

Polychronic-Monochronic Tendency Scale .........................................................20

Multitasking Preference Inventory ……………….......................................20

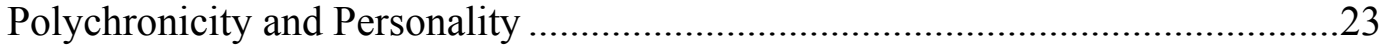

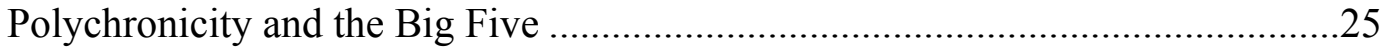

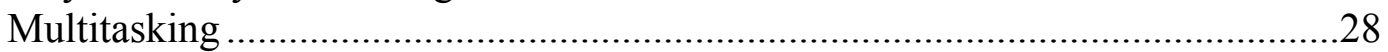

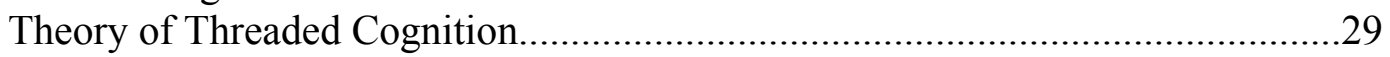

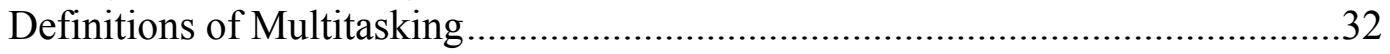

Multitasking ability as an Individual Difference ................................................33

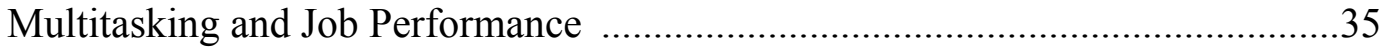

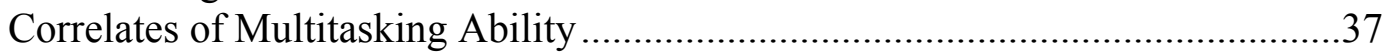

Cognitive Predictors of Multitasking ....................................................................

Non-Cognitive Individual Differences and Multitasking ......................................38

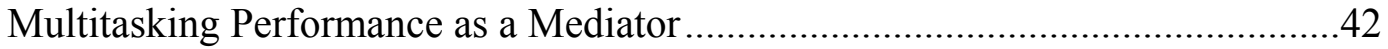

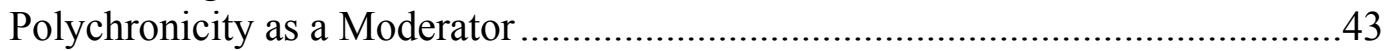

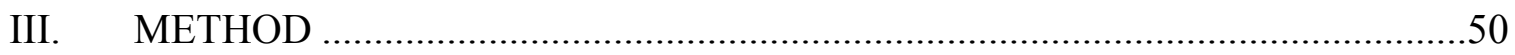

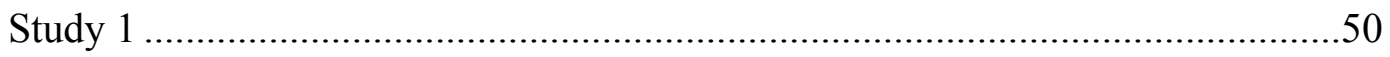

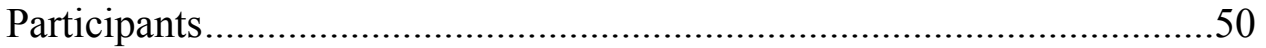

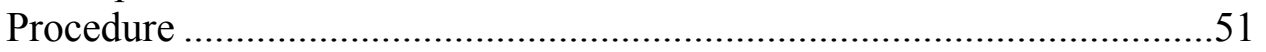

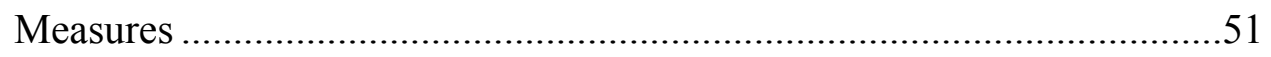

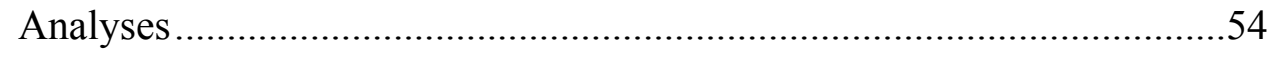

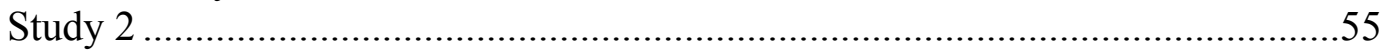

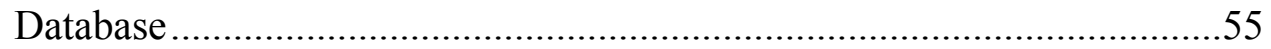




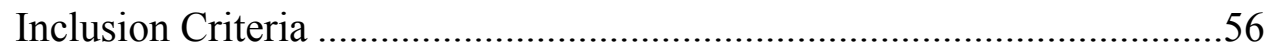

Meta-Analytic Procedure …………………………………...................57

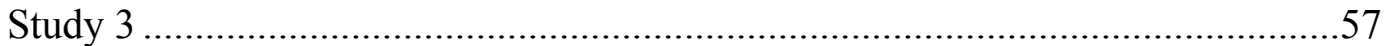

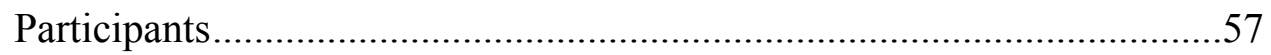

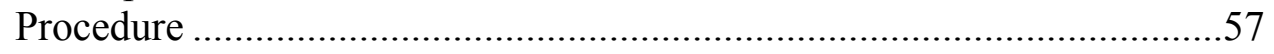

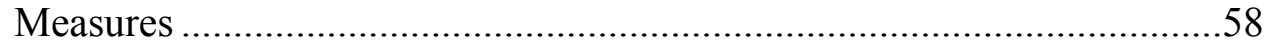

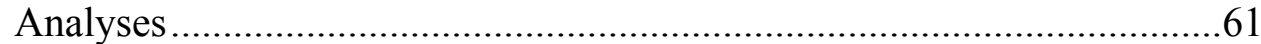

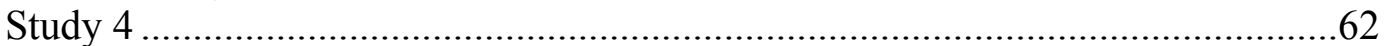

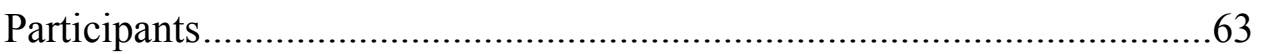

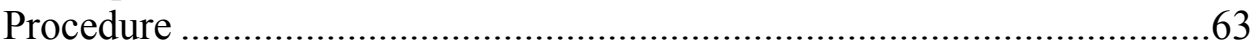

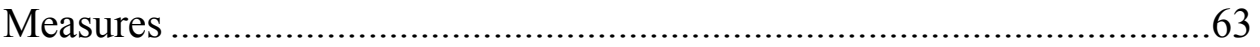

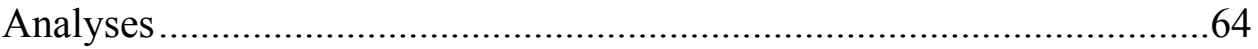

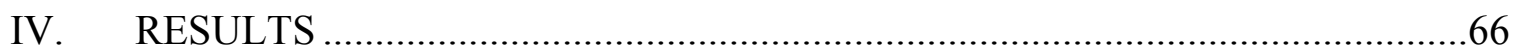

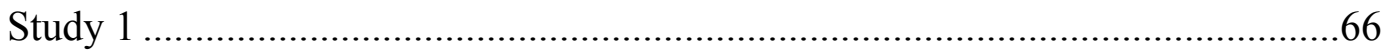

Descriptive Statistics.........................................................................66

Principal Components Analysis ............................................................68

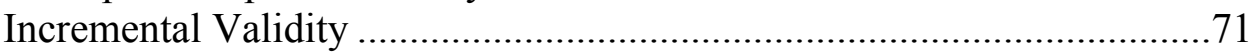

Test of Competing Models........................................................................72

Correlations between Polychronicity and the Big Five ………………...... 74

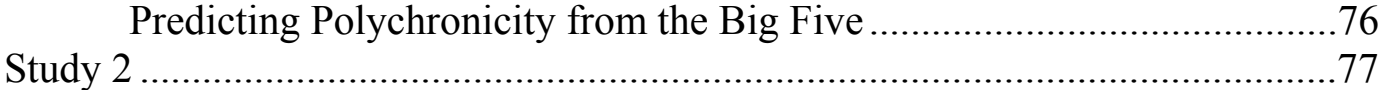

Observed Correlations .............................................................................

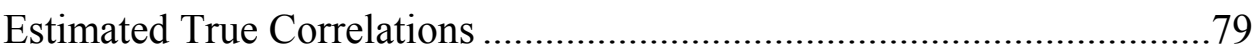

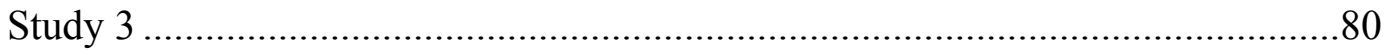

Correlations among Key Variables ........................................................8 80

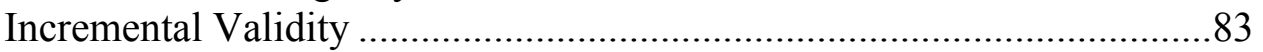

Multitasking Performance as a Mediator ...................................................84

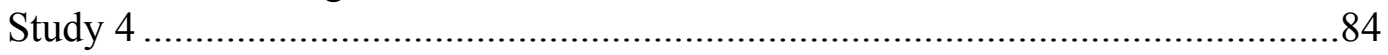

Correlations among Key Variables .........................................................85

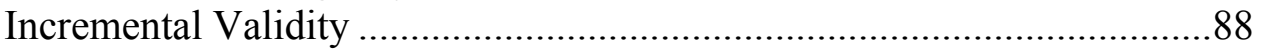

Multitasking Performance as a Mediator ..................................................8

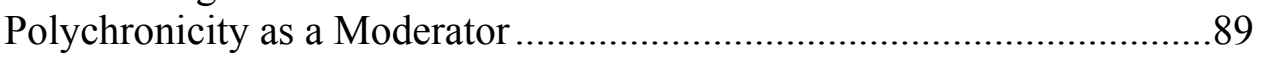

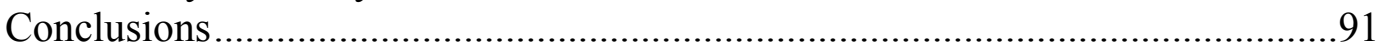

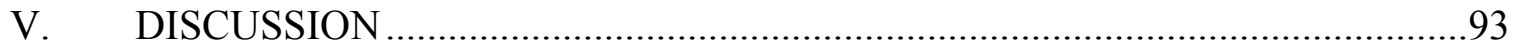

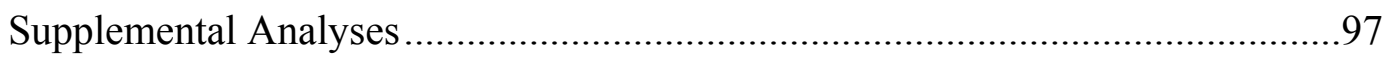

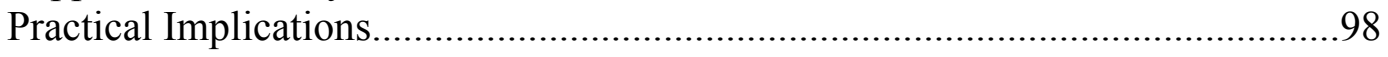

Strengths and Limitations ............................................................................102

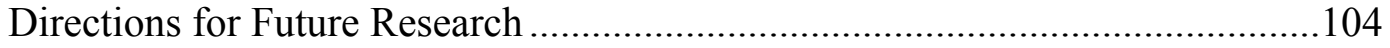

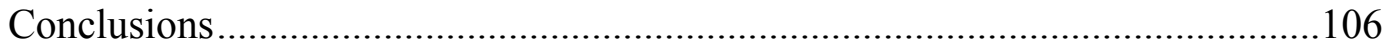

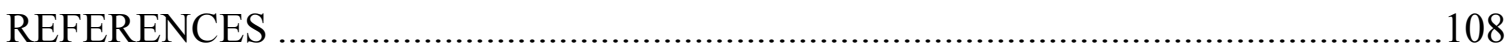

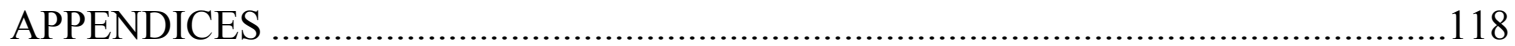




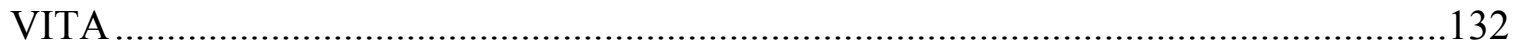




\section{LIST OF TABLES}

TABLE

PAGE

1. Correlations among Polychronicity Scales and the Big Five. .68

2. Pattern Matrix for Scale Items

3. Communalities for Scale Items ............................................................... 70

4. Study 1 Correlations between Polychronicity, Dutifulness, and Achievement Striving .75

5. Predicting Polychronicity Scales from the Big Five. .77

6. Meta-Analysis of Polychronicity and Personality .79

7. Frequency Weighted and Sample Size Weighted Reliabilities...........................79

8. Correlations Among Key Variables in Study 3 .............................................82

9. Incremental Validity of Multitasking Ability for the Criteria of Multitasking Performance and Overall Performance in Study 3

10. Correlations Among Key Variables in Study 4

11. Incremental Validity of Multitasking Ability for the Criteria of Multitasking Performance and Overall Performance in Study 4 .88

12. Moderating Effects of Polychronicity on the Multitasking Ability-Performance Relationships....

13. d Values for Scores on Polychronicity Scales by Age, Gender, and Race from Study 1

14. Incremental Validity of IPV. 120

15. Incremental Validity of PAI.

16. Incremental Validity of MPI

17. Incremental Validity of PMTS.

18. Incremental Validity of IPV, PAI, and PMTS over MPI. 130 


\section{CHAPTER I: INTRODUCTION}

We live in a world where managing conflicting priorities has essentially become a necessity. The proliferation of technology into our lives allows us to be interrupted by emails, phone calls, and text messages in a mobile workplace that we carry with us wherever we go. Today's workers are constantly interrupted in jobs that require juggling multiple competing demands at any given time. The ability to switch attention between multiple tasks at any time is now a common component of many job descriptions and critical job demands (Ishizaka, Marshall, \& Conte, 2001). The behavioral manifestation of this ability, referred to as multitasking, is commonly identified as a key competency in job analyses (Kinney, Kung, Walvoord, \& Shoemaker, 2010). Some argue that multitasking ability is now essential for nearly all jobs, and organizations should strive to identify individuals with the capability to successfully multitask in order to maximize job performance (Buhner, König, Pick \& Krumm, 2006).

The assumption that time is tangible is an important one in organizational research (Palmer \& Schoorman, 1999) in that time can be managed, saved, wasted, and spent and is thus an asset, both monetarily and non-monetarily, to the individual and to the organization. Understanding differences in time orientation and how individuals respond to the conflicting demands of multiple tasks may be an important consideration in predicting job performance in today's work environment. Accordingly, temporal research in many different fields of study is on the rise (Ancona, Okhuysen, \& Perlow, 2001). However, until very recently, research in the area of time orientation as a predictor of performance in the context of organizations has been scant. 
Early research identifies time orientation as an important dimension in organizational culture (Schriber \& Gutek, 1987) and conceptualizes time orientation as an individual difference consisting of many components including schedules and deadlines, punctuality, future orientation, time boundaries, quality versus speed, synchronization and coordination of work with others through time, awareness of time use, work pace, allocation of time, sequencing of tasks through time, intraorganizational time boundaries, autonomy of time use, and variety versus routine (Schriber \& Gutek, 1987), while other conceptualizations of time orientation are more parsimonious consisting of time urgency, time awareness, and time use (Landy, Rastegary, Thayer, \& Colvin, 1991). Time urgency has been identified as an individual difference variable with important implications for behavior in organizations (Landy et al., 1991). Time orientation is a broadly defined construct, but in the existing time orientation literature, two relevant streams of research have emerged: polychronicity and multitasking.

The focus of this dissertation is on two time-oriented variables: polychronicity (i.e., preference for engaging in two or more tasks simultaneously) and multitasking (i.e., the behavior of engaging in multiple tasks essentially at the same time). Whereas multitasking refers to an ability to handle multiple tasks and switch between them as needed for successful performance, polychronicity refers to a preference for such working environments (Poposki \& Oswald, 2010). Although related, multitasking and polychronicity are distinct constructs (Branscome \& Grynovicki, 2007; Ishizaka et al., 2001; Kantrowitz \& Kinney, 2009; König, Buhner \& Murling, 2005; Oberlander, 2008; Poposki et al., 2009a; Poposki \& Oswald, 2010). 


\section{Polychronicity}

Individuals who exhibit a preference to attend to one task at a time are referred to as monochronic, whereas individuals who exhibit a preference to attend to multiple tasks at a time are referred to as polychronic. These points are two ends of a continuum of time orientation (Bluedorn, Kaufman \& Lane, 1992; Conte, Rizzuto \& Steiner, 1999). The definition of polychronicity has evolved over the years. In the early conceptualizations, the term polychronicity referred to two main components: the extent to which individuals prefer to engage in two or more tasks at the same time, and the belief that this preference is the most effective way to get things done (Bluedorn et al., 1992). In latter conceptualizations (e.g., Poposki \& Oswald, 2010), the two components have been disentangled and polychronicity has been restricted to the extent to which individuals prefer to engage in two or more tasks at the same time.

Polychronicity was first introduced in studies of culture with an emphasis on an individual's orientation towards time, an important dimension in which cultures are thought to differ (Hall, 1959; Palmer \& Schoorman, 1999). Polychronicity was originally thought to be reflection of cultural values. E. T. Hall's (1959) original definition of polychronicity suggested that the construct is comprised of two components: the preference for multitasking, and the belief that multitasking is the best way to get things done.

Subsequently, the definition was refined by multiple researchers to specifically include mental processes (Persing, 1999) and providing clarity into the multi-dimensional structure of the construct (Palmer \& Schoorman, 1999). In 1999, Bluedorn, Kalliath, Strube and Martin developed a well-known scale and definition of polychronicity, "the 
extent to which people in a culture: prefer to be engaged in two or more tasks or events simultaneously; and believe their preference is the best way to do things", (p. 207).

More recently, polychronicity has been studied as an individual difference variable, but there are still some discrepancies related to the structure of the construct (Lindquist \& Kaufman-Scarborough, 2007). The latest definition of polychronicity, developed by Poposki \& Oswald (2010) focuses on polychronicity as an individual difference, and restricts the construct to preference only: "a non-cognitive variable reflecting an individual's preference for shifting attention among ongoing tasks, rather than focusing on one task until completion and then switching to another task" (p. 250).

The lack of conceptual clarity in the definition of polychronicity has been cited as an impediment to research on polychronicity (e.g., Palmer \& Schoorman, 1999; Poposki \& Oswald, 2010). The relationship of polychronicity with a variety of outcomes has yielded mixed results to be reviewed in detail in the sections below. One possible reason for the equivocal results is that the four commonly used scales to measure polychronicity are based on slightly different conceptual definitions. Some conceptualize polychronicity as a cultural difference (Bluedorn et al., 1999; Kaufman, Lane \& Lindquist, 1991) with two dimensions including preference and the belief that multitasking is the best way to accomplish tasks. Other scales are based on polychronicity as a multi-dimensional construct including five facets (Lindquist \& Kaufman-Scarborough, 2007) while others focus on polychronicity as strictly the preference to switch attention among tasks (Poposki \& Oswald, 2010). Clarification of the construct, as well as an investigation of the overlap among measures of polychronicity is necessary for meaningful conclusions to be drawn from future research. 
Polychronicity is now studied as an individual difference variable. Polychronicity has more recently received more attention as increasingly educated workers have begun to prefer jobs that can employ a variety of their skills as well as maintain their interest by offering a multitude of diverse responsibilities (Lindbeck \& Snower, 2000). This preference has largely changed the nature of specialized work, making employees more versatile, and the ability to multitask more important than ever. Polychronicity is thought to be an especially useful predictor of constructs related to time orientation as it combines an individual's stable predisposition of preference for multitasking as well as knowledge of past success in multitasking environments (Poposki \& Oswald, 2010).

The preference for multitasking, polychronicity, is thought to be a stable trait persisting over time (Conte \& Jacobs, 2003; Landy et al., 1991; Slocombe \& Bluedorn, 1999). Existing research has linked polychronicity to a variety of differences in personality (for example, Conte \& Gintoft, 2005; Conte \& Jacobs, 2003; Conte et al., 1999; Ishizaka et al., 2001; Kantrowitz, Grelle, Beaty \& Wolf, 2012; Schell \& Conte, 2008; Taylor, Locke, Lee \& Gist, 1984). Although the research examining the relationship between polychronicity and personality is somewhat limited, existing findings show that polychronicity is related to a variety of non-cognitive predictors, including some dimensions of the Big Five conceptualization of personality. The Big Five factors of personality provide an integrative framework for the measurement of personality encompassing many facets of personality (Goldberg, 1990).

Polychronicity has proved to be a valuable construct as it provides unique predictive validity in multiple organizational outcomes above and beyond that of personality, cognitive ability, and demographic characteristics (Conte \& Jacobs, 2003; 
Conte \& Gintoft, 2005). Some researchers suggest that the fit between the time oriented preferences of an individual and the employing organization is predictive of performance (König \& Waller, 2010). Results of research examining polychronicity as a predictor of job performance have been mixed. Some studies found that polychronicity predicts qualitative and quantitative productivity (Taylor et al., 1984), objective and subjective performance criteria (Kantrowitz et al., 2012), perceptual speed and accuracy (Kanrowitz \& Kinney, 2009), and overall organizational performance (Onken, 1999). Yet other studies have not found polychronicity to predict job performance (Hambrick, Rench, Jones, Oswald, \& Moon, 2007; Kinney, 2007). Furthermore, polychronicity is related to employee job satisfaction (Arndt, Arnold \& Landry, 2006; Hecht \& Allen, 2005). This brief review of the literature on polychronicity clearly suggests that it is an important variable in organizational contexts, and in need of further exploration.

\section{Multitasking}

Multitasking refers to switching between multiple tasks, shifting attention between tasks that may occur over a short time span (Oswald, Hambrick \& Jones, 2007). A common component of definitions of multitasking is the requirement of task switching in relatively short periods of time and the shifting of cognitive resources (e.g., Delbridge, 2000; Oswald et al., 2007; Salvucci \& Taatgen, 2011). One frequently referenced definition describes multitasking as "accomplishing multiple task goals in the same time period by engaging in frequent switches between individual tasks" and is characterized by making progress towards multiple goals over time (Delbridge, 2000, p. 1). Delbridge (2000) identified three critical components of multitasking: task switching, the degree of uncertainty regarding when task switching will be required, and salient time pressures. 
An environment requiring multitasking hinders the completion of any one task, which can itself foster a sense of urgency (Delbridge, 2000). According to this three component conceptual framework, interruptions in work necessitate the re-prioritization of efforts towards task accomplishment (Delbridge, 2000). These three components are critical to the definition of multitasking and in considering when assessing multitasking performance is appropriate in an organizational context. Differences in multitasking involve both the actual time (objective differences) and the perceived time (subjective differences) lapsed between switching tasks (Oswald et al., 2007). A review of the research shows the necessity to multitask generally hinders task performance (Kinney, 2007).

Multitasking is commonly identified as a key competency in job analyses, and is becoming more critical as the complexity and simultaneous demands of jobs increase. The utility of assessing multitasking rests on the assumption that there are individual differences that determine whether a person can perform effectively in an environment demanding multitasking (Delbridge, 2000). Research has shown that there are differences in the way individuals react to the pressures of multitasking due to non-cognitive differences (Oswald et al., 2007) and other differences that are based on cognitive differences such as cognitive ability, working memory, fluid intelligence, and the ability to prioritize and sequence tasks (e.g., Delbridge, 2000; Hambrick, Oswald, Darowski, Rench \& Brou, 2010; Ishizaka et al., 2001; Kinney, 2007; König et al., 2005). In light of the nature of the jobs in the current work environment, it is likely that an individual who demonstrates effective multitasking performance is also likely to successfully multitask on the job, and thus receive favorable ratings of overall job performance. However, much 
of the existing research has relied on assessing the multitasking ability of undergraduate students and relating it to academic performance measures, clearly a limitation to the usefulness of this research for organizational applications. The short duration of time involved in experimental studies limits the ability to draw meaningful and practical conclusions from the results of these studies.

The typical assessment used to measure multitasking ability involves a computerbased simulation presenting multiple task demands and the requirement to switch tasks frequently at unpredictable intervals in the presence of imposed time constraints. The goal of a multitasking assessment is to measure task performance while the participant is both focusing attention on one task, and continuing to attend to a second task (Delbridge, 2000). The assessments are designed to mimic the types of multitasking behaviors essential for successful performance on the job, reflecting the actual work environment. The intention of the simulation is to determine whether or not the test taker has the ability to effectively perform in a multitasking environment. A test taker's performance in the multitasking simulation is typically measured by the degree of speed and accuracy with which the individual completes problem solving and information retrieval tasks (Delbridge, 2000). Thus, it is likely that an individual who demonstrates proficiency in multitasking ability on the assessment is also likely to perform well in aspects of the job requiring multitasking performance, but further research utilizing organizational samples is needed. 


\section{Purpose of the Dissertation}

This dissertation consists of four studies designed to assess the nomological networks and outcomes of two constructs measuring the preference and behavioral manifestation of time orientation: polychronicity and multitasking.

Study 1. The purpose of study one is to investigate the nomological network of polychronicity. Specifically, four commonly used scales to measure polychronicity were administered to participants and scores were factor analyzed to determine how the commonly used measures overlap. The analysis was restricted to specific measures of polychronicity, and did not include broader measures of time orientation. The confirmatory factor analysis tests competing models and reveals the subcomponents of polychronicity, helping to provide a more precise definition of polychronicity as a construct. The different dimensions of polychronicity are examined across the four scales to determine the conceptual overlap. The common variance across dimensions and scales is identified, as well as the common variance across scales for specific dimensions. Additionally, the scale specific variance is identified.

In addition to investigating the internal structure of the construct, study one examines the external personality correlates of polychronicity. Study one sought to examine individual difference correlates of multiple measures of polychronicity within the Big Five framework of personality. Specifically, I tested in study one whether the four commonly used scales of polychronicity have similar patterns of correlations with the Big Five factors of personality. A deeper understanding of the nomological network of polychronicity serves to clarify further its construct validity. 
Study 2. As a follow up to the examination of external personality correlates of polychronicity examined in study one, study two investigates the relationship between polychronicity and external personality correlates, specifically the Big Five factors of personality. In recent years, many studies have examined individual difference correlates of polychronicity, but have presented mixed results. Study two aimed to clarify the somewhat inconclusive relationships between polychronicity and the Big Five factors of personality (i.e., conscientiousness, extraversion, neuroticism, agreeableness, and openness to experience) by the results of existing studies to a meta-analysis. The metaanalysis is a method that interprets results from previous research and integrates them into a united framework resulting in a deeper understanding of the external correlates of polychronicity. The quantitative review of the existing literature provides clarity regarding the relationship of polychronicity and the Big Five factors of personality, to further establish the nomological network of polychronicity.

Study 3. Multitasking has become an essential skill for successful performance in a variety of jobs, sparking researchers and selection consultants to examine multitasking ability as a predictor of job performance in multitasking environments. Multitasking has been conceptualized as an ability, establishing it as a construct distinct from preference. Recent research has called for further investigation of the relationships between multitasking ability and non-cognitive variables (Poposki, Oswald \& Chen, 2009b), and study three answers this call by examining the relationships between multitasking ability and the Big Five, as well as cognitive ability. Study three also aims to examine the usefulness of multitasking assessments in the prediction of job performance in an organizational sample. Specifically, study three assesses the predictive validity of 
multitasking ability for both multitasking performance and overall job performance in an organizational sample of employees, as most of the extant literature relies on student samples. Study three examines the relationships between multitasking ability and individual difference variables such as cognitive ability and the Big Five factors of personality. The incremental validity of multitasking ability above and beyond the effect of other traditional predictors (i.e., Big Five and cognitive ability) in predicting both supervisor ratings of multitasking performance and overall job performance is assessed. Finally, supervisor ratings of multitasking performance as a mediator of the relationship between multitasking ability and supervisor ratings of overall job performance is tested.

Study 4. Similar to study three, study four investigates the following in a second organizational sample: 1) the relationship between multitasking ability, preference for multitasking, and job performance, 2) the relationships between multitasking ability and individual difference variables such as cognitive ability and personality, 3) the incremental validity of multitasking ability above and beyond the effect of other traditional predictors (i.e., Big Five and cognitive ability) in predicting both supervisor ratings of multitasking performance and overall job performance, and 4) supervisor ratings of multitasking performance as a mediator of the relationship between multitasking ability and supervisor ratings of overall job performance. Additionally, a unique contribution of study four is a model that was developed and empirically tested where polychronicity (i.e., preference) moderates the relationship between multitasking ability and both multitasking performance as well as overall job performance. 


\section{Summary}

In this dissertation, two aspects of time orientation (polychronicity and multitasking) are explored across four studies. Study one investigates the internal factor structure of polychronicity and empirically investigates the conceptual overlap across scales. Both studies one and two empirically evaluate the external personality correlates of polychronicity, specifically the Big Five factors of personality.

Studies three and four were undertaken to explore the relationships between multitasking ability, polychronicity, cognitive ability, Big Five factors of personality, supervisory ratings of multitasking performance, and supervisory ratings of overall job performance. Studies three and four compare the nomological networks of multitasking in multiple organizational samples. The mediating role of multitasking performance is investigated in the relationship between multitasking ability and overall job performance. The validity of multitasking ability as well the moderating effects of polychronicity on the validity are explored. Finally, whether multitasking ability adds unique value beyond cognitive ability and Big Five factors of personality is assessed in both studies three and four. Study four also tests polychronicity as a moderator in the relationship between multitasking ability and both multitasking performance and overall job performance.

The next chapter provides a detailed literature review of the research on polychronicity and multitasking relevant to this dissertation. First, the history of the construct of polychronicity is recounted and a review of the definitional discrepancies and existing measures of polychronicity are provided. More detail on the various conceptualizations of polychronicity are described. Next, the literature examining the personality correlates of polychronicity, specifically the Big Five factors of personality, is 
reviewed. Then, the nomological network of multitasking ability, including its predictive validity and incremental validity over Big Five and cognitive ability, is discussed.

Finally, a review on the distinction between multitasking and polychronicity is given. A summary of the importance of polychronicity as relevant to organizational outcomes is provided as well as further justification behind the proposed moderating relationship (i.e., preferences moderating the ability-performance relationship). 


\section{CHAPTER II: LITERATURE REVIEW}

In this chapter I will review the literature on time orientation in organizations and develop the hypotheses that will be tested in this dissertation. I will begin with a discussion of polychronicity to provide the background for the purpose of studies one and two. Next, I will review the research on multitasking to develop the reasoning for studies three and four. Additionally, I will discuss the relationship between polychronicity and multitasking, which will be empirically investigated in study four.

\section{Polychronicity}

Polychronicity, the preference for multitasking, is seen as a continuum ranging from monochronic (preference to engage in only one task at a time until completion) to polychronic (preference to engage in multiple tasks at the same time) with a wide range of gradation in between these two end points (Bluedorn et al., 1992). The "same time" can literally refer to simultaneous completion (e.g., eating dinner while watching television), or can refer to switching between two or more tasks within a given time period (e.g., eating dinner, being interrupted by a telephone call, and then finishing dinner) (Bluedorn \& Jaussi, 2007). The term polychronicity does not imply that more is accomplished when switching tasks, but simply refers to the preference for engaging in multiple tasks simultaneously, or switching between tasks until they are completed (Bluedorn \& Jaussi, 2007).

Polychronicity as a Cultural Difference. As mentioned in the first chapter, polychronicity was originally studied as a cultural difference (Hall, 1959; Palmer \& Schoorman, 1999). The early research found that there are differences across cultures in perceptions of time use, and those differences can affect work behavior (Hall, 1959). 
Originally studied by E. T. Hall (1959), the term polychronicity was defined as consisting of two distinct components: the preference for multitasking, and the belief that multitasking is the "right" way to accomplish tasks.

In 1990, polychronicity was defined as "a culture in which people value, and hence practice, engaging in several activities and events at the same time. Monochronic cultures are more linear than polychronic cultures in that people prefer to be engaged in one thing at a time" (Hall \& Hall, 1990, p. 13). These researchers studied cultural orientations towards time and found that polychronic cultures tend to be spontaneous, relationship oriented, and borrow/lend property with others freely. In contrast, monochronic cultures are task focused, governed by schedules and plans, value promptness, and express awareness and worry about the privacy of others.

Schein (1990) asserted that time orientation is an important consideration in the study of organizational culture, and it is integral in communicating the norms and expectations of the workplace (Schriber \& Gutek, 1987). Polychronic cultures have been compared to organic organizations in that they are fluid and flexible environments marked by a widespread flow of information and communication (Onken, 1999). Slocombe and Bluedorn (1999) present data showing that the greater perceived fit between individual polychronicity and time oriented expectations, the greater the employee's organizational commitment. Another study found perceived fit of polychronicity between the individual and the organization to be related to job satisfaction (Arndt et al., 2006). It is thought that to the extent possible, individuals manage workloads and seek work environments in accordance with their preferences for polychronicity (Conte et al., 1999). 
The foundational research on polychronicity, conducted by E. T. Hall, provides a model in which the three dimensions typically cluster. The preference for multitasking, polychronic time orientation, is associated with high context communication and time intangibility. Conversely, monochronic time orientation is associated with low context communication and time tangibility, which will be described in further detail below. Thus, according to Hall, the term polychronicity generally describes not only the preference for multitasking, but also one's communication style and perspective regarding the nature of time. A construct validation study found polychronicity to be negatively related to organization and general hurry, but provided evidence that polychronic individuals do not complete tasks more slowly than monochronic individuals (Conte et al., 1999). One dimension on which polychronic individuals are thought to differ from monochronic individuals is the subjective perception of time structure (Bond \& Feather, 1988). Individual variability in perceptions of time structure result in viewing time as either uninterrupted and smooth or as rigidly "structured and purposive" (Bond \& Feather, 1988, p. 321).

Definitions of Polychronicity. In 1999, Persing expanded on Hall's original definition of polychronicity to address mental tasks. Persing's definition states that polychronicity involves the preference to engage in several tasks at the same time, which is not limited to visible tasks, but also includes mental labor or "tasks of thought." Persing's definition also states that polychronicity is a "relatively enduring preference" (Persing, 1999, p. 365). Palmer and Schoorman also further refined Hall's original definition of polychronicity in 1999 to include the multi-dimensional structure of the construct identifying three independent facets including preference for time use, time 
tangibility, and context. These facets were included in Hall's original research on polychronicity, but Palmer and Schoorman investigated the definitions and interrelationships among these facets further.

The first facet, time use preference is defined as the degree to which individuals or cultures prefer to multitask. The second facet, context, refers to how the meaning of a message is conveyed. For low context, the direct meaning is obvious in the content and there is no need for inference. Alternatively, in high context, the importance of the message is in the environmental cues, or how the message is conveyed. The third facet, time tangibility, refers to the notion that time is a concrete commodity (Hall, 1959).

Palmer \& Schoorman (1999) investigated the relationship among the three facets and proposed a model of temporality in which the three dimensions described above are not correlated. These researchers factor analyzed scores on a commonly used measure of polychronicity, and provide evidence that the three dimensions are in fact independent of each other. In the culturally diverse sample tested for this study, all eight types proposed in the model of temporality emerge, representing combinations of the three facets.

In 1999, Bluedorn and colleagues defined polychronicity as a cultural variable as "the extent to which people in a culture: prefer to be engaged in two or more tasks or events simultaneously; and believe their preference is the best way to do things" (p. 207). In this conceptualization, polychronicity consists of the preference for engaging in multiple tasks simultaneously as well as switching attention between tasks. Many of the prominent definitions up to this point considered polychronicity to be a cultural variable, and included not only the individual preference for multitasking but also the belief that others should multitask (Poposki \& Oswald, 2010). The lack of conceptual clarity in the 
definition of polychronicity has been cited as an impediment to research on polychronicity (e.g., Palmer \& Schoorman, 1999; Poposki \& Oswald, 2010). The relationship of polychronicity with a variety of outcomes has yielded mixed results to be reviewed in detail in the sections below.

Polychronicity as an Individual Difference. Currently, polychronicity is commonly studied as an individual variable. As such, researchers have adapted the definitions of polychronicity to be applicable to the individual level, but largely maintaining a similar dual component structure. However, some researchers argue that polychronicity is a multifaceted construct and includes the following five dimensions: preference for polychronic versus monochronic behavior, the degree to which preferences match behavior, level of comfort with behavior, preference for juggling multiple activities simultaneously, and perception of preferred behavior as the best way to accomplish tasks (Lindquist \& Kaufman-Scarborough, 2007).

Recently, Poposki and Oswald (2010) sought to provide definitional clarity by revising the definition of polychronicity to be more precise, and more oriented towards measuring polychronicity on an individual level. Poposki and Oswald argue that although one's cultural values largely influence beliefs, individual preferences may differ from cultural norms. Additionally, these researchers reason that personal preference and the belief that others should also comply with that preference are distinct concepts. Poposki and Oswald distinguish between preference and behavior, stating that external pressures may result in behavior (multitasking) that is not congruent with individual preferences (polychronicity), as some earlier studies have inferred polychronicity by the presence of multitasking behavior. The latest definition of polychronicity, developed by Poposki \& 
Oswald (2010) is “a non-cognitive variable reflecting an individual's preference for shifting attention among ongoing tasks, rather than focusing on one task until completion and then switching to another task" (p. 250).

Measures of Polychronicity. There are several scales used to measure polychronicity in the extant literature. In the sections below I review the most common scales: Polychronic Attitude Index (PAI), Inventory of Polychronic Values (IPV), Polychronic-Monochronic Tendency Scale (PMTS), and the Multitasking Preference Inventory (MPI). Each of the four scales reflect different definitions of polychronicity and are therefore designed to measure varying dimensions encompassed in the definitions of polychronicity. Study one aims to answer the following question: Is there a common core construct and overlap across scales used to measure polychronicity?

Polychronic Attitude Index (PAI). The 4-item Polychronic Attitude Index (PAI), developed by Kaufman and colleagues (1991) was the first published measure of individual level polychronicity and captures both the preference and expected behavior aspects of multitasking. The PAI was designed to predict polychronic consumer behavior. However, in the scale construction research, the researchers found that only one factor emerged from the four items, providing evidence for the scale as an overarching measure of polychronicity. In the scale construction research, the PAI demonstrated somewhat low internal consistency reliability estimates. Although the PAI was the first published measure of polychronicity, researchers now frequently employ other scales due to its marginally acceptable psychometric properties and advances in the field.

Inventory of Polychronicity Values (IPV). In an effort to improve on the existing measure (PAI), Bluedorn and colleagues (1999) developed a 10-item scale to measure 
polychronicity in the workplace called the Inventory of Polychronic Values (IPV), which is the most commonly used polychronicity scale in research today (Poposki \& Oswald, 2010). Criticisms of this widely used measure include that it was originally intended to measure cultural and not individual preferences, and it contains items that measure three dimensions including preference, behavior, and belief (Poposki \& Oswald, 2010). These criticisms led to the development two new measures, the 5-item PolychronicMonochronic Tendency Scale (PMTS) and the 14-item Multitasking Preference Inventory (MPI).

Polychronic-Monochronic Tendency Scale (PMTS). The PolychronicMonochronic Tendency Scale research is an extension of the PAI scale development research conducted by Lindquist and Kaufman-Scarborough (2007). The PMTS was designed to tap the latent construct of polychronicity by drawing inferences from measures of behaviors and feelings. The PMTS is designed to be an interdisciplinary measure of polychronicity intended to be non-specific to situations or contexts. The PMTS is reported to tap all five facets of polychronicity described by Lindquist and Kaufman-Scarborough (2007). However, the scale construction research and validation studies report all five items to load on one factor, providing evidence of an overarching factor of polychronicity. The PMTS was rigorously validated and has been found to be resistant to socially desirable responding (Lindquist \& Kaufman-Scarborough, 2007). These researchers suggest that the PMTS is psychometrically strong, and should replace the PAI for measurement of polychronicity.

Multitasking Preference Inventory (MPI). The Multitasking Preference Inventory (MPI), formerly referred to as POLY (Oberlander, 2008; Poposki, Oswald \& 
Brou, 2009a), is a 14-item measure developed based on Poposki and Oswald's (2010) definition of polychronicity ("a noncognitive variable reflecting an individual's preference for shifting attention among ongoing tasks, rather than focusing on one task until completion and then switching to another task", p. 250). This scale attempted to resolve some psychometric deficiencies of the PAI and IPV including the item format (i.e., references to "we" as opposed to "I"), and lack of precision in measurement of extreme levels of polychronicity (i.e., all items are geared towards a moderate level of polychronicity, Oberlander, 2008). Factor analysis in the scale development research found, as expected, all items to load on one factor representing only the preference for multitasking, and not the belief that multitasking is the best way to accomplish tasks, as articulated in Poposki and Oswald's (2010) definition.

It is suggested by the scale authors that the POLY (later referred to as the MPI) addresses the construct contamination of existing scales that measure not only preference, but also beliefs for appropriate behavior (Oberlander, 2008). Poposki and Oswald's scale development research found the MPI to be significantly correlated with the PAI and IPV, but conceptually and empirically distinct due to the definitional differences that were considered when items for each of the scales were written. Although each of the scales reviewed above were constructed based on variations of the definition of polychronicity, existing scale development evidence demonstrates that the IPV, PAI, and POLY/MPI remain highly correlated (Oberlander, 2008) suggesting that these scales all measure an overarching factor representing polychronicity.

Hypothesis 1: An overarching factor emerges from all measures of polychronicity, representing the construct of polychronicity. 
Given the variations of definitions considered in the construction of the scales reviewed above, it is hypothesized that two subfactors exist in the construct domain: the preference to multitask and the belief that multitasking is the best way to accomplish tasks. Similar to the framework proposed in the multiple commitment literature (Cohen, 2003), which presents several foci of commitment (i.e., organization, work group, union, job, etc.), I propose that there are multiple foci of polychronicity (i.e., individual, work group, team, organization, nation, etc.). That is, we can discuss polychronicity as a variable capturing differences across individuals, teams, organizations and even nations. Further, just as the theory of multiple types of organizational commitment proposes various bases for commitment (i.e., normative, affective, and continuance commitment), I propose that there are multiple bases within polychronicity (i.e., preference and belief). In combination, these two variables form a matrix of possible types of polychronicity illustrated below.

\begin{tabular}{|c|l|l|l|}
\hline \multirow{2}{*}{} & & \multicolumn{2}{|c|}{ Type } \\
\cline { 2 - 4 } & & Preference & Belief \\
\cline { 2 - 4 } & Individual ("I") & & \\
\cline { 2 - 4 } & Group ("We") & & \\
\cline { 2 - 4 } & Team & & \\
\cline { 2 - 4 } & Organization & & \\
\cline { 2 - 4 } & Nation & & \\
\hline
\end{tabular}

Although Hall (1959) and other early conceptualizations defined polychronicity as a cultural variable, this dissertation focuses on polychronicity at the individual level. Specifically, it is expected that the items from the MPI (as a consequence of the restricted definition of polychronicity), as well as some items from the IPV, PAI, and PMTS will emerge as one factor representing the preference for multitasking. A second 
factor is expected to be comprised of remaining items from the IPV, PAI, and PMTS representing the belief that multitasking is the best way to accomplish tasks.

Hypothesis 2: Two subfactors of polychronicity will emerge - preference to multitask and belief that it is the best way to accomplish tasks.

Although I hypothesized two subfactors of polychronicity, I also expected (Hypothesis 1) substantial overlap so as to justify the overall construct of polychronicity. Therefore, subsequent hypotheses focus on this overarching factor of polychronicity as my goal in the dissertation is to investigate the two time-related constructs (polychronicity and multitasking) in organizational research.

\section{Polychronicity and Personality}

Time orientation has been widely researched as an individual difference, and it is thought to be a trait difference, that is, consistent over time (Conte \& Jacobs, 2003; Landy et al., 1991; Slocombe \& Bluedorn, 1999). In fact, Conte and colleagues (1999) provided evidence of agreement on one's polychronic nature as measured by multiple independent raters familiar to the participants. Kaufman and colleagues (1991) introduced the term "time personality" to reflect individual differences in use of time, from strictly a behavioral perspective.

In 1999, Francis-Smythe and Robertson extended this construct to a multidimensional time personality to include differences in behavior, thoughts, and affect. These researchers developed a multifaceted measure of time personality, called the Time Personality Indicator, consisting of five factors representing leisure time awareness, punctuality, planning, polychronicity, and impatience. An individual scoring high on this measure of time personality is characterized by being aware of time, governed by 
deadlines, managed by plans, engaging in many activities at the same time, and is generally hurried (Francis-Smythe \& Robertson, 1999). Interestingly, this study provides evidence of significant differences in time personality across occupations, suggesting that individual differences in time personality play a role in attraction to certain occupations in support of person-environment fit theory (i.e., mechanistic organizations with highly scheduled, monochronic jobs will attract a certain type of time oriented employees, whereas organic organizations with highly flexible, polychronic jobs will attract a different type of time oriented employees).

Existing research has found polychronicity to be related to measures of many aspects of personality including the Big Five, Type A, Achievement Striving, Irritability, Goal Orientation and other facets of personality (for example, Conte \& Gintoft, 2005; Conte \& Jacobs, 2003; Conte et al., 1999; Ishizaka et al., 2001; Kantrowitz et al., 2012; Shell \& Conte, 2008; Taylor et al., 1984). Another study found various facets of personality to relate to measures of time related attitudes (Calabresi \& Cohen, 1968). These findings are not surprising, as the definition of polychronicity consists of preference for work styles, which is likely to covary with other personality traits. In general, research findings show that individuals high in polychronicity are calm in the face of stress, enthusiastic, sociable, and trusting (Kantrowitz et al., 2012). Because polychronicity is an attitude and preference towards the use of time has been found to be related to many non-cognitive variables, it is not surprising that no support has been found for the relationship between polychronicity and cognitive variables such as memory, judgment, perceptions, and cognitive styles (Goonetelike \& Luximon, 2009) and other studies have shown small correlations (both in the negative and positive 
direction) between cognitive ability and polychronicity (Conte \& Jacobs, 2003; König et al., 2005).

\section{Polychronicity and the Big Five}

Although the Five Factor Model of Personality is the most commonly used framework to assess personality, the number of research studies relating the Big Five to polychronicity is minimal. As a result of the small numbers of studies investigating these relationships, the existing literature provides inconclusive evidence, as results of these few studies are somewhat mixed. In my dissertation I quantitatively integrate the results of these studies, both published and unpublished, that have examined the relationships between the Big Five and polychronicity.

The five factors include extraversion, emotional stability (the inverse is labeled neuroticism), conscientiousness, agreeableness, and openness to experience.

Extraversion is marked by sociability, and extraverts tend to be active, talkative and friendly (Barrick \& Mount, 1991). Because of higher activity levels, extraverts may be more easily distracted by other tasks in the workplace. Furthermore, individuals high in polychronicity tend to be more concerned with social interactions than schedules and deadlines (Arndt et al., 2006). Polychronic cultures have traditionally been described as spending more time in social interactions than planning and scheduling deadlines (Hall, 1983).

Extraverts may seek out social interactions in the workplace and thus through these sporadic experiences may be more skilled at shifting attention between tasks and activities. In addition, extraverts may not be as stressed by the pressures to meet deadlines as others. In the existing literature, extraversion is consistently reported as a 
correlate of polychronicity (e.g., Conte \& Gintoft, 2005; Conte \& Jacobs, 2003;

Kantrowitz et al., 2012; König et al., 2005; Poposki et al., 2009a). Thus, I expected individuals high in levels of extraversion to exhibit a preference for engaging in multiple tasks.

Hypothesis 3: Extraversion will be positively related to polychronicity.

Individuals low in emotional stability (labeled neuroticism) are characteristically anxious, insecure, self-doubting, and exhibit ineffective coping strategies (McCrae \& Costa, 1987). Negative affect is a central characteristic of neuroticism, and neuroticism is frequently accompanied by anxiety. An important element of the ability to successfully multitask is the ability to remain calm and control anxiety that is produced by the need to switch tasks (Oswald et al., 2007). Because multitasking requires an individual to switch attention between tasks, often unexpectedly and in the presence of time pressures (Delbridge, 2000), it is expected that anxious individuals will perform less effectively in such an environment as consistent with previous research (Oswald et al., 2007).

Generally, the existing literature reports weak negative correlations between neuroticism and polychronicity, although some not reaching the level of significance (Conte \& Gintoft, 2005; Conte \& Jacobs, 2003; Oswald et al., 2007; Poposki et al., 2009a) but one study reports positive correlations using multiple measures of polychronicity (Stachowski, 2011). If individuals high in neuroticism are not successful multitaskers, it is expected that they will prefer to work on only one task at a time.

Hypothesis 4: Neuroticism will be negatively related to polychronicity.

Conscientiousness is characterized by moralistic, dutiful, methodical, and careful behaviors (Barrick \& Mount, 1991). Polychronicity is related to other constructs such as 
preference for organization and general hurry suggesting that individuals high in polychronicity are likely to be less organized than others (Conte et al., 1999; Conte, Mathieu, \& Landy, 1998). The relationship between polychronicity and conscientiousness has been studied sparsely in the extant research. Published studies report negligible relationships (Conte \& Gintoft, 2005; Conte \& Jacobs, 2003; Kantrowitz et al., 2012) and a brief review of some unpublished research reports nonsignificant or near zero relationships (Girgis, 2010; Stachowski, 2011).

Polychronic individuals may find it difficult to work effectively in highly organized settings (Arndt et al., 2006). It is likely that individuals high in conscientiousness will prefer to work on one task at a time through to completion, according to their preferred schedule. The polychronic nature of work does not seem to align with the methodical nature of conscientious workers. It is expected that individuals high in levels of conscientiousness prefer to complete one task at a time. Therefore, it is likely that conscientiousness individuals will not be polychronic.

Hypothesis 5: Conscientiousness will be negatively related to polychronicity.

Agreeableness is a personality trait marked by flexibility, trusting, tolerance, and cooperativeness (Barrick \& Mount, 1991). It is likely that flexibility will be associated with a willingness to shift attention between tasks when interrupted. Polychronicity is related to tolerance for ambiguity and unstructured work environments (Haase, Lee \& Banks, 1979). Furthermore, previous meta-analytic research has found agreeableness to be related to job satisfaction (Judge, Heller \& Mount, 2002), another attitudinal construct positively related to polychronicity (Arndt et al., 2006). Therefore it is likely that 
individuals who are highly agreeable will also exhibit a preference for completing multiple tasks at the same time, that is, highly polychronic.

Hypothesis 6: Agreeableness will be positively related to polychronicity.

Openness to experience is characterized as artistic, intelligent, open minded, cultured, and exhibiting broad interests (Barrick \& Mount, 1991). Openness to experience has not exhibited significant correlations with other attitudinal variables such as job satisfaction in past meta-analytic research (Judge et al., 2002) and is not expected to demonstrate a strong relationship with polychronicity. I have no compelling justification as to why openness to experience will be related to polychronicity, as most of the existing research reports weak non-significant positive relationships (e.g., Conte \& Jacobs, 2003; Conte \& Gintoft, 2005).

Hypothesis 7: Openness to experience will not be significantly related to polychronicity.

Study one tests hypotheses $1-7$. Study two explores hypotheses 3-7. I will now provide a discussion of multitasking, which will include a review of existing theoretical conceptualizations and seminal definitions. Additionally, below I will develop hypotheses $8-17$, which will be tested in Studies three and four.

\section{Multitasking}

As described in Chapter 1, multitasking refers to the ability for switching between multiple tasks and shifting attention between tasks that may occur over a short time span (Oswald et al., 2007). Different conceptualizations of multitasking have been developed over the years. Taken as a whole, the recently developed theory of threaded cognition (Salvucci \& Taatgen, 2011) provides an apt framework to the study of multitasking. 


\section{Theory of Threaded Cognition}

Multitasking behavior has been explained by a theory of threaded cognition, which asserts that multitasking behavior is a result of multiple threads of cognition happening simultaneously where each of the thoughts signifies a different goal of task accomplishment (Salvucci \& Taatgen, 2008; 2011). Activities can be carried out to the extent that cognitive, perceptual, and motor resources are available. The theory of threaded cognition proposes three key elements, each described as a continuum, which are relevant to the multitasking research. These three continuums provide a framework by which seemingly disparate methodologies in the multitasking research can be seen as unified efforts in the study of multitasking. According to Salvucci and Taatgen, multitasking can be most thoroughly understood when considering empirical data collected at all levels of the three continuums.

The first continuum is referred to as multitasking, where on one end, tasks are switched at intervals smaller than one second, and switched up to every few seconds. This behavior is referred to as concurrent multitasking, where tasks are occurring essentially simultaneously. Examples of concurrent multitasking provided by Salvucci \& Taatgen (2011) include talking while eating, driving or walking. The authors further explain that even when one task hinders the others, such as the interruption in talking while eating, the disruption is short and both activities continue essentially simultaneously. Concurrent multitasking can result in "confusion of task elements, cooperation between task processes, and competition for task resources" (Wickens, 1991; p. 3). 
At the other end of this first multitasking continuum proposed by Salvucci and Taatgen (2011) is behavior involving tasks that are switched only after a long duration of time has lapsed, referred to as sequential multitasking. There are a variety of multitasking behaviors that can take place in between these extreme ends of the continuum. Salvucci and Taatgen (2011) explain the reason for making this distinction is that two streams of multitasking research have emerged: concurrent multitasking ("cognitive bottlenecks" in lab experiments), and sequential multitasking (interruptions necessitating the alternation between tasks). Salvucci and Taatgen argue that these types of behaviors (i.e., concurrent and sequential multitasking) are not distinct, but variations of a unified concept of multitasking behavior.

The second dimension relevant to multitasking research delineated in the theory of threaded cognition is called the application continuum. The second continuum refers to the degree to which the measures of multitasking used in research (i.e., tasks or simulation) are representative of examples of multitasking activities in the real world context. The existing multitasking research assesses a wide range of simple tasks (highly controlled laboratory multitasking tasks) to complex applied tasks (germane real world multitasking tasks), with varying levels in between. The application continuum represents the similarity and conceptual overlap between the assessment used to draw conclusions about multitasking ability and the real world application of multitasking ability. An example of this range of tasks as provided by Salvuuci and Taatgen is writing and sending an email (applied task), interacting with a computer including typing and operating the mouse (basic task), and editing text on a computer (in the middle of the application continuum between applied and basic tasks). 
The third continuum described in the theory of threaded cognition is that of abstraction, which "speaks to the theories that we develop about these task domains, as well as the particular data and measures used to validate these theories" (Salvucci \& Taatgen, 2011, p. 14). The third continuum refers to the level of detail in data collection and analysis of multitasking research. According to Salvucci and Taatgen, in the study of multitasking behavior, the continuum of abstraction can range from the fine-grained cognitive information, to other "bands" including biological ("neural and physiological processes"), cognitive information ("actions and unit tasks"), rational ("tasks ranging from minutes to hours") and social information ("long term behavior"), (p. 15). A study of multitasking behavior at these varying levels of abstraction allows researchers to collect data and draw conclusions at the level most relevant to the theory being proposed or tested.

It is possible that a fourth continuum exists in which tasks range from very similar to very dissimilar. On the basis of Salvucci and Taatgen's propositions that tasks compete for cognitive resources, it stands to reason that performance may be facilitated when tasks are similar yet hindered when tasks are dissimilar.

Savlucci and Taatgen $(2008 ; 2011)$ summarize the theory of threaded cognition tenets as follows: multiple tasks can be engaged by concurrent threads of cognition which each represent differing task goals; cognitive resources are allocated to serve one thread at a time; threads consume and release cognitive resources as needed; and when multiple threads compete for cognitive resources, priority is given to the task associated with the highest level of urgency. This conceptual framework provides a foundation for the review 
of the various conceptualizations of multitasking and the existing research to follow in the sections below.

\section{Definitions of Multitasking}

Seminal definitions of multitasking include task switching as a critical component (e.g., Delbridge, 2000; Oswald et al., 2007; Salvucci \& Taatgen, 2011). A commonly cited definition of multitasking is "accomplishing multiple task goals in the same time period by engaging in frequent switches between individual tasks" and is comprised of three components: task switching or interrupted tasks, uncertainty about when the need to switch will arise, and salient time pressures resulting from the need to reprioritize and switch tasks (Delbridge, 2000, p. 1). A clear distinction is made between multitasking and task completion due to these three characteristics (Delbridge, 2000). The first, task switching, involves the frequent requirement to switch attentional resources to other tasks. The need to attend to another task causes distraction in task performance. The second component concerns the degree of uncertainty regarding when task switching will be required. Finally, multitasking involves time pressures requiring completion of the tasks within a restricted time period.

An alternative conceptualization defines multitasking as consisting of the following components: "performing multiple tasks, performance requires a conscious shifting from one task to another, and performance on multiple tasks, with shifts in attention, must occur over a short time span" (Oswald et al., 2007, p. 81). The first element of this definition distinguishes tasks on the following criteria: physical nature of the task, demands required to perform the task, outcome of the task, and individual's 
perception of the task as separate tasks or one cohesive overall task. Oswald and colleagues provide the following example to clarify the second component of this definition: even when tasks are performed simultaneously (e.g., listening to the radio and driving a car), multitasking exists when attention is shifted between two or more tasks. The third element of this definition states that objective information including time intervals between engaging in tasks, and subjective information such as individual perceptions determine whether or not multitasking ability is required for successful performance (Oswald et al., 2007).

\section{Multitasking Ability as an Individual Difference}

Multitasking ability, sometimes referred to as timesharing ability, is conceptualized as a general aptitude which determines successful completion of multiple tasks (Brookings \& Damos, 1991). Differences in multitasking ability across individuals have been researched for many years (see Brookings \& Damos, 1991 for comprehensive review). Early research on multitasking ability found that performance on simultaneous tasks (e.g., reading and writing) decreased as compared to performance on these single tasks (Sharp, 1899). Furthermore, Oswald and colleagues (2007) explain that individuals can react very differently in the face of multitasking demands, such that some may perceive the situation as "interesting and exciting", while others may perceive the same situation as "threatening and stressful," (Oswald et al., 2007; p. 82).

The degree of performance decrement varies across individuals. Sharp's (1899) early study provided the foundation for research on individual differences in multitasking ability, however, it suffered from some methodological flaws limiting the validity of results. In 1917, McQueen further researched multitasking ability in children by 
analyzing performance on tasks such as mental addition, counting, and shape comparison tasks. Small performance differences in single versus multiple task completion in this study led to the conclusion that multitasking ability, as an overarching skill, did not exist (McQueen, 1917). Subsequent studies have been mixed, with some providing evidence of differences in single versus multiple task performance, pointing to a general multitasking ability skill (Ackerman, Schneider \& Wickens, 1984), some have found no differences, questioning the existence of an overarching ability for multitasking (Fogarty, 1987; Sverko, Jerneic \& Kulenovic, 1983; Wickens, Mountford \& Schreiner, 1981), while others point to the existence of process specific timesharing abilities (Brookings, 1990; Jennings \& Chiles, 1977). Differences in results across studies can be partially attributed to the methodological flaws and analytical shortcomings in many of these studies (Brookings \& Damos, 1991).

Mental capacity, or cognitive resources, has been identified as an important determinant of multitasking performance (Wickens, 1991). Wickens explains that the increased mental exertion of "trying harder" can result in improved performance, with more effort (i.e., resources) required for more difficult tasks. According to a resource scarcity theory, the total amount of resources is fixed and when shared between two or more activities, task performance will decline (Wickens, 1991). The resource scarcity theory extends to suggest that resources can be voluntarily allocated to certain tasks. Multiple task performance may be facilitated when the tasks require different types of resources, as increased cognitive burden for one task will not negatively affect performance as drastically as in another dissimilar task, requiring different mental resources, referred to as competition (Wickens, 1991). Another theory asserts that tasks 
requiring similar mental processes will assist in simultaneous task completion, referred to as cooperation, whereas tasks requiring different mental processes will interfere and hinder simultaneous task completion, referred to as confusion (Wickens, 1991).

Other researchers have suggested performance in a task switching environment is reliant on an individual's "mental representation" of the next task to be performed (Altmann \& Gray, 2008, p. 1). In sequential multitasking, interruptions in tasks result in the need to rebuild the cognitive setting surrounding completion of the task (Altmann \& Gray, 2008). In simultaneous multitasking, the individual must ensure that adequate attention is being distributed among all tasks (Altmann \& Gray, 2008; Salvucci \& Taatgen, 2008) to ensure effective performance.

\section{Multitasking and Job Performance}

Many early studies on multitasking as a predictor of job performance have relied on experimental tasks involving undergraduate students in either the United States (e.g., Poposki \& Oswald, 2010) or in Europe (Buhner et al., 2006). The short time frame involved in experimental studies while addressing the question whether individual differences in multitasking ability relate to individual differences in the experimental task, fails to address whether the multitasking ability is observed (over longer time frame) and valued in the overall job performance assessments in actual workplaces. One line of research (Gopher \& Kahneman, 1971; Gopher, 1982) tested a sample of pilots and found that performance on a dichotic listening task was predictive of overall job performance. Otherwise, scant research that investigated the predictive validity of multitasking ability on job performance has been positive (e.g., Hambrick, Rench, Poposki, Darowski, Roland, Bearden, Oswald, \& Brou, in press) but more research is needed. 
Research has found that perceived workload plays a role in multitasking performance such that when perceived levels of workload are high, performance is enhanced (Branscome \& Grynovicki, 2007). Individual differences in multitasking ability can stem from two causes: differences in single task performance which are typically related to working memory capacity, and differences in ability to effectively prioritize and sequence tasks (Hambrick et al., 2010). Working memory is a critical determinant of multitasking ability as it predicts the utilization of successful task accomplishment approaches (Hambrick et al., 2010; König et al., 2005; Liberman \& Rosenthal, 2001). In fact, research has shown that individuals generally remember interrupted tasks twice as effectively as completed tasks (Zeigarnik, 1927). Referred to as "the Zeigarnik effect", this drastic difference is likely due to the psychological tension induced by unfinished tasks (Zeigarnik, 1927). Zeigarnik explains that when a task is completed it can be forgotten, but when a task is interrupted it is perceived as unfinished business and is likely to stay in the forefront of one's memory.

As this brief review suggests, more empirical research have related individual differences in polychronicity with performance in organizations than those assessing the predictive validity of multitasking ability. In studies three and four I empirically investigate the predictive validity of multitasking for overall job performance as well as for supervisory assessments of multitasking performance in two organizational samples.

Hypothesis 8: Multitasking ability predicts overall job performance.

Hypothesis 9: Multitasking ability predicts multitasking performance. 


\section{Correlates of Multitasking Ability}

Organizational researchers have explored several individual differences variables that predict organizational outcomes such as performance, satisfaction, and leadership. Cognitive ability has been found to be a strong predictor of overall job performance and training performance (Schmidt \& Hunter, 1998) and the Big Five factors of personality have been linked to several outcomes (Barrick \& Mount, 1991). The Big Five factors include Agreeableness, Conscientiousness, Emotional Stability (or the reverseNeuroticism), Extraversion and Openness to Experience. Recent research has called for further investigation of the relationships between multitasking ability and non-cognitive variables (Poposki et al., 2009b). In fact, researchers have argued that when new constructs such as multitasking ability and emotional intelligence are proposed for use in organizational assessment, the correlates of the new construct with these traditional predictors (cognitive ability, Big Five factors of personality) be examined (cf. VanRooy \& Viswesvaran, 2004; Landy, 2005; Locke, 2005).

\section{Cognitive Predictors of Multitasking}

There are several cognitive differences that are linked to multitasking ability. Measures of working memory have also shown incremental predictive validity over cognitive ability in predicting job performance (Buhner et al., 2006; Hambrick et al., 2010; König et al., 2005). König and colleagues (2005) found fluid intelligence and attention to also be important predictors of multitasking ability. Hambrick and colleagues (2010) found that individuals with higher processing speed were able to successfully

multitask. Additionally, information processing ability has been found to explain unique incremental variance in the prediction of multitasking ability above the effects of 
cognitive ability (Kinney, Reeder, \& O'Connell, 2008). The incremental validity of multitasking ability over cognitive ability is critical since cognitive ability has been linked to multitasking performance. Cognitive ability is also one of the strongest predictors of task performance in a variety of settings (Schmidt \& Hunter, 1998) and this relationship is strengthened as task complexity increases (Hunter \& Hunter, 1984).

Not surprisingly, cognitive ability has been shown to be a strong predictor of multitasking performance (Delbridge, 2000; Ishizaka et al., 2001; König et al., 2005; Kinney et al., 2008; Kinney, 2007; Kinney, Reeder \& O’Connell, 2009; Oswald et al., 2007). It is possible that cognitive ability predicts performance in a complex multitasking environment because higher ability individuals adopt more successful approaches and demonstrate quicker learning ability (Kinney et al., 2008). Thus, a review of this literature suggests that cognitive ability will be related to multitasking and raises the question of whether multitasking ability will have predictive validity beyond cognitive ability in assessing job performance.

\section{Non-Cognitive Individual Differences and Multitasking}

The relationships between multitasking ability and non-cognitive individual differences have been researched in many studies (e.g., Delbridge, 2000; Kinney, 2007; Oswald et al., 2007; Stachowski, 2011). Meta-analytic research has also demonstrated relationships between the five factors of personality and job performance (Barrick \& Mount, 1991; Barrick, Mount \& Judge, 2001).

Neuroticism is characterized by anxiety, worry, and insecurity (Barrick \& Mount, 1991). Not only is neuroticism a predictor of job performance across a variety of occupations (Barrick et al., 2001), neuroticism has also been found to be negatively 
related to multitasking performance (Oswald et al., 2007; Poposki et al., 2009b; Szymura \& Necka, 1998). Highly neurotic individuals are more likely to experience more stress and anxiety that hinders performance in an environment requiring performance on multiple tasks simultaneously, the need for frequent switching of attention, and the presence of time pressures (Oswald et al., 2007). Later research identified differences in anxiety levels elicited by multitasking simulations as a possible reason for this difference, as anxiety partially mediates the relationship between neuroticism and multitasking ability (Poposki et al, 2009b). More specifically, Oswald and colleagues tested multitasking performance in both "routine" and simulated "emergency" settings. They provide evidence that individuals high in neuroticism perform more poorly than individuals low in neuroticism in the routine setting, but not in the simulated emergency setting. The reasoning for this finding is that anxiety is provoked for everyone in the emergency setting, but only for those individuals high in neuroticism in the routine setting, with anxiety identified as the hindrance of multitasking performance (Oswald et al., 2007).

Conscientiousness is characterized by reliability, striving for achievement, concern for detail and organization (Barrick \& Mount, 1991). Conscientiousness is a strong and consistent predictor of performance across a variety of jobs (Barrick et al., 2001), and has been found to be negatively related to multitasking performance such that individuals high in conscientiousness performed less effectively in simulated emergency environments due to their careful and methodical nature, where emergency situations require swift and automatic responding (Oswald et al., 2007). Accordingly, when 
emergency type multitasking is a key component of job responsibilities, conscientious individuals may perform less effectively.

Openness to experience is characterized as being creative, inquisitive, intelligent, and cultured (Barrick \& Mount, 1991). Although it may be intuitive to think, as hypothesized by Delbridge (2000), that individuals high in levels of openness to experience will be more malleable to the demands of a multitasking environment and fare more favorably in an environment requiring frequent change, empirical findings linking openness to experience to performance have been lacking (Delbridge, 2000; Barrick et al., 2001), although some report weak relationships (Kinney, 2007). Agreeableness is marked by being cooperative, flexible and accepting. Although agreeableness is not empirically related to job performance (Barrick et al., 2001), flexibility may be an important prerequisite for successful performance in a multitasking environment.

Extraversion is illustrated by friendliness, confidence, and liveliness (Barrick \& Mount, 1991). Extraversion has been found to be positively related to polychronicity (Conte \& Gintoft, 2005; Conte \& Jacobs, 2003; König et al., 2005) and multitasking performance (Kinney, 2007). Some previous research studies have shown extraverts are more successful at multitasking (Lieberman \& Rosenthal, 2001; Szymura \& Necka, 1998), while others have shown no relationship (König et al., 2005). Specifically, Lieberman and Rosenthal (2001) found that introverts exhibit a deficiency in nonverbal decoding ability only in a multitasking setting, where nonverbal decoding is a secondary goal. In a series of four studies, this research concludes that the multitasking performance decrement of introverts can be generalized beyond nonverbal decoding to other abilities, including working memory (Lieberman \& Rosenthal, 2001). Szymura and Necka (1998) 
concluded that extraverts are more successful multitaskers due to their ability to thrive in a stimulating environment. Because extraverted individuals are more likely to prefer engaging in multiple tasks, it is possible that extraverts will be more likely to gravitate towards a work environment which demands multitasking and will exhibit more effective performance in these environments.

Given the results of previous research pointing to relationships among individual difference variables and multitasking performance as well as overall job performance, it is likely that these relationships will also be found in this study. Additionally, it is likely that the five factors of personality and cognitive ability will predict multitasking performance. In this dissertation, the nomological network of multitasking ability is explored by examining the correlates between multitasking and the traditional predictors (cognitive ability and Big Five factors of personality). The correlations between polychronicity and measures of cognitive ability and Big Five factors of personality are reported. In addition, the incremental predictive validity of the understudied constructmultitasking —over cognitive ability and Big Five factors for predicting organizational performance (both multi-tasking performance and overall job performance) is tested. Hypothesis 10: Cognitive ability will predict both multitasking performance and overall job performance.

Hypothesis 11: The five factors of personality will predict both supervisor ratings of multitasking performance and overall job performance.

Hypothesis 12: Cognitive ability will correlate with multitasking ability. 
Hypothesis 13: The five factors of personality will correlate with multitasking ability. I hypothesize Agreeableness, Extraversion, and Emotional stability to have a positive and Conscientiousness to have a negative correlation with multitasking ability.

Hypothesis 14: Multitasking ability will explain incremental variance in the prediction of both multitasking performance and overall job performance, above and beyond that explained by measures of cognitive ability and personality.

\section{Multitasking Performance as a Mediator}

Overall job performance is a multidimensional construct (Campbell, Gasser, \& Oswald, 1996; Viswesvaran, Schmidt, \& Ones, 2005) and different models have been presented to conceptualize how different dimensions relate to one another and to overall job performance (cf. Viswesvaran, 1993 or Viswesvaran \& Ones, 2000 for a review). Rotundo and Sackett (2002) demonstrate how task performance and organizational citizenship behaviors will contribute to overall job performance. Given these conceptualizations, it is likely that multitasking performance will also contribute to assessments of overall job performance.

Multitasking ability is useful to I/O Psychologists in that it predicts multitasking behavior on the job, which is then expected to predict effective job performance in a multitasking environment. Thus, multitasking performance on the job, measured by supervisor rating of multitasking performance, is expected to mediate the relationship between multitasking ability and a composite measure of job performance.

Hypothesis 15: Supervisor ratings of multitasking performance mediate the relationship between multitasking ability and overall job performance. 


\section{Polychronicity as a Moderator}

Measures of polychronicity are useful to I/O Psychologists to the extent that they predict job performance. Results have been mixed, and studies have shown that the effectiveness of polychronicity in predicting job performance depends largely on the nature of the job, and that polychronicity predicts job performance only if the work environment demands multitasking (König \& Waller, 2010). Some research has suggested that person-environment fit may be a contributing factor in determining how accurately polychronicity predicts performance (König \& Waller, 2010).

The notion of fit as an important determinant of the outcomes of polychronicity includes the possibility that individuals working in multitasking environments may become polychronic, or develop the preference for multitasking as it has become a learned and practiced behavior (König \& Waller, 2010). König and Waller (2010) propose a theory in which personal preferences and the environment interact to influence individual polychronicity. This theory is grounded in two assumptions: different work environments demand different degrees of multitasking behavior, and that being forced to switch attention among multiple tasks will foster the preference for doing so (König \& Waller, 2010). König and Waller's (2010) theory is grounded in the belief that polychronicity is a malleable attribute that can increase or decrease, and not a stable inherent trait.

Misfit occurs when an individual's preferences for time use are not congruent with the allowable methods for completing tasks (Hecht \& Allen, 2005). One study found that polychronic individuals demonstrated greater creativity when afforded the opportunity to rotate through tasks, while the opposite effect was found for monochronic 
individuals who were more creative when sequentially completing tasks (Madjar \& Oldham, 2006). These results indicate that performance on creative assignments is better when tasks are completed in such a manner that is aligned with individual preferences.

Furthermore, some researchers suggest that polychronic individuals will be more satisfied with jobs that require multitasking ability and uninterested in jobs that do not (Poposki \& Oswald, 2010) and those who prefer multitasking environments may intentionally engage in switching between multiple tasks while engaging in both work and home environments (Oswald et al., 2007). Previous research has shown significant positive relationships between polychronicity and measures of both objective and subjective performance as reviewed below.

The relationship between polychronicity and job performance has been more widely researched in multiple samples. Conte and Gintoft (2005) report data indicating that individual differences in polychronicity were related to supervisory ratings of customer service, sales performance and overall performance in a sample of 174 computer retail sales employees, yet Conte and Jacobs (2003) report data indicating that polychronicity is negatively related to supervisory ratings of performance in scheduled attendance, dependability, and attentiveness for train operators. Moreover, polychronicity contributes incremental variance in these outcomes beyond measures of the Big Five (Conte \& Jacobs, 2003).

Hecht and Allen (2005) found in a sample of 746 Canadian employees relationships between polychronicity and criteria such as job satisfaction and psychological strain. Polychronicity has been related to satisfaction and turnover as well as supervisor ratings of performance in a sample of retail employees (Arndt et al, 2006). 
Souitaris and Mastero (2010) have related polychronicity in strategic decision processes in top management teams and performance of new technology ventures. Taylor and colleagues (1984) found polychronicity to be related to both quantitative and qualitative measures of research productivity in a sample of university professors. In another study, polychronicity was found to be a significant predictor for of both objective and subjective performance criteria in polychronic jobs (Kantrowitz et al., 2012). Yet in other studies, polychronicity has not been found to be a significant predictor of job performance (Hambrick et al., 2007; Kinney, 2007) providing somewhat mixed support for the predictive value of this construct.

Some research has shown that polychronicity predicts valuable performance criteria such as perceptual speed and accuracy and customer service ability (Kantrowitz \& Kinney, 2009). In a study conducted with call center employees, polychronicity predicted objective performance measures including average call handling time and other quality assurance measures (Kantrowitz \& Kinney, 2009). Additionally, polychronicity has been found to contribute significant unique incremental variance in performance over other predictors including biodata, judgment and reasoning tests, personality assessments, and call center simulations. (Kantrowitz \& Kinney, 2009). Polychronicity predicts a variety of outcomes including supervisor ratings of job performance, organizational citizenship, revenue focus, multitasking ability, handle time, quality assurance, customer satisfaction, issue resolution, conscientiousness, citizenship behavior, and overall performance ratings (Kantrowitz \& Kinney, 2009; Kantrowitz et al., 2012).

These findings suggest that polychronicity is also related to overall managerial performance due to positive correlations with supervisory ratings of potential teamwork, 
influence, integrity, judgment/problem solving, strategy/vision, achievement and service orientation (Kantrowitz et al., 2012). Polychronicity proved to be a significant predictor of supervisor ratings and added unique incremental validity for the majority of the criteria above and beyond the effect of all other predictors. In fact, polychronicity has been found to be related to overall organizational performance (Onken, 1999).

Thus, the literature on polychronicity clearly suggests that it is an important variable in organizational contexts. In fact, early literature failed to distinguish between polychronicity and multitasking ability. Polychronicity is more of a non-cognitive variable whereas multitasking is an ability (cf. Poposki \& Oswald, 2010). Empirical research examining the relationship between the two related but distinct concepts is somewhat scant. In the extant research, polychronicity has been found to be unrelated to multitasking ability in some studies (Branscome \& Grynovicki, 2007; Ishizaka et al., 2001; Kantrowitz \& Kinney, 2009; König et al., 2005).

However, Stachowski (2011) found that after controlling for personality, attentional control, and a measure of cognitive ability (student GPA), polychronicity was a significant predictor of multitasking behavior. It is likely that a polychronic individual will fully utilize his/her multitasking ability because those skills are congruent with his/her preferences. Polychronicity is related to time use behaviors, and the relationship becomes stronger in environments where autonomy is high (Stachowski, 2011). Conversely, when an individual is capable of multitasking but does not prefer to engage in multitasking behaviors, he/she is less likely to utilize those skills on the job.

Other studies also report polychronicity to be related to self-motivated multitasking behavior (Goonetelike \& Luximon, 2009; König, Oberarcher, \& Kleinmann, 
2010) indicating that when an individual prefers engaging in multiple tasks simultaneously, the individual may be more likely to engage in multiple tasks simultaneously. Taken together, the results of these studies reinforce the notion that preferences will drive behavior. It may also be expected that those who engage in multitasking behaviors more frequently will become more skilled in switching attention among tasks.

A widely accepted theory of job performance asserts that performance is a multiplicative function of both ability and motivation (Maier, 1955; Vroom, 1964). This theory defines ability as potential for successfully completing a task (i.e., "can do") and motivation as a requirement for effective performance (i.e., "will do"), (Maier, 1955; Vroom, 1964). Furthermore, some researchers have argued that both ability and motivation data should be assessed when assessing the predictive validity of ability tests (Lawler, 1967). Therefore, both ability (in this case, multitasking ability) and motivation (in this case, polychronicity) are important considerations in the evaluation of the utility of multitasking assessments. I expect that polychronicity will serve as a motivational variable influencing the relationship between multitasking ability and job performance.

Thus, the relationship between multitasking ability and job performance is likely to be moderated by the preference for multitasking (i.e., polychronicity). Studies 3 and 4 consider the relationship between multitasking, Big Five, Cognitive ability, multitasking performance and overall job performance. Study 4 will further seek to examine the potential moderating role of polychronicity in the relationships between multitasking ability and both multitasking performance and overall job performance. It is expected that polychronicity will moderate the relationship between multitasking ability and job 
performance such that when an individual prefers to engage in multiple tasks simultaneously (that is, polychronic) the relationship between multitasking ability and job performance will be stronger than when an individual prefers not to engage in multiple tasks simultaneously (that is, monochronic).

Hypothesis 16: Polychronicity will moderate the relationship between multitasking ability and multitasking performance such that the relationship will be stronger when polychronicity is high.

Hypothesis 17: Polychronicity will moderate the relationship between multitasking ability and overall job performance such that the relationship will be stronger when polychronicity is high.

In conclusion, I propose 17 hypotheses in this dissertation to test the factor structure and compare alternative models of the construct of polychronicity, examine internal and external correlates of polychronicity and multitasking ability, assess the predictive validity of multitasking ability as well as the incremental validity of multitasking ability above and beyond that of traditional predictors, examine multitasking performance as a mediator of the relationship between multitasking ability and overall job performance, and investigate polychronicity as a moderator of the relationship between multitasking ability and both multitasking performance and overall job performance. Four studies were designed to test these 17 hypotheses. Specifically, study one tests the factor structure of polychronicity as well as correlations with the Big Five (hypotheses $1-7$ ). Study two tests the external personality correlates of polychronicity (hypotheses $3-7$ ). Study three tests the predictive validity, external correlates, and incremental validity of multitasking ability, as well as multitasking performance as a 
mediator (hypotheses $8-15$ ). Study four tests the predictive validity of multitasking ability, external correlates, and incremental validity of multitasking ability, as well as multitasking performance as a mediator, polychronicity as a moderator, and the personality correlates of polychronicity (hypotheses $3-17$ ). 


\section{CHAPTER III: METHOD}

\section{Study 1}

Study one is an investigation of the factor structure of commonly used scales to measure polychronicity. The analysis was restricted to the four scales in the extant literature that strictly measure polychronicity, and other broader measures of time orientation were not included. Specifically, study one examines the different dimensions of polychronicity across these four scales to determine the conceptual overlap, identifies common variance across dimensions and scales, determines the common variance across scales for specific dimensions, and identifies the scale specific variance. Additionally, study one assesses the relationship between the dimensions of polychronicity and the Big Five factors of personality. Thus, study one focuses on hypotheses 1-7.

\section{Participants}

772 undergraduate students from a large research university completed the survey questionnaire. The university-based research participant management system was used to recruit participants, and participation was completely voluntary and anonymous.

University research credits were given to students in exchange for participation. After the data were screened for random responding, data from 732 participants were included for analysis. In order to meet the inclusion criteria, participants must have responded to four out of five "dummy" questions correctly (i.e., "Please select answer choice strongly agree"). The majority of participants were females (74\%). Approximately two thirds of participants reported race to be Hispanic (67\%), followed by White (15\%) and African American (10\%). A majority (83\%) of participants report age within the range of $18-24$ years. 


\section{Procedure}

After logging into the university sponsored research management system, participants were presented with a link to access the questionnaire. Presentation of the scales was randomized across participants. The questionnaire was administered through Qualtrics online survey software. Confidentiality and anonymity of the participants was maintained throughout the study, and one university research credit was provided for completion of the survey. All standards set forth by the Institutional Review Board (IRB) were followed precisely. Completion of the questionnaire required approximately 60 minutes.

\section{Measures}

Polychronicity. Study one compared the factor structure and conceptual overlap of four commonly used scales to measure polychronicity, described below. In addition to investigating the internal structure of polychronicity, study 1 examined the relationship between polychronicity and external personality correlates.

Polychronic Attitudes Inventory (PAI). The PAI is a 4-item measure developed by Kaufman et al. (1991). Items are scored on a 5-point Likert scale with the following response options (1: Strongly disagree; 2: Disagree; 3: Neither agree nor disagree; 4:

Agree; 5: Strongly agree). Three of the four items are reverse coded prior to computing the scale score. Sample items include: "People should not try to do many things at once" and "When I sit down at my desk, I work on one project at a time." In the scale development research, the PAI demonstrated a moderately low Cronbach's alpha reliability estimate (.68). 
Inventory of Polychronic Values (IPV). The IPV is a 10-item measure developed by Bluedorn et al. (1999). Items are scored on a 7-point Likert scale with the following response options (1: Strongly disagree; 2: Moderately disagree, 3: Slightly disagree, 4: Neither agree or disagree, 5: Slightly agree, 6: Moderately agree, 7: Strongly agree). Five of the 10 items are reverse coded prior to computing the scale score. The IPV was originally intended to measure group level (i.e., cultural) preferences. It is widely accepted methodology to substitute the word "I" for "We" in the items to measure individual level polychronicity. Sample items include: "We like to juggle several activities at the same time"; "We believe people do their best work when they have many tasks to complete" and "We would rather complete an entire project every day than complete parts of several projects." This scale was developed and validated on multiple samples, in which the scale demonstrated adequate internal consistency, with the Cronbach's alpha reliability estimates ranging from .76 to .93 .

Polychronic-Monochronic Tendency Scale (PMTS). The PMTS is a 5-item measure developed by Lindquist and Kaufman-Scarborough (2007). The PMTS proves to be psychometrically sound with Cronbach's alpha reliability estimates exceeding .90 in all of the validation studies, higher than any other scale used in the scale construction research. Items are scored on a 5-point Likert scale with the following response options (1: Strongly disagree; 2: Disagree; 3: Neither agree nor disagree; 4: Agree; 5: Strongly agree). Sample items include: "Doing two or more activities at the same time is the most efficient way to use my time"; "I am comfortable doing more than one activity at the same time. 
Multitasking Preference Inventory (MPI). The MPI is a 14-item measure developed by Poposki \& Oswald (2010). Items are scored on a five point Likert scale with the following response options (1: Strongly disagree; 2: Disagree; 3: Neither agree nor disagree; 4: Agree; 5: Strongly agree). Seven of the 14 items are reverse coded prior to computing the scale score. The MPI was intended to measure only one aspect of the original definition of polychronicity, the preference to engage in multiple tasks simultaneously. Sample items include: "I prefer to work on several projects in a day, rather than completing one project and then switching to another"; "I lose interest in what I am doing if I have to focus on the same task for long periods of time, without thinking about or doing something else", "It makes me uncomfortable when I am not able to finish one task completely before focusing on another task." The scale was developed and validated on multiple samples, in which the scale demonstrated adequate internal consistency, with the Cronbach's alpha reliability estimates ranging from .88 to .91 .

Personality. The 50-item International Personality Item Pool (IPIP) scale will be used to measure each of the dimensions in the Five Factor Model, referred to as the Big Five (10 items for each factor). These measures are non-proprietary and available to the public on the IPIP scale website. Participants were instructed to rate how well each item describes them on a scale of one to five (1: Very Inaccurate, 2: Moderately Inaccurate, 3: Neither Inaccurate nor Accurate, 4: Moderately Accurate, 5: Very Accurate). Item scores were averaged to obtain a scale score for each of the five factors.

Sample items for agreeableness include "Sympathize with others' feelings" and a reverse coded item is "Insult people." Sample items for extraversion include "Am the life of the party" and a reverse coded item is "Don't like to draw attention to myself." Sample 
items for conscientiousness include "Am always prepared" and a reverse coded item is "Shirk my duties." Sample items for emotional stability include "Seldom feel blue" and a reverse coded item is "Get stressed out easily." Sample items for openness to experience include "Have a vivid imagination" and a reverse coded item is "Have difficulty understanding abstract ideas.”

Demographics. Demographics collected include gender, ethnicity, age, and employment status.

\section{Analyses}

Data were entered into SPSS and an exploratory factor analysis was conducted on all items of polychronicity across scales, to further investigate the factor structure of the construct. The incremental validity of each of the scales over the others was tested in the prediction of each of the Big Five factors of personality.

A confirmatory factor analysis was employed through AMOS 18.0 using a maximum likelihood algorithm to determine the factor structure of the items and conceptual overlap of the scales used to measure polychronicity (including the PAI, IPV, PMTS, and MPI). Specifically, alternate models were tested. The original proposed competing theoretical models of polychronicity were not all able to be evaluated for fit with the data as some were classified as underidentified and the analysis could not be completed. The two factor model was altered into a simplified model in which IPV, PAI and PMTS measured belief, and MPI measured preference. As more than one measure of each latent factor is required, items from the MPI were randomly assigned to create two subscale scores to measure preference. Additionally, scale scores were computed for the personality variables and the patterns of correlations were examined through correlational analysis. 


\section{Study 2}

Study two is a meta-analysis of studies empirically investigating the relationship between polychronicity and the Big Five factors of personality. Study two focused on the investigation of the external correlates of polychronicity, specifically the Big Five factors of personality. This quantitative review aimed to provide clarity to these relationships by integrating previous findings and controlling for statistical artifacts as results in the extant literature have been mixed. Thus, Study two is designed to test Hypotheses 3-7.

\section{Database}

The electronic search of relevant studies was conducted through four databases: PsycInfo, ABI/Inform, ProQuest Dissertations \& Theses, and Google Scholar. All studies were slated for inclusion (no date limitations) that examined the relationship between polychronicity and the Big Five factors of personality. The search terms "polychronicity" and "personality" were used. PsycInfo retrieved a total of 16 studies, of which three were selected for inclusion. ABI/Inform retrieved a total of 108 studies, of which one additional study was selected for inclusion (not including duplicates from the original search). ProQuest Dissertations \& Theses retrieved a total of 61 studies, of which one study was selected for inclusion (not including duplicates from earlier searches). Google Scholar yielded a total of 781 sources. The only restrictions placed on this search were studies that were published in English, and in the Social Sciences, Arts and Humanities category. Three additional sources (not including duplicates from the other searches) were selected for inclusion. The search in Google Scholar was restricted by studies published in English, and in the Social Sciences, Arts and Humanities category to produce a reasonable number of results. Additionally, conference programs for both 
Society for Industrial and Organizational Psychology and Academy of Management were searched.

As a result of the multiple search methods used, there were some studies that used the same dataset as other studies identified as appropriate for inclusion. In this case, only one of the datasets was included in the analysis and the duplicate(s) were discarded. One paper (Konig \& Waller, 2010), although not empirical in itself, reported correlations from two additional unpublished studies. Finally, personal communication with a researcher yielded one additional paper (Kantrowitz et al., 2012), which consists of two independent studies. A total of 11 sources, containing 14 independent studies, were selected for inclusion in this meta-analysis. Additionally, some studies reported correlations between personality variables and two or more measures of polychronicity. In these instances, each measure of polychronicity was treated as a separate study, yielding a total of 20 studies.

\section{Inclusion criteria}

The purpose of this meta-analysis was to examine the relationship between polychronicity and the Big Five factors of personality. As such, the studies selected for inclusion had to meet the following criteria: a) one or more measures of polychronicity were employed, b) one or more measures of at least one of the Big Five factors of personality, or facets that could be mapped to the Big Five, were employed, and c) a correlation was reported between a measure of polychronicity and a measure of one or more of the Big Five, or facets that could be mapped back to the Big Five. 


\section{Meta-Analytic Procedure}

The bare bones meta-analysis method was employed to quantitatively review the coded data. The use of this meta-analytic procedure provides a quantitative review of the data by correcting for sampling error in the measures.

\section{Study 3}

Study three investigates the predictive validity of multitasking ability for both multitasking performance and overall job performance. Study three also examined the external correlates of multitasking ability, and determined the incremental validity of multitasking ability above and beyond that of traditional predictors. Finally, study three aimed to investigate multitasking performance as a mediator of the relationship between multitasking ability and overall job performance. Thus, Study three tests hypotheses 815.

\section{Participants}

Study three tested a sample of 175 employees from an engineering firm. The sample included software engineers, engineer technicians and program managers serving in professional roles. The majority of participants were male (78\%), and $54 \%$ of participants reported less than 40 years of age. Approximately half (48\%) of participants reported race to be White/Caucasian, 5\% report Hispanic/Latino, 7\% report Black/African American, 21\% Asian, and 1\% Native American.

\section{Procedure}

Job analysis revealed the importance of multitasking as a key competency for successful performance of the target job in study three. As part of a concurrent validation study, incumbents were sent the link to the online assessment including measures of 
multitasking ability, cognitive ability, and personality. The researcher obtained the data from a global assessment firm. Performance ratings were collected via an online rating form. Supervisors were emailed a link that took them to an online survey. The supervisors filled out individual survey forms for each of their employees who were participating in the research. Supervisors could complete ratings of all employees in one sitting or could choose to complete the ratings over multiple sittings.

\section{Measures}

Multitasking Ability. Multitasking ability was assessed using the Multitasking Ability Test, which measures performance on two simultaneous tasks. The first task is a general problem-solving task related to the work environment including aspects of deductive reasoning and quantitative ability. A time limitation was placed for the test taker to answer each of these questions. The second task is an email simulation designed to assess the reading comprehension and ability to recall information. In this exercise, emails are presented sequentially, some of which require a response. The test taker can view each email for only a limited amount of time, imposing time pressures and forcing the test taker to shift attention between the two tasks. The test taker is then asked to recall information related to the content of the emails. A total multitasking ability score was computed from a weighted combination of the problem solving and information retrieval components of the test.

Personality. The Global Personality Inventory-Adaptive (GPI-A) was used to assess the personality characteristics of the participants based on the Big Five factors of personality. The Global Personality Inventory - Adaptive (GPI-A) is a general assessment of individual differences in personality consisting of 13 scales intended for 
use in selection and development of employees across a wide range of employmentrelated settings. Examinees were presented with two statements representing different levels of a personality trait, from which they selected the one that most accurately describes them. Next, two additional statements were presented which are selected using an updated trait level estimate determined by their previous responses, creating a unique test for each participant. Sequences of statement pairs were selected in a manner that maximizes item information at each step. Twelve scales from GPI-A were selected for use in this study: composure, influence, innovation, confidence \& optimism, achievement, collaboration, flexibility, independence, reliability, self development, sense of duty, and thoroughness. These scales were mapped to Big 5 dimensions of personality and composites were created.

A composite score for emotional stability was created by combining scores on the following dimensions: composure, confidence/optimism, and independence. A score for extraversion was comprised of only a score on the dimension of influence. A composite score for openness to experience was created by combining scores on the following dimensions: innovation, flexibility, and self-development. A composite score for conscientiousness was created by combining scores on the following dimensions: achievement, reliability, sense of duty, and thoroughness. A score for agreeableness was comprised of only a score for the dimension of collaboration.

The GPI-A demonstrates criterion related validity across a variety of job levels. Validation studies show that the GPI-A has near zero correlations with measures of cognitive ability, demonstrating divergent validity (see GPI-A technical manual). 
Cognitive Ability. Cognitive ability was assessed through the use of a computer adaptive test of both verbal ability and deductive reasoning called the Global Cognitive Index (GPI). The scores on verbal ability and deductive reasoning were averaged to form a composite score of cognitive ability. The verbal ability component consists of sentence completion, reading comprehension, analogies, and antonym/synonym problems. The deductive reasoning component consists of logic problems and scenarios where the participant provides answers to missing information based on a pre-specified set of rules. The GCI demonstrates criterion related validity across a variety of job levels.

Additionally, the GCI demonstrates convergent validity with other measures of cognitive ability and divergent validity with measures of personality. The GCI is a highly reliable measure, as the "stopping rule" for the computer adaptive test is met when the internal consistency reliability threshold of .80 is achieved.

Performance Ratings. Participants were rated on 27 specific performance dimensions, as well as 8 global measures of performance, by supervisors. Participants were rated by supervisors on a variety of specific performance dimensions on a 7 point Likert scale. Raters were provided with a diagram depicting the 7 point scale with values 1-7 across the top from left to right. Under the values of 1-7, three categorizations were provided: ratings of 1-2 (ineffective performance) 3-5 (acceptable performance) and 6-7 (highly effective performance). Sample performance dimensions include: analyzing problems, communicating in writing, effort and productivity, and organization and time management. For each performance area, a definition of the dimension was provided to the rater, along with 3-5 statements describing various behaviors falling within the dimension. For example, "sets high personal standards of performance" was listed as an 
example behavior for the Driving to Excel dimension. The ratings on the specific performance dimensions were averaged to create a specific performance area composite score.

Eight items were included to assess the global performance of the employee. Supervisors were asked to rate employees on a 5 point Likert scale for each item. Sample items include: "If you had your choice of job candidates, would you hire this employee again?” (1: Definitely no, 2: Probably not, 3: Unsure, 4: Probably yes, 5: Definitely yes), and "This employee's productivity level is:" (1: Below average, 2: Average, 3: Above average, 4: Well above average, 5: One of the best). The eight items were averaged to form a global composite score. Finally, the average specific performance rating and the average global performance rating were combined to form a composite supervisor rating of overall job performance for each participant.

Supervisors also rated participants' multitasking performance on the job as a single item measure on a 7-point Likert scale. The definition of multitasking was provided along with four examples of multitasking behaviors. The supervisor then rated the employee on the 7 point scale described above.

\section{Analyses}

Data were entered into SPSS for analysis. Scale scores were created for the variables of interest (i.e., overall job performance, multitasking ability, cognitive ability, conscientiousness, extraversion, emotional stability, agreeableness, and openness to experience). Correlational analyses provided preliminary information about the relationships of interest. 
Two hierarchical regressions were used to test the incremental validity of multitasking ability. Specifically, each multitasking performance and overall job performance served as the dependent variables. Cognitive ability and each of the five factors of personality were entered in the first step. Multitasking ability was entered in the second step. An examination of the $\Delta R^{2}$ revealed the incremental validity of multitasking ability.

A series of regression analyses were conducted to assess multitasking performance as a mediator of the relationship between multitasking ability and overall job performance as outlined in Baron and Kenny's (1986) recommendations. First, overall job performance was regressed on multitasking ability. Next, overall job performance was regressed on multitasking performance. Finally, overall job performance was regressed on both multitasking ability and multitasking performance. An examination of the change in beta weights determined whether or not multitasking performance serves as a mediator.

\section{Study 4}

Study four sought to replicate the findings of study three in a second organizational sample, as well as investigate the relationship between polychronicity and the Big Five factors of personality.

Finally, study four aimed to examine preference (i.e., polychronicity) as a moderator in the relationship between multitasking ability and both multitasking performance and overall job performance. Thus, study four tests hypotheses 3-17. 


\section{Participants}

Study four included a sample of 119 employees serving in professional occupations including Finance, Human Resources, Legal, Sales, and Services. It was determined by subject matter experts that multitasking ability is an important competency for successful performance of these positions. The sample of participants was comprised of $66 \%$ males, and $49 \%$ reported age to be less than 40 years old. Approximately half $(46 \%)$ of the participants reported race to be White/Caucasian, $2 \%$ reported Hispanic/Latino, 2\% reported Black/African American, 40\% Asian, and 1\% Native American.

\section{Procedure}

Job analyses revealed the importance of multitasking as a key competency for successful performance of the target jobs. As part of a concurrent validation study, incumbents were sent the link to the online assessment including measures of multitasking ability, cognitive ability, personality, and polychronicity. The researcher obtained this data from a global assessment firm. The sample procedure was followed as in study 3 to obtain supervisor ratings of performance.

\section{Measures}

Multitasking Ability. Multitasking ability was assessed using the Multitasking Ability Test, the same measure employed in study three.

Personality. The Global Personality Inventory-Adaptive (GPI-A) was used to assess the personality characteristics of the participants based on the Big Five factors of personality, consistent with study three. 
Cognitive Ability. Cognitive ability was assessed through the use of a computer adaptive test of both verbal ability and deductive reasoning called the Global Cognitive Index (GPI), consistent with study three.

Performance Ratings. Consistent with the measures of performance used in study three, participants were rated on 27 specific performance dimensions, 8 global measures of performance, and a single item measure of multitasking performance, by supervisors.

Polychronicity. Employee attitudes and preferences for working on tasks sequentially or simultaneously were measured with a 13 -item scale. Items were scored on a 5-point Likert scale. A sample item includes "Switching between tasks causes you stress."

Analyses

Data were entered into SPSS for analysis. Scale scores were created for the variables of interest (i.e., overall job performance, multitasking ability, cognitive ability, conscientiousness, extraversion, emotional stability, agreeableness, and openness to experience, and polychronicity). Analyses were conducted consistent with the methods employed in study three.

Additionally, to test polychronicity as a moderator of the relationship between both multitasking ability and multitasking performance, and multitasking ability and overall job performance, a series of hierarchical regressions were conducted. Specifically, multitasking performance and overall job performance served as the dependent variables, and multitasking ability, polychronicity and the interaction term (Polychronicity $\mathrm{x}$ Multitasking Ability) served as the predictors. Prior to analysis the interaction term was 
computed and the variables were centered. Multitasking ability and polychronicity were entered in the first step, and the interaction term was entered in the second step, for each of the dependent variables (multitasking performance and overall job performance). An examination of the $\Delta R^{2}$ revealed the incremental validity of the interaction between polychronicity and multitasking ability, providing evidence for polychronicity as a moderator. 


\section{CHAPTER IV: RESULTS}

Results for four studies examining polychronicity and multitasking are presented below. Study one evaluates the factor structure of polychronicity, the incremental validity of the scales over the others, the fit of competing models of polychronicity, and presents correlations with external correlates of polychronicity. Study two meta-analyzes the results of existing studies, both published and unpublished, investigating the relationship between polychronicity and the Big Five. Studies three and four investigate the predictive validity of multitasking ability, the incremental validity of multitasking ability over traditional predictors, and multitasking performance as a mediator of the relationship between multitasking ability and performance. Study four additionally presents data examining the role of polychronicity as a moderator between multitasking ability and performance. Results for the four studies are presented below.

\section{Study 1}

Study one examines the factor structure of polychronicity. Correlations among the scale scores were examined. A principal components analysis tested the factor structure of polychronicity. An analysis of incremental validity provided information about the unique variance in polychronicity explained by each of the scales. Two competing models were tested: one presenting preference and belief as sub-factors of polychronicity, and the other presenting an overarching construct of polychronicity.

\section{Descriptive Statistics}

Correlations among each of the scale scores of polychronicity were examined to provide information about measurement issues and scale overlap. These results serve to 
investigate Hypotheses 1 and 2. Descriptive statistics and intercorrelations are shown in Table 1. The diagonal represents Cronbach's alpha, the internal consistency of each scale. All scales exhibited acceptable reliability coefficients $(\mathrm{IPV}=.88, \mathrm{PAI}=.81, \mathrm{MPI}=.92$, PMTS $=.92$ ). Table 1 also reports the means and standard deviations for the variables of interest. Each of the polychronicity scales was significantly related to the others $(r=.72$ to $.83, p<.05)$. The IPV was significantly related to all three scales, most strongly to the MPI $(r=.83)$, the PAI $(r=.75)$, and the PMTS $(r=.73)$. The PAI was significantly related to all three scales, most strongly to the IPV $(r=.75)$, PMTS $(r=.75)$, and the MPI $(\mathrm{r}=.73)$. The MPI was significantly related to all three scales, most strongly the IPV $(\mathrm{r}=$ $.83)$, the PAI $(r=.73)$, and the PMTS $(r=.72)$. Finally, the PMTS is significantly related to all three scales, most strongly to the PAI $(r=.75)$, the IPV $(r=.73)$ and the MPI $(r=$ $.72)$.

Gender was significantly related to scores on the IPV, MPI, and PMTS such that women were more likely to score higher on these measures. Race was not significantly correlated to scores on any of the measures of polychronicity. 
Table 1. Correlations among Polychronicity Scales and the Big Five

\begin{tabular}{|c|c|c|c|c|c|c|c|c|c|c|c|c|}
\hline & 1 & 2 & 3 & 4 & 5 & 6 & 7 & 8 & 9 & 10 & 11 & 12 \\
\hline 1. IPV & $(.88)$ & & & & & & & & & & & \\
\hline 2. PAI & $.75^{* *}$ & $(.81)$ & & & & & & & & & & \\
\hline 3. MPI & $.83 * *$ & $.73 * *$ & $(.92)$ & & & & & & & & & \\
\hline 4. PMTS & $.73 * *$ & $.75^{* *}$ & $.72 * *$ & $(.92)$ & & & & & & & & \\
\hline 5. Extraversion & $.12 * *$ & $.14 * *$ & $.17 * *$ & $.16^{* *}$ & $(.88)$ & & & & & & & \\
\hline 6. Agreeableness & .04 & $.11 * *$ & $.09 *$ & $.13 * *$ & $.25 * *$ & $(.78)$ & & & & & & \\
\hline 7. Conscientiousness & -.04 & .00 & -.07 & .02 & $.12 * *$ & $.18^{* *}$ & $(.73)$ & & & & & \\
\hline 8. Neuroticism & -.04 & -.06 & -.01 & -.04 & $-.16 * *$ & $-.11 * *$ & $-.23 * *$ & $(.86)$ & & & & \\
\hline 9. Openness & $.12 * *$ & $.18^{* *}$ & $.13^{* *}$ & $.20^{* *}$ & $.32 * *$ & $.30 * *$ & $.21 * *$ & $-.14 * *$ & $(.77)$ & & & \\
\hline 10. Age & .03 & $.07 *$ & .06 & $.10^{* *}$ & .01 & .03 & .05 & $-.15^{* *}$ & .01 & - & & \\
\hline 11. Gender & $.08 *$ & .07 & $.12 * *$ & $.08 *$ & .04 & $.17 * *$ & .00 & $.28 * *$ & $-.09 *$ & -.03 & - & \\
\hline 12. Race & -.04 & -.02 & -.05 & .00 & .00 & .04 & .02 & .05 & -.04 & $-.08 *$ & .07 & - \\
\hline Mean & 3.44 & 2.99 & 2.76 & 4.29 & 3.18 & 4.07 & 3.58 & 2.93 & 3.80 & 1.01 & 1.74 & 1.67 \\
\hline SD & 1.15 & 0.86 & 0.74 & 1.50 & 0.78 & 0.53 & 0.56 & 0.76 & 0.52 & 0.10 & 0.44 & 0.47 \\
\hline
\end{tabular}

Notes. IPV = Inventory of Polychronic Values, PAI = Polychronic Attitude Index,

MPI = Multitasking Preference Inventory, PMTS = Polychronic-Monochronic Time Scale.

$N=731-732 . * p<.05, * * p<.01$.

\section{Principal Components Analysis}

In order to examine the factor structure of all polychronicity scale items, a total of 33 items were subjected to a principal components analysis. Prior to performing the principal components analysis, the data were determined to be appropriate for this analysis. Examination of the correlation matrix revealed that nearly all correlations exceeded .3 in magnitude. The Kaiser-Mayer-Oklin value was deemed to be acceptable (.97) and Bartlett's Test of Sphericity was statistically significant $(p<.001)$.

Although the analysis yielded five factors with eigenvalues exceeding 1 , the eigenvalue of factor 1 was 15.2 and explained $46 \%$ of the variance alone. The remaining factors had eigenvalues of less than 2 , and explained 5.5\%, 4.3\%, 3.6\%, and 3.0\%, respectively. The five component solution explained a total of $62.5 \%$ of the variance. An oblimin rotation was performed to facilitate the interpretation of the factors. The pattern matrix and communalities are shown in Tables 2 and 3. 
Table 2. Pattern Matrix for Scale Items

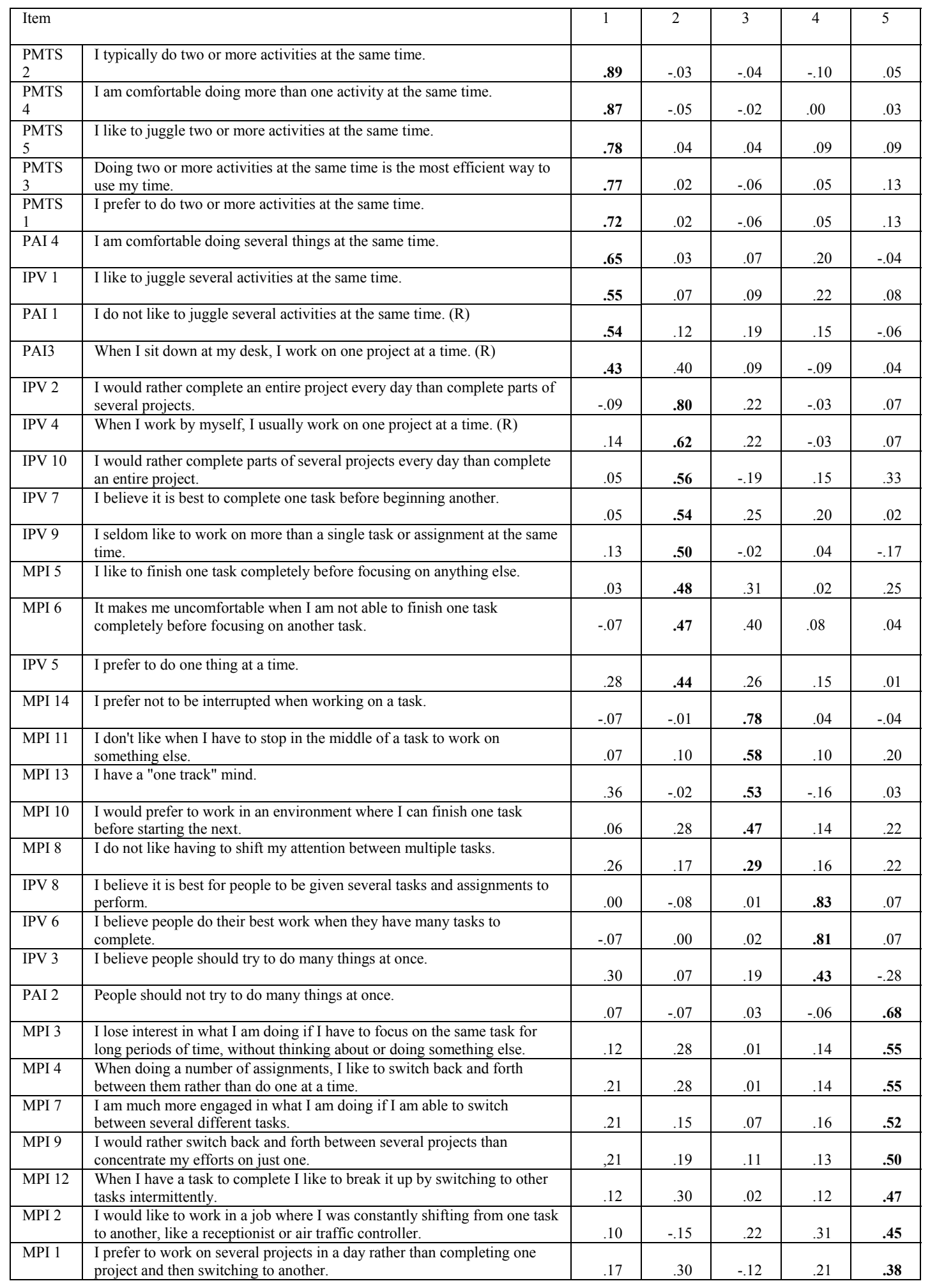


Table 3. Communalities for Scale Items

\begin{tabular}{|c|c|c|}
\hline \multicolumn{2}{|l|}{ Item } & \multirow{2}{*}{$\begin{array}{c}\text { Communalities } \\
.65\end{array}$} \\
\hline IPV 1 & I like to juggle several activities at the same time. & \\
\hline IPV 2 & I would rather complete an entire project every day than complete parts of several projects. & .60 \\
\hline IPV 3 & I believe people should try to do many things at once. & .67 \\
\hline IPV 4 & When I work by myself, I usually work on one project at a time. & .69 \\
\hline IPV 5 & I prefer to do one thing at a time. & .75 \\
\hline IPV 6 & I believe people do their best work when they have many tasks to complete. & .66 \\
\hline IPV 7 & I believe it is best to complete one task before beginning another. & .67 \\
\hline IPV 8 & I believe it is best for people to be given several tasks and assignments to perform. & .69 \\
\hline IPV 9 & I seldom like to work on more than a single task or assignment at the same time. & .29 \\
\hline IPV 10 & I would rather complete parts of several projects every day than complete an entire project. & .62 \\
\hline PAI 1 & I do not like to juggle several activities at the same time. & .61 \\
\hline PAI 2 & People should not try to do many things at once. & .50 \\
\hline PAI 3 & When I sit down at my desk, I work on one project at a time. & .53 \\
\hline PAI 4 & I am comfortable doing several things at the same time. & .66 \\
\hline MPI 1 & $\begin{array}{l}\text { I prefer to work on several projects in a day rather than completing one project and then switching to } \\
\text { another. }\end{array}$ & .55 \\
\hline MPI 2 & $\begin{array}{l}\text { I would like to work in a job where I was constantly shifting from one task to another, like a } \\
\text { receptionist or air traffic controller. }\end{array}$ & .52 \\
\hline MPI 3 & $\begin{array}{l}\text { I lose interest in what I am doing if I have to focus on the same task for long periods of time, without } \\
\text { thinking about or doing something else. }\end{array}$ & .46 \\
\hline MPI 4 & $\begin{array}{l}\text { When doing a number of assignments, I like to switch back and forth between them rather than do } \\
\text { one at a time. }\end{array}$ & .70 \\
\hline MPI 5 & I like to finish one task completely before focusing on anything else. & .66 \\
\hline MPI 6 & $\begin{array}{l}\text { It makes me uncomfortable when I am not able to finish one task completely before focusing on } \\
\text { another task. }\end{array}$ & .54 \\
\hline MPI 7 & I am much more engaged in what I am doing if I am able to switch between several different tasks. & .67 \\
\hline MPI 8 & I do not like having to shift my attention between multiple tasks. & .60 \\
\hline MPI 9 & I would rather switch back and forth between several projects than concentrate my efforts on just one. & .70 \\
\hline MPI 10 & I would prefer to work in an environment where I can finish one task before starting the next. & .71 \\
\hline MPI 11 & I don't like when I have to stop in the middle of a task to work on something else. & .62 \\
\hline MPI 12 & When I have a task to complete I like to break it up by switching to other tasks intermittently. & .60 \\
\hline MPI 13 & I have a "one track" mind. & .49 \\
\hline MPI 14 & I prefer not to be interrupted when working on a task. & .56 \\
\hline $\begin{array}{l}\text { PMTS } \\
1\end{array}$ & I prefer to do two or more activities at the same time. & .74 \\
\hline $\begin{array}{l}\text { PMTS } \\
2 \\
\end{array}$ & I typically do two or more activities at the same time. & .68 \\
\hline $\begin{array}{l}\text { PMTS } \\
3\end{array}$ & Doing two or more activities at the same time is the most efficient way to use my time. & .70 \\
\hline $\begin{array}{l}\text { PMTS } \\
4\end{array}$ & I am comfortable doing more than one activity at the same time. & .73 \\
\hline $\begin{array}{l}\text { PMTS } \\
5\end{array}$ & I like to juggle two or more activities at the same time. & .82 \\
\hline
\end{tabular}




\section{Incremental Validity}

A series of multiple regressions were conducted to build a model for predicting each of the Big Five from measures of polychronicity. The incremental validity of each scale above and beyond the others was assessed to see if any of the measures offer unique variance in the prediction of personality. The IPV offered unique incremental validity in predicting only one of the Big Five, agreeableness, $\Delta R^{2}=.011, \mathrm{p}<.01$, whereas the other analyses of incremental validity fell short of statistical significance. The PAI offered unique incremental validity in predicting only one of the Big Five, openness to experience, $\Delta R^{2}=.005, \mathrm{p}<.05$, whereas the others analyses of incremental validity fell short of statistical significance. The MPI offered unique incremental validity in predicting two of the Big Five, extraversion, $\Delta R^{2}=.009, \mathrm{p}<.05$, and conscientiousness, $\Delta R^{2}=.009$, $\mathrm{p}<.05$, whereas the others analyses of incremental validity fell short of statistical significance. The PMTS offered unique incremental validity in predicting two of the Big Five, agreeableness, $\Delta R^{2}=.007, \mathrm{p}<.05$, and conscientiousness, $\Delta R^{2}=.012, \mathrm{p}<.05$, whereas the others analyses of incremental validity fell short of statistical significance.

Because the IPV, PAI, and PMTS focus on the measurement of two factors of polychronicity (the preference for engaging in multiple tasks at the same time and the belief that it is the best way to get things done) whereas the MPI is derived from the definition of polychronicity as only the a single factor (preference), it is expected that the IPV, PAI, and PMTS will together contribute significant incremental validity in the prediction of each of the Big Five above and beyond the effects of the MPI alone. The IPV, PAI, and PMTS offered unique incremental validity in predicting two of the Big Five, agreeableness, $\Delta R^{2}=.019, \mathrm{p}<.01$, and openness to experience, $\Delta R^{2}=.027, \mathrm{p}<.01$, 
whereas the others analyses of incremental validity fell short of statistical significance. Detailed results of additional analyses of the incremental validity of each of the polychronicity scales are presented in Appendix one. In summary, each of the measures are highly correlated with each other, and predict little unique incremental variance in the prediction of personality, providing support for Hypothesis 1 .

\section{Test of Competing Models}

Structural equation modeling was employed to investigate the factor structure of the polychronicity construct. Specifically, two models were tested. The first model depicts an overarching construct of polychronicity measured by all four scales, whereas the second model depicts a two factor construct (i.e., preference and belief), with the IPV, PAI and PMTS representing measures of belief and the MPI representing a measure of preference.

The fit of both the one and two factor models depicted in Figures 1 and 2 were evaluated with AMOS 18.0 using a maximum likelihood algorithm. The models are both statistically overidentified. A variety of indices of model fit were evaluated. For the one factor model, the overall chi square test of model fit was statistically significant $\left(X^{2}(2)=\right.$ 43.92, $\mathrm{p}<0.001$ ), the Root Mean Square Error of Approximation (RMSEA) was .17 and the $\mathrm{p}$ value for the test of close fit was $\mathrm{p}<.001$, providing indicators of poor model fit. The Tucker Lewis index was .91, providing an indicator of marginally adequate model fit. The Comparative Fit index was .98, providing an indicator of good model fit. Figure 1 presents the standardized parameter estimates for the measurement model. The residuals for each of the observed measures were generally low, suggesting that the measures represent reasonable indicators of the constructs in question. 
Figure 1. One Factor Model of Polychronicity

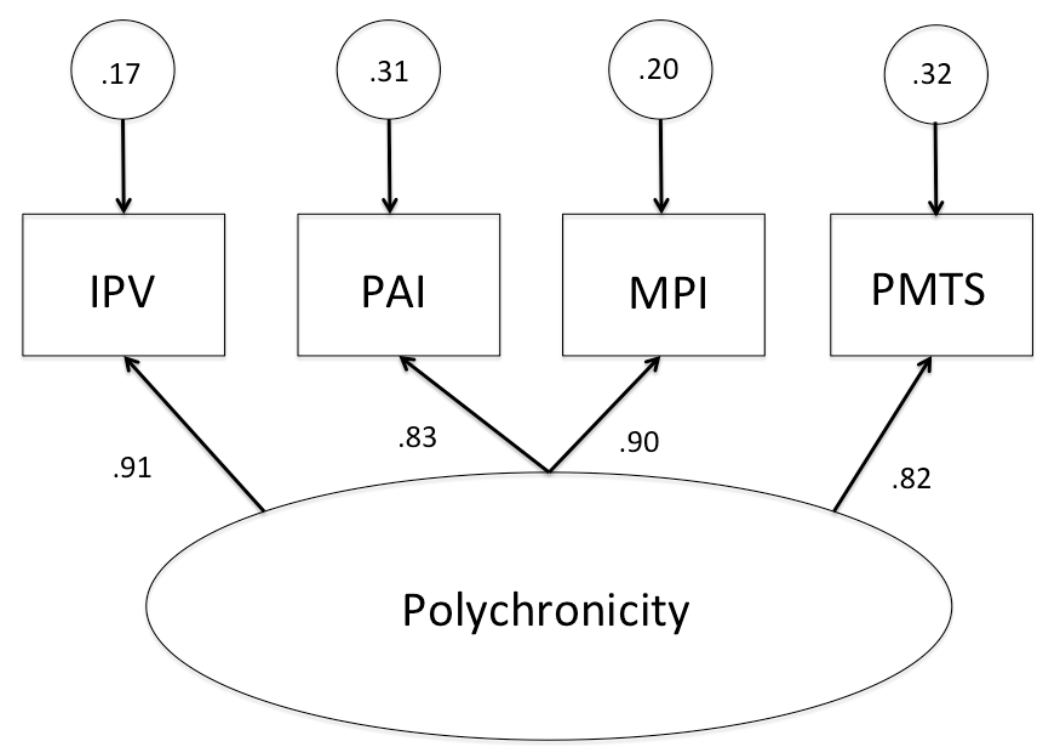

For the two factor model, the overall chi square test of model fit was statistically significant $\left(X^{2}(4)=52.92, \mathrm{p}<.001\right)$, the Root Mean Square Error of Approximation (RMSEA) was .13, and the $\mathrm{p}$ value for the test of close fit was less than 0.01 , providing indicators of poor model fit. The Comparative Fit index was .99 and the Tucker Lewis index was .95 , both indicators of good model fit. Figure 2 presents the standardized parameter estimates for the measurement model. The residuals for each of the observed measures were generally low, suggesting that the measures represent reasonable indicators of preference and belief. 
Figure 2. Two Factor Model of Polychronicity

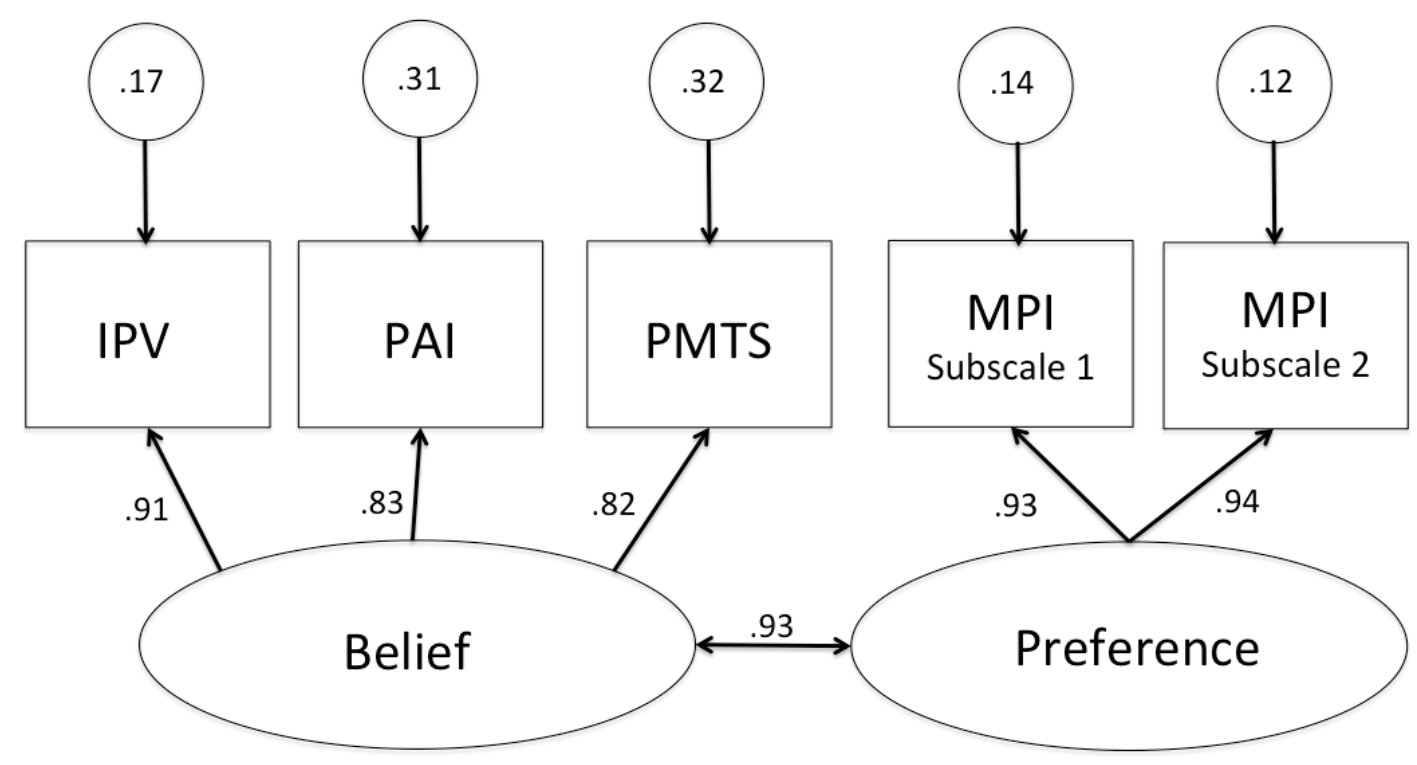

Although the $X^{2}$ is statistically significant for both models tested, it is widely recognized that this index is often significant with 400 or more cases (Kenny, 2011). Inspection of the other fit indices show that neither of the models have overall satisfactory fit. The estimated correlation between the preference and belief is .93, statistically significant $(\mathrm{p}<.05)$. The magnitude of this correlation suggests that they are not conceptually distinct. In combination, the examination of the competing models, analysis of incremental validity predicted by the scales, and investigation of the emerging factor pattern, the results of this analysis provide support for Hypothesis 1, with an overarching factor of polychronicity emerging.

\section{Correlations between Polychronicity and the Big Five}

The correlations between each of the polychronicity scales (IPV, PAI, MPI, and PMTS) and each of the Big Five factors of personality (extraversion, agreeableness, conscientiousness, neuroticism, and openness to experience) are presented in Table 1. 
These correlations serve to investigate Hypotheses 3 - 7. It is noteworthy that the pattern of correlations of measures of polychronicity (IPV, PAI, MPI, and PMTS) were similar across the Big Five measures of personality indicating that the relationships with personality are consistent across scales. As expected, extraversion was significantly related to the IPV $(\mathrm{r}=.12, \mathrm{p}<.01)$, the PAI $(\mathrm{r}=.14, \mathrm{p}<.01)$, the MPI $(\mathrm{r}=.17, \mathrm{p}<.01)$ and the PMTS $(\mathrm{r}=.16, \mathrm{p}<.01)$ providing support for Hypothesis 3. Unexpectedly, neuroticism was not significantly related to any of the polychronicity scales $(\mathrm{p}<.05)$, failing to provide support for Hypothesis 4.

Hypothesis 5 predicted that conscientiousness would be related to polychronicity. However, conscientiousness did not exhibit significant correlations with any of the polychronicity scales, failing to provide support for Hypothesis 5. Supplemental analyses were conducted to determine whether facets of conscientiousness would relate differentially to polychronicity and multitasking. Results are summarized in Table 4 below, and indicate that achievement striving is the driving force in the relationship between conscientiousness and polychronicity. Dutifulness exhibited non-significant, near zero correlations which may have diluted the observed correlation between conscientiousness and polychronicity in this study.

Table 4. Study 1 Correlations between Polychronicity, Dutifulness, and Achievement Striving

\begin{tabular}{lcc}
\hline Scale & Dutifulness & Achievement Striving \\
\hline IPV & -.03 & .07 \\
PAI & .02 & $.15^{* *}$ \\
MPI & -.02 & .07 \\
PMTS & .01 & $.11^{* *}$ \\
\hline $\mathrm{p}<.05,{ }^{* *} \mathrm{p}<.01$. & &
\end{tabular}


Hypothesis 6 postulated that agreeableness would be positively related to polychronicity. Hypothesis 6 is partially supported, as agreeableness was significantly related to the PAI $(\mathrm{r}=.11, \mathrm{p}<.01)$, the MPI $(\mathrm{r}=.09, \mathrm{p}<.05)$ and the PMTS $(\mathrm{r}=.13, \mathrm{p}<$ $.01)$, yet not significantly related to the IPV $(\mathrm{p}<.05)$. Hypothesis 7 predicted that openness to experience would not be significantly related to polychronicity. Unexpectedly, openness to experience was significantly related to all four measures of polychronicity including the IPV $(r=.12, \mathrm{p}<.01)$, the PAI $(\mathrm{r}=.18, \mathrm{p}<.01)$, the MPI $(\mathrm{r}$ $=.13, \mathrm{p}<.01)$ and the PMTS $(\mathrm{r}=.20, \mathrm{p}<.01)$.

\section{Predicting Polychronicity from the Big Five}

A series of multiple regressions were used to predict each of the polychronicity scale scores (i.e., IPV, PAI, MPI, PMTS) from demographic controls and the Big Five (i.e., extraversion, agreeableness, conscientiousness, neuroticism, and openness to experience). As shown in Table 5, each model is statistically significant. The model predicting IPV was significant, $F(6,728)=4.57, R^{2}=.191, p<.01$. Gender, extraversion, conscientiousness, and openness to experience were significant unique predictors ( $p<$ $.05)$. The model predicting PAI was also significant $F(6,727)=6.48, R^{2}=.051, p<.01$. Age, extraversion and openness to experience were significant unique predictors of PAI. The model predicting MPI was also significant $F(6,728)=7.72, R^{2}=.060, p<.01$. Gender, extraversion, conscientiousness, and openness to experience were significant unique predictors of MPI. The model predicting PMTS was also significant $F(7,727)=$ $7.72, R^{2}=.070, p<.01$. 
Table 5. Predicting Polychronicity Scales from the Big Five

\begin{tabular}{llccc}
\hline & IPV & PAI & MPI & PMTS \\
Predictors & $\beta$ & $\beta$ & $\beta$ & $\beta$ \\
\hline Age & -- & $.08^{*}$ & -- & $.10^{* *}$ \\
Gender & $.11^{* *}$ & -- & $.13^{* *}$ & $.09^{*}$ \\
Extraversion & $.08^{*}$ & $.09^{*}$ & $.13^{* *}$ & $.09^{*}$ \\
Agreeableness & -.03 & .05 & .01 & .04 \\
Conscientiousness & $-.08^{*}$ & -.06 & $-.12^{* *}$ & -.05 \\
Neuroticism & -.05 & -.02 & -.04 & -.02 \\
Openness to & $.13^{* *}$ & $.15^{* *}$ & $.12^{* *}$ & $.17^{* *}$ \\
Experience & & & & \\
\hline$R^{2}$ & $.037^{* *}$ & $.051^{* *}$ & $.060^{* *}$ & \\
& & & & $.070^{* *}$ \\
\hline
\end{tabular}

Notes. Demographic controls entered only when zero order correlations were significant. $\mathrm{N}=727-732 . * \mathrm{p}<.05, * * \mathrm{p}<.01$.

\section{Study 2}

Study two quantitatively reviews the existing research investigating the relationships between measures of polychronicity and the Big Five. Results of the metaanalysis of polychronicity and personality are provided in Table 6 . The first column identifies the personality variable being analyzed for its relationship with polychronicity. The number of studies, total $\mathrm{N}$ across studies, average correlation corrected for sampling error, observed standard deviation, residual standard deviation, percent variance due to sampling error, and the $95 \%$ credibility interval are presented.

\section{Observed Correlations}

As expected the sample size weighted mean correlation between extraversion and polychronicity indicated a positive relationship (.30). For this estimate, the $95 \%$ credibility interval did not include zero, providing support for the significant relationship between extraversion and polychronicity. The finding of a significant relationship between extraversion and polychronicity provides support for Hypothesis 3 . 
For neuroticism, the sample size weighted mean correlation with polychronicity was -.34 . However, for this estimate, the $95 \%$ credibility interval included zero. Thus, the relationship between neuroticism and polychronicity fell short of statistical significance, failing to provide support for Hypothesis 4 .

The sample size weighted mean correlation between conscientiousness and polychronicity was .25 . However, for this estimate, the $95 \%$ credibility interval included zero. Thus, the relationship between conscientiousness and polychronicity fell short of statistical significance, failing to provide support for Hypothesis 5.

For agreeableness, the sample size weighted mean correlation with polychronicity was .31 . However, for this estimate, the $95 \%$ credibility interval included zero. Thus, the relationship between agreeableness and polychronicity fell short of statistical significance, failing to provide support for Hypothesis 6.

The sample size weighted mean correlation between openness to experience and polychronicity was .35 . For this estimate, the $95 \%$ credibility interval excluded zero, providing support for a significant relationship between openness to experience and polychronicity. No relationship was predicted between openness to experience and polychronicity, thus the significant relationship detected failed to provide support for Hypothesis 7. 
Table 6. Meta-Analysis of Polychronicity and Personality

\begin{tabular}{lccccccc}
\hline Variable & $k$ & $N$ & $r$ & SD $_{\text {obs }}$ & SD Res & \% Var SE & CI \\
\hline Extraversion & 19 & 7056 & .30 & .1137 & .1022 & 19.1167 & $.01-.50$ \\
Neuroticism & 18 & 6934 & -.34 & .2298 & .2245 & 4.5123 & $-.78-.10$ \\
Conscientiousness & 12 & 5811 & .25 & .1923 & .1872 & 5.2131 & $-.11-.62$ \\
Agreeableness & 10 & 5675 & .31 & .1895 & .1852 & 4.5313 & $-.05-.67$ \\
Openness & 10 & 5675 & .35 & .1652 & .1603 & 5.9357 & $.03-.66$ \\
\hline
\end{tabular}

Note. $k=$ number of correlations; $N=$ total sample size; $r=$ average correlation corrected for sampling error; SDObs $=$ observed standard deviation; SDRes $=$ standard deviation remaining after sampling error variance is removed ; \% Var SE $=$ percent variance due to sampling error; $\mathrm{CI}=95 \%$ credibility interval.

\section{Estimated True Correlations}

The reliability of the measures and sample size weighted average reliability for the variables of interest were computed to correct the correlations for unreliability to estimate true correlations. The average reliabilities and sample size weighted average reliabilities are presented below in Table 7.

Table 7. Frequency Weighted and Sample Size Weighted Reliabilities

\begin{tabular}{|c|c|c|c|c|c|c|}
\hline & $\mathrm{k}$ & $\mathrm{N}$ & $\begin{array}{c}\text { Frequency } \\
\text { Weighted } \\
\text { Average }\end{array}$ & $\begin{array}{c}\text { Frequency } \\
\text { Weighted } \\
\text { SD }\end{array}$ & $\begin{array}{c}\text { Sample Size } \\
\text { Weighted } \\
\text { Average }\end{array}$ & $\begin{array}{l}\text { Sample Size } \\
\text { Weighted } \\
\text { SD }\end{array}$ \\
\hline Polychronicity & 19 & 7098 & .80 & .11 & .69 & .12 \\
\hline Extraversion & 17 & 6787 & .86 & .05 & .89 & .04 \\
\hline Neuroticism & 16 & 6665 & .82 & .06 & .77 & .05 \\
\hline Conscientiousness & 10 & 5542 & .84 & .06 & .83 & .03 \\
\hline Agreeableness & 9 & 5453 & .81 & .04 & .83 & .03 \\
\hline $\begin{array}{l}\text { Openness to } \\
\text { Experience }\end{array}$ & 9 & 5453 & .79 & .03 & .80 & .02 \\
\hline
\end{tabular}

After correcting for unreliability in the measures, the estimated true relationships between polychronicity and the estimate became stronger. The corrected correlation for the relationship between polychronicity and extraversion is .38 . The corrected correlation for the relationship between polychronicity and neuroticism is -..49. The corrected 
correlation for the relationship between polychronicity and conscientiousness is .33 . The corrected correlation for the relationship between polychronicity and agreeableness is .41 . The corrected correlation for the relationship between polychronicity and openness to experience is .47 .

\section{Study 3}

Study three investigates the nomological network of multitasking ability as well as its validity in the prediction of supervisor rating of multitasking performance and overall job performance. Additionally, study three examines supervisor rating of multitasking performance as a mediator of the relationship between multitasking ability and overall job performance.

\section{Correlations among Key Variables}

The correlations between cognitive ability, Big Five factors of personality, multitasking ability, multitasking performance, and overall performance, are presented in Table 8. These correlations are used to investigate hypotheses 3 - 15.

As hypothesized, multi-tasking ability was related to overall job performance ( $\mathrm{r}$ $=.13$ ) with the $90 \%$ confidence interval ranging from .01 to .25 . Thus, hypothesis 8 was supported. However, multitasking ability was not predictive of supervisory ratings of multitasking performance $(\mathrm{r}=.04)$ indicating no support for hypothesis 9 .

As expected, cognitive ability was strongly related to overall job performance ( $\mathrm{r}$ $=.25$ ), supporting hypothesis 10 . Unexpectedly, the other individual difference variables of interest (extraversion, openness to experience, conscientiousness, agreeableness, and emotional stability) did not exhibit significant relationships with overall job performance. For the criterion of multitasking performance, again only cognitive ability had a 
predictive validity of .13 ( $90 \%$ confidence interval of .02 to .25 ) and none of the Big Five factors of personality predicted multitasking performance. Thus, hypothesis 11 was not supported, as none of the Big Five factors of personality were predictive of overall job performance and multitasking performance.

Hypothesis 12 postulated that cognitive ability and Big Five factors of personality would correlate with a measure of multitasking ability. I hypothesized and found a strong correlation between cognitive ability and multitasking ability (.63), providing support for hypothesis 12. I expected and found negative correlations between conscientiousness and multitasking ability (-.20) with the $90 \%$ confidence interval extending between -.08 to -.32 . However, the pattern of correlations with the other Big Five variables was low (ranging between .02 to .06 ), providing partial support for hypothesis 13. 
Table 8.

Correlations Among Key Variables in Study 3

\begin{tabular}{|c|c|c|c|c|c|c|c|c|c|}
\hline & 1 & 2 & 3 & 4 & 5 & 6 & 7 & 8 & 9 \\
\hline 1. MT Ability & -- & & & & & & & & \\
\hline 2. MT Performance & .04 & -- & & & & & & & \\
\hline 3. Overall Job Perf & .13 & $.74 *$ & -- & & & & & & \\
\hline 4. Cognitive Ability & $.63^{*}$ & .13 & $.25^{*}$ & -- & & & & & \\
\hline 5. Extraversion & -.06 & -.08 & -.06 & -.01 & -- & & & & \\
\hline 6. Openness & -.02 & -.01 & .07 & .07 & $.40^{*}$ & -- & & & \\
\hline 7. Conscientiousness & $-.20 *$ & .02 & .01 & $-.24 *$ & $.36 * *$ & $.31 *$ & -- & & \\
\hline 8. Agreeableness & -.03 & -.09 & -.05 & .02 & $.13^{*}$ & $.33 *$ & $.28 *$ & -- & \\
\hline 9. Emotional Stability & -.06 & .08 & .05 & .08 & $.38 *$ & $.41^{*}$ & $.41^{*}$ & $.22 *$ & -- \\
\hline Mean & 12.87 & 4.99 & 4.22 & 0.90 & 5.69 & 5.92 & 5.89 & 5.83 & 5.76 \\
\hline SD & 19.85 & 1.18 & 0.79 & 0.64 & 0.84 & 0.54 & 0.51 & 0.78 & 0.50 \\
\hline
\end{tabular}


Consistent with the supplemental analyses conducted in study one, the relationship between multitasking and conscientiousness was further explored at the facet level. Achievement striving was not significantly related to either multitasking ability or multitasking performance ( $\mathrm{r}=.00$ and .05 , respectively) and sense of duty was not significantly related to either multitasking ability or multitasking performance $(r=-.08$ and .03 , respectively).

\section{Incremental Validity}

The incremental validity of multitasking ability over cognitive ability and Big Five factors of personality was examined using hierarchical regressions. In the first step, cognitive ability and the Big Five factors of personality (extraversion, openness to experience, conscientiousness, agreeableness, and emotional stability) were entered. Multitasking ability was entered in the second step. The analyses were conducted separately for the criterion of multitasking performance and for the criterion of overall job performance.

As shown in Table 9, none of the individual predictors had significant unique effects. Multitasking ability did not add incremental variance beyond cognitive ability and Big Five factors of personality for predicting either multitasking performance or overall job performance $\left(\Delta R^{2}=.001\right.$ and .003 , respectively). Thus, hypothesis 14 was not supported. 
Table 9.

Incremental Validity of Multitasking Ability for of the Criteria of Multitasking Performance and Overall Performance in Study 3

\begin{tabular}{lcccc} 
& \multicolumn{2}{c}{ Multitasking Performance } & \multicolumn{2}{c}{ Overall Job Performance } \\
\cline { 2 - 5 } & Step 1 & Step 2 & Step 1 & Step 2 \\
Cognitive Ability & $\beta$ & $\beta$ & $\beta$ & $\beta$ \\
\cline { 2 - 5 } Extraversion & .05 & .02 & .16 & .12 \\
Openness & -.11 & -.11 & -.13 & -.13 \\
Conscientiousness & .02 & .02 & .09 & .09 \\
Agreeableness & .08 & .08 & .10 & .10 \\
Emotional Stability & -.20 & -.20 & -.18 & -.18 \\
MT Ability & .09 & .09 & .02 & .03 \\
\hline$R^{2}$ & - & .04 & - & .07 \\
\hline$\Delta R^{2}$ & .045 & .046 & .060 & .062 \\
$\mathrm{~N}=130$ & - & .001 & - & .003
\end{tabular}

\section{Multitasking Performance as a Mediator}

Evidence that multitasking performance partially mediates the relationship between multitasking ability and overall job performance was found. When multitasking ability was the only predictor of overall job performance the beta weight was .13, but when both multitasking ability and multitasking performance were predictors of overall job performance the beta weight for multitasking ability dropped $(\beta=.10)$, providing support for hypothesis 15 . Supervisor rating of multitasking performance was a significant unique predictor of overall job performance $(\beta=.74)$.

\section{Study 4}

Study four investigates the nomological networks of multitasking ability and polychronicity as well as the validity of multitasking ability in the prediction of both supervisor rating of multitasking performance and overall job performance. Study four also examines supervisor rating of multitasking performance as a mediator of the 
relationship between multitasking ability and overall job performance. Additionally, study 4 investigates polychronicity as a moderator of the relationship between multitasking ability and both supervisor rating of multitasking performance and overall job performance.

\section{Correlations among Key Variables}

Correlations among the key variables included in study four are summarized in Table 13 and are referred to infer support for hypotheses 3 - 15. It is informative to note that the correlation between polychronicity and multitasking ability was only .13 suggesting the distinctiveness of the two constructs. Preference and ability are positively correlated ( $90 \%$ confidence interval of -.02 to .27$)$ but unique.

The correlation between multitasking ability and overall job performance was .18 and the $90 \%$ confidence interval includes zero (.00 to .32 ), failing to provide support for hypothesis 8 . The predictive validity of multitasking ability for predicting supervisory ratings of multitasking performance was a robust 30 (with $90 \%$ confidence interval ranging from .15 to .43$)$. This pattern of robust predictive validity for the criterion of multitasking performance but weaker validity for the criterion of overall job performance was opposite to the pattern found in study three (where multitasking ability predicted overall job performance .13 and multitasking performance with a validity of .04). With a validity of .30, hypotheses 9 was supported in study four.

For hypotheses 10 and 11, I refer to the correlations between cognitive ability and the Big Five personality factors with the two criteria: overall job performance and ratings of multitasking performance. The correlations in Table 10 indicate that cognitive ability has useful levels of predictive validity for the two criteria (.16 and .11, respectively), 
providing support for hypothesis 10 . Among the Big Five factors, none had a significant correlation with either overall performance or multitasking performance ratings (where the $90 \%$ confidence interval did not include zero). Thus, hypothesis 11 was not supported in this sample.

While cognitive ability was strongly correlated with multitasking ability (.43), it only correlated .05 with polychronicity. Polychronicity scores had strong correlations with extraversion (.48), openness (.37), conscientiousness (.32) and emotional stability (.40). This pattern of correlations clearly distinguishes between polychronicity as a noncognitive measure of preference that correlates highly with four of the Big Five personality factors (except agreeableness) and low with cognitive ability whereas the opposite is noted for multitasking ability.

Consistent with the supplemental analyses conducted in studies one and three, the relationship between polychronicity and conscientiousness was further explored at the facet level. Achievement striving was significantly positively related to polychronicity ( $\mathrm{r}$ $=.33)$, but not significantly related to multitasking ability or multitasking performance $(\mathrm{r}$ $=-.04$ and -.01 , respectively) .

Sense of duty was significantly positively related to polychronicity $(r=.20)$ but not significantly related to either multitasking ability or multitasking performance $(r=-.16$ and -.14 , respectively). 
Table 10.

Correlations Among Key Variables in Study 4

\begin{tabular}{|c|c|c|c|c|c|c|c|c|c|c|}
\hline & 1 & 2 & 3 & 4 & 5 & 6 & 7 & 8 & 9 & 10 \\
\hline 1. MT Ability & -- & & & & & & & & & \\
\hline 2. MT Performance & $.30^{*}$ & -- & & & & & & & & \\
\hline 3. Overall Job Perf & .18 & $.77^{*}$ & -- & & & & & & & \\
\hline 4. Cognitive Ability & $.43^{*}$ & .11 & .16 & -- & & & & & & \\
\hline 5. Extraversion & .03 & -.08 & -.10 & .04 & -- & & & & & \\
\hline 6. Openness & .00 & .00 & .00 & .09 & $.45^{*}$ & -- & & & & \\
\hline 7. Conscientiousness & -.11 & -.02 & -.02 & -.10 & $.41^{*}$ & $.40^{*}$ & -- & & & \\
\hline 8. Agreeableness & -.05 & .09 & .05 & .11 & .04 & $.27 *$ & $.33 *$ & -- & & \\
\hline 9. Emotional Stability & .05 & -.15 & -.10 & .01 & $.48^{*}$ & $.50 *$ & $.52 *$ & .19 & -- & \\
\hline 10. Polychronicity & .13 & -.07 & -.04 & .05 & $.48^{*}$ & $.37 *$ & $.32 *$ & .01 & $.40^{*}$ & -- \\
\hline Mean & 14.02 & 5.27 & 4.53 & 1.04 & 5.95 & 6.07 & 5.91 & 5.96 & 5.79 & 1.49 \\
\hline SD & 18.80 & 1.17 & 0.81 & 0.45 & 0.83 & 0.51 & 0.53 & 0.73 & 0.55 & 0.50 \\
\hline
\end{tabular}




\section{Incremental Validity}

Hierarchical regressions were used to test the incremental validity of multitasking ability in predicting both multitasking performance and overall performance above and beyond the effect of traditional predictors (i.e., cognitive ability and personality), as shown in Table 11. For predicting multitasking performance, none of the individual predictors had significant unique effects. The two-step model including multitasking ability explained significant incremental variance, $R^{2}=.136, \Delta R^{2}=.077$. For predicting overall job performance, the model including cognitive ability and the Big Five factors of personality fell short of statistical significance, $R^{2}=.061$. The two-step model including multitasking ability did not explain significant incremental variance, $R^{2}=.074, \Delta R^{2}=$ .014 , showing partial support for hypothesis 14 .

Table 11.

Incremental Validity of Multitasking Ability for the Criteria of Multitasking Performance and Overall Performance in Study 4

\begin{tabular}{lcccc} 
& \multicolumn{2}{c}{ Multitasking Performance } & \multicolumn{2}{c}{ Overall Job Performance } \\
\cline { 2 - 5 } & Step 1 & Step 2 & Step 1 & Step 2 \\
\cline { 2 - 5 } & $\beta$ & $\beta$ & $\beta$ & $\beta$ \\
Cognitive Ability & .12 & -.02 & .19 & .13 \\
Extraversion & -.08 & -.08 & -.14 & -.13 \\
Openness & .03 & .03 & .04 & .03 \\
Conscientiousness & .10 & .12 & .11 & .11 \\
Agreeableness & .08 & .09 & .01 & .02 \\
Emotional Stability & -.19 & -.21 & -.11 & -.11 \\
MT Ability & - & $.31^{*}$ & - & .13 \\
\hline$R^{2}$ & .059 & .136 & .061 & .074 \\
\hline$\Delta R^{2}$ & - & $.077^{*}$ & - & .014 \\
$\mathrm{~N}=89$ & & & & \\
${ }^{*} \mathrm{p}<.05$ & & & &
\end{tabular}




\section{Multitasking Performance as a Mediator}

A series of regressions were used to test multitasking performance as a mediator of the relationship between multitasking ability and overall job performance. Evidence that multitasking performance partially mediates the relationship between multitasking ability and overall job performance was found, providing support for hypothesis 15 . When both multitasking performance and multitasking ability were analyzed as predictors of overall job performance, the beta weight for multitasking ability dropped significantly (from $\beta=.18$ to $\beta=-.05$ ). Supervisor rating of multitasking performance was a significant unique predictor of overall job performance $(\beta=.77)$.

\section{Polychronicity as a Moderator}

Hierarchical regressions were used to test for moderating effects of polychronicity on the relationship between multitasking ability and multitasking performance, as shown in Table 12. Multitasking ability was a significant unique predictor of multitasking performance. The interaction term (multitasking ability x polychronicity) was entered in the second step, which significantly increased the fit of the model $\left(\Delta R^{2}=.146 \mathrm{p}<.05\right)$ to the data indicating that polychronicity moderates the relationship between multitasking ability and multitasking performance. Thus, hypothesis 16 was supported. The relationship between multitasking ability and multitasking performance was stronger for those high on polychronicity.

The moderating effect of polychronicity on the multitasking-overall job performance relationship is also summarized in table 12. As shown in table 12, neither multitasking ability nor polychronicity had a significant unique effect. The interaction 
term (multitasking ability $\mathrm{x}$ polychronicity) was entered in the second step, the increase in variance explained, $\Delta R^{2}$, was $.077(\mathrm{p}<.01)$, and the product term had a positive beta weight suggesting that the relationship between multitasking ability and overall job performance was stronger for polychronic individuals. Thus, support for hypothesis 17 was inferred.

Table 12.

Moderating Effects of Polychronicity on the Multitasking Ability-Performance Relationships

\begin{tabular}{lcccc} 
& \multicolumn{2}{c}{ Multitasking Performance } & \multicolumn{2}{c}{ Overall Job } \\
& \multicolumn{3}{c}{ Performance } \\
\cline { 2 - 5 } & Step 1 & Step 2 & Step 1 & Step 2 \\
\cline { 2 - 5 } MT Ability & $\beta$ & $\beta$ & $\beta$ & $\beta$ \\
Polychronicity & $.31^{*}$ & $.30^{*}$ & .18 & .17 \\
MT Ability x Poly & -.10 & -.06 & -.04 & -.01 \\
\hline$R^{2}$ & - & $.22^{*}$ & - & $.28^{*}$ \\
\hline$\Delta R^{2}$ & .098 & .146 & .033 & .110 \\
$\mathrm{~N}=88$ & - & $.048^{*}$ & - & $.077^{*}$ \\
${ }^{*} p<.05$ & & & &
\end{tabular}

The two moderating effects are depicted in Figures 3 and 4. The sample was split into two halves based on polychronicity scores (median split) to depict this interaction effect. 
Figure 3.

Relationship between Multitasking Ability and Multitasking Performance

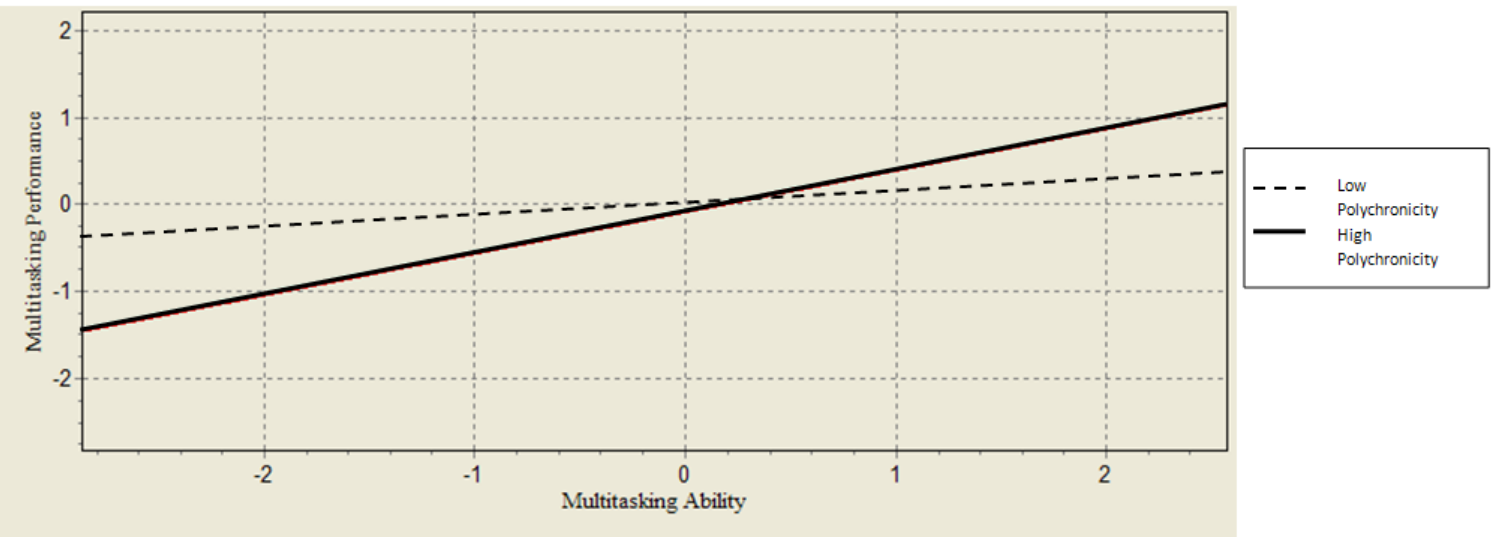

Figure 4.

Relationship between Multitasking Ability and Overall Job Performance

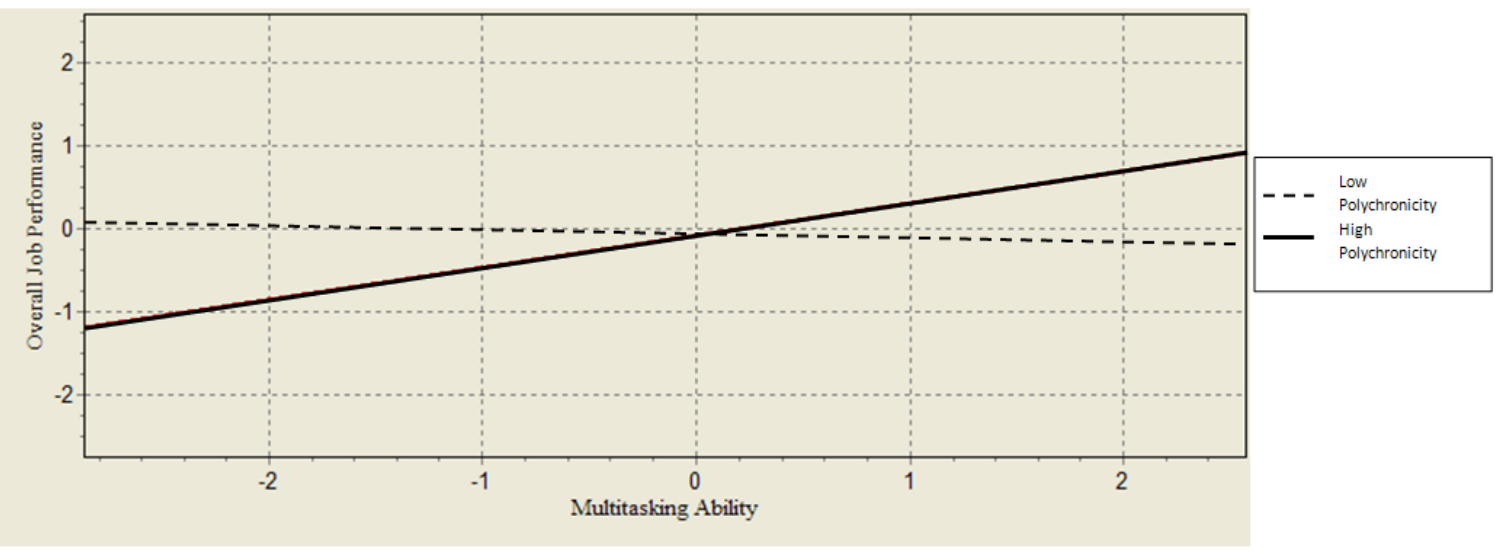

\section{Conclusions}

In conclusion, polychronicity appears to consist of one overarching factor, with each measure explaining incremental validity in only a few external criteria. Results of studies one and two converge to identify extraversion and openness to experience as consistent external correlates of all measures of polychronicity. Both studies three and four found multitasking ability to be significantly related to cognitive ability and study four found multitasking ability to be significantly related to multitasking performance. 
Studies three and four found supervisor ratings of multitasking performance to partially mediate the relationship between multitasking ability and an overall composite of job performance. Study four found multitasking ability to contribute significant unique incremental variance in supervisor ratings of multitasking performance above and beyond that of traditional predictors. Study four found polychronicity to moderate the relationship between multitasking ability and both supervisor ratings of multitasking performance and overall job performance. 


\section{CHAPTER V: DISCUSSION}

This series of four studies examined two important constructs related to time orientation in organizations: polychronicity and multitasking. Study one examined the internal factor structure of polychronicity and the external correlates of polychronicity in a large sample of undergraduate students. Study two meta-analyzed the results of existing studies to draw conclusions about the relationships between polychronicity and the Big Five factors of personality. Studies three and four investigated the predictive validity of multitasking ability, the incremental validity of multitasking ability above and beyond that of traditional predictors, and supervisor rating of multitasking performance as a mediator of the relationship between multitasking ability and overall job performance in two organizational samples. Study four also examined the preference for multitasking (polychronicity) as a moderator of the relationship between multitasking ability and both supervisor rating of multitasking performance and overall job performance. Results of these studies help to clarify the construct validity of polychronicity and multitasking as well as raise important implications for practitioners.

Study one tested the internal structure of polychronicity by evaluating two models: one representing the overarching construct of polychronicity, and the other representing the two subfactors of polychronicity (preference and belief). In addition to structural equation modeling, study 1 examined the incremental validity of each of the scales above and beyond that of the others to determine whether the various methods of

measuring polychronicity will explain unique variance in the construct. Results found all four scales of polychronicity to be highly correlated, despite their definitional differences. One primary factor emerged from a principal components analysis of all the scale items. 
Additionally, in almost all cases, each of the scales did not explain additional incremental variance in predicting measures of personality above and beyond that of the other three scales. In combination, the results of study one strongly support the model representing the overarching factor of polychronicity in a sample of young, Hispanic females in a public university.

Study one also further investigated the measurement of polychronicity and external correlates of polychronicity, by examining the relationships of scale scores to the Big Five factors of personality. The patterns of correlations with these personality factors were similar across the four measures of polychronicity, indicating that the relationships are consistent across scales. Extraversion and openness to experience were positively related to all four measures of polychronicity, agreeableness was positively related to three of the four scales, and neither neuroticism nor conscientiousness was significantly related to any of the measures.

Study two quantitatively reviewed the relationships between polychronicity and the Big Five factors of personality. Results were mostly consistent with the examination of personality correlates of polychronicity conducted in study one. Extraversion and openness to experience were positively related to polychronicity, whereas neuroticism, conscientiousness, and agreeableness were not significantly related to polychronicity.

Study three found multitasking ability to be highly correlated with cognitive ability, and both were related to overall job performance. Multitasking ability was negatively related to conscientiousness and not significantly related to the other factors of personality. However, the predictive ability of cognitive ability, personality, and multitasking ability were not as robust as expected. Multitasking ability failed to 
demonstrate incremental validity in the prediction of both multitasking performance and overall job performance. Evidence was found that supervisor rating of multitasking performance partially mediates the relationship between multitasking ability and overall job performance.

Study four found that cognitive ability was significantly related to multitasking ability. The predictive ability of cognitive ability, personality, and multitasking ability were useful. Multitasking ability was the only significant unique predictor of multitasking performance; none of the other individual predictors demonstrated a unique predictive effect for either multitasking performance or overall job performance. Multitasking ability demonstrated incremental validity (beyond cognitive ability and Big Five factors of personality) in the prediction of multitasking performance. Consistent with study three, evidence was found that multitasking performance mediates the relationship between multitasking ability and overall job performance, highlighting the utility of assessing multitasking ability in a hiring context only when multitasking is a critical determinant of successful job performance.

Furthermore, polychronicity was found to moderate the relationship between multitasking ability and supervisor rating of multitasking performance suggesting that individuals who exhibit a preference for multitasking will be more successful in a multitasking environment. Polychronicity also moderated the relationship between multitasking ability and overall job performance. The results in study 4 also clearly indicated a distinct pattern of correlations between multitasking ability and polychronicity with other factors (i.e, cognitive ability and personality). Multitasking ability had a correlation of .43 with cognitive ability and very low correlations with 
personality factors (highest was -.20 and -.11 with Conscientiousness in studies 3 and 4 , respectively). In contrast polychronicity correlated only .05 with cognitive ability but highly with four of the Big Five personality factors (except with Agreeableness). Along with a correlation of .13, the results clearly indicate that multitasking ability and polychronicity are distinct.

The correlates of polychronicity and personality were somewhat inconsistent across studies. Study four found polychronicity to be significantly related to four of the five factors (extraversion, openness to experience, conscientiousness, and neuroticism), results inconsistent with those of studies one and two, which found polychronicity to be consistently related to only extraversion and openness to experience. Differences in results could be attributed to differences in the student and working populations. Additionally, study four measured polychronicity with a proprietary measure, while studies one and two measured polychronicity with four published measures.

The relationships between personality and multitasking ability, multitasking performance, and overall job performance were weak in studies three and four. The lack of significant relationships between personality and overall job performance is inconsistent with previous research (Barrick \& Mount, 1991; Barrick, et al., 2001; Oswald et al., 2007). However, these weak validities for personality variables are consistent with the caveats raised in some recent reviews of the validity of the Big Five factors of personality (e.g., Morgeson, Campion, Dipboye, Hollenbeck, Murphy \& Schmitt, 2007). It should be noted that the analyses were conducted at the level of the Big Five factors of personality. It is possible that some of the narrower dimensions had stronger validities for predicting overall job performance. However, in study three, none 
of the narrower facets had validity greater than .13 . Similarly in study four, only 2 of the 12 narrow facets had correlations higher than .13 for predicting overall job performance. Moreover, I do not elaborate on these facet validities as this paper was not written to summarize the validity of personality for predicting job performance; rather to investigate how multitasking mapped into the personality domain. Given that the focus was on the nomological network of multitasking and the frequent use of the Big Five, the analyses were situated within this framework.

\section{Supplemental Analyses}

In study one, the original one factor theoretical models of polychronicity could not all be evaluated for fit with the data as AMOS classified it as underidentified and the analysis could not be completed. The one factor model was altered into a simplified model, but examination of the fit indices for both models revealed unsatisfactory fit. As a supplementary analysis, two subscale scores were created for each the IPV, PAI, and PMTS based on a logical mapping of items (detailed in Appendix 2) designed to measure each preference and belief as depicted in Figure 3. The overall chi square test of model fit was statistically significant $\left(X^{2}(13)=322.39, p<.001\right)$, the Root Mean Square Error of Approximation (RMSEA) was .18 and the p value for the test of close fit was $p<.001$, the Tucker Lewis index was .82, and the Comparative Fit index was .92, uniformly providing indicators of poor model fit. Figure 3 presents the standardized parameter estimates for the measurement model. The estimated correlation between the preference and belief is .99 , statistically significant $(p<.05)$. Given the magnitude of this correlation, these results support the conclusion that preference and belief are not conceptually distinct. 
Figure 3. Two Factor Model of Polychronicity with Subscales

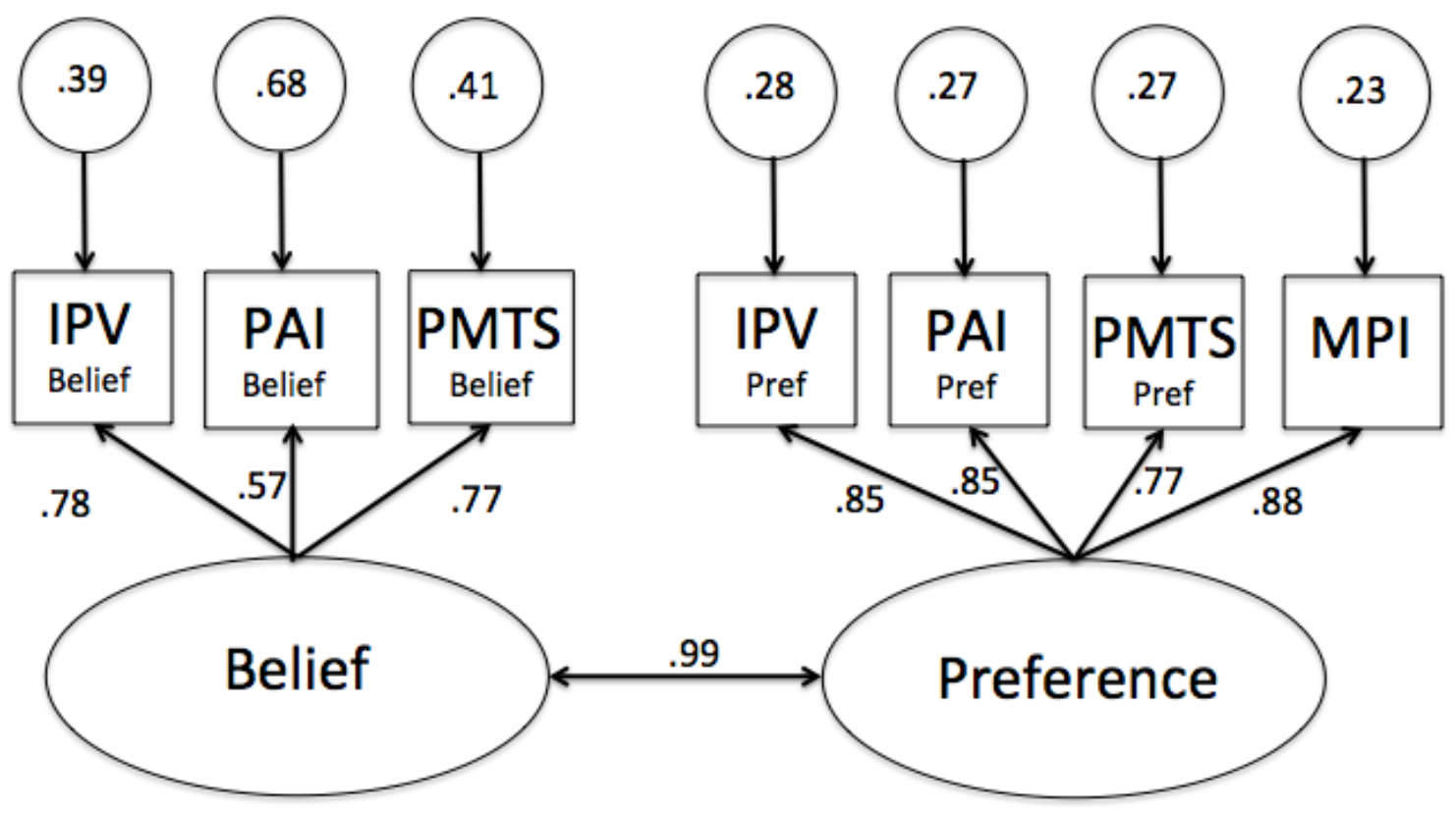

The linearity of the multitasking-performance relationship also needs to be considered. In the data from studies three and four ( $\mathrm{N}=175$ and 119), no non-linearities were detected. For example, the incremental variance was only .001 $(p>.70)$ when the square term (of multitasking ability) was added to the polynomial regression between multitasking ability and overall job performance in study four (In study three, the incremental variance was $.014, p>.15$ ). Although no empirical support for curvilinear relationships was found, theoretically such relationships are plausible. Multitasking to some extent may enrich the job, increase the motivating potential score, but at excessive levels may result in a deterioration of performance.

\section{Practical Implications}

Multitasking is an important aspect of today's work environment (e.g., Lindbeck $\&$ Snower, 2000). The dynamic and rapid changes taking place in the workplace (cf., 
Howard, 1996) and the technological advances taking place in how communications are handled in the workplace, make multitasking an essential and integral competency in the workplace (Ilgen \& Pulakos, 1999). Early attempts by organizational researchers to assess individual differences in multitasking did not investigate the moderating effects of "preference" for multitasking. In study four I demonstrate clearly that multitasking has predictive validity for job performance but such predictive validity is stronger for polychronic individuals.

Results of these studies point to the importance of distinguishing between preference and ability for multitasking. Evidence that these constructs are distinct, and polychronicity moderates the relationship between multitasking ability and performance provide support for the notion that performance can be conceptualized as a function of ability and motivation, with polychronicity serving as a motivational variable. These results have important implications for selection practitioners. It may be appropriate to assess applicants for motivational fit in conjunction with multitasking ability tests when selecting employees to work in a multitasking environment. As this finding is a novel contribution to the existing research focused on time orientation in organizations, more research is needed to further explore the influence of polychronicity on the predictive validity of multitasking assessments.

Polychronicity and multitasking ability demonstrate distinct patterns of correlations with cognitive and non-cognitive variables, and the relationship between polychronicity and multitasking ability is low (.13 in study four). The overlap between these constructs could be influenced by factors such as field dependence. Field dependence is the degree to which individuals are guided by situational cues, as opposed 
to internal knowledge, or the extent to which an individual utilizes internal versus external referents (Witkin \& Goodenough, 1977). Individuals who are field-independent are more skilled in cognitive processing and mental structuring, and individuals who are field-dependent are likely to rely on social cues to shape their attitudes (Witkin \& Goodenough, 1977). For field-dependent individuals, the preference for multitasking (polychronicity) may be influenced by cues in the working environment. Furthermore, one study found working memory to be a critical determinant of field dependence, suggesting that individuals differ in field dependence as a result of variations in the efficiency of cognitive resources (Miyake, Witzki, \& Emerson, 2001). Because multitasking ability is closely related to cognitive ability (Delbridge, 2000; Ishizaka et al., 2001; Kinney et al., 2008; Kinney et al., 2009; Oswald et al., 2007) and working memory (Hambrick et al., 2010; König et al., 2005; Liberman \& Rosenthal, 2001) it is likely that multitasking ability will also be related to field dependence.

An additional practical implication of this study is an analysis of potential predictive bias of both polychronicity and multitasking assessments. To evaluate potential predictive bias, $d$ values were computed for each of the relevant demographic variables (age, gender, and race) and all measures of polychronicity and in study one. As shown in Table 13, predictive bias did not occur in this sample. However, it is important to consider that adverse impact may occur based on the selection ratio. 
Table 13.

d values for Scores on Polychronicity Scales by Age, Gender and Race from Study 1

\begin{tabular}{lccc}
\hline & Age & Gender & Race \\
\hline IPV & -.28 & -.17 & .09 \\
PAI & -.70 & -.15 & .03 \\
MPI & -.56 & -.26 & .12 \\
PMTS & -.97 & -.17 & -.01 \\
\hline
\end{tabular}

Note. Age compares less than 45 years old (1) vs. 45 years and older (2); Gender compares male (1) vs. female (2); Race compares non-Hispanic (1) vs. Hispanic (2).

Consistent with previous research (Delbridge, 2000; Ishizaka et al., 2001; König, et al., 2005; Kinney et al., 2008; Kinney et al., 2009; Oswald et al., 2007) in both study 3 and study 4, cognitive ability was strongly positively related to multitasking ability. In fact, the observed correlation between cognitive ability and multitasking ability was .63 in study three (.43 in study four) and is likely to be higher when corrected for the attenuating effects of unreliability in the two measures. The high correlation between multitasking ability and cognitive ability in studies three and four also raises the intriguing possibility of using multitasking ability tests as a proxy for cognitive ability tests. At a minimum, multitasking ability tests are likely to be more face valid than traditional cognitive ability tests and thus generate more favorable applicant reactions (Hauskencht, Day, \& Thomas, 2004). Chan, Schmitt, DeShon, Clause and Delbridge (1997) found that positive perceptions are likely to reduce group differences in test scores. In fact, Chan \& Schmitt (1997) found that the use of video-based items reduced group differences in a cognitive ability test.

Although multitasking simulations are likely to have lower ethnic group differences compared to traditional cognitive ability tests, the reverse may be true for gender. Gender differences in cognitive ability tests are small (Hyde, 2005) but 
differences have been noted in the use of technology (Kirnan, Farley \& Geisinger, 1989). Thus, it is imperative to assess gender differences in assessments of multitasking ability.

Age is another demographic correlate to consider. The ADEA designates individuals over 40 years of age as a protected group. Differences between younger and older workers in technology use have been documented (Czaja \& Sharit, 1999; Czaja, Charness, Fisk, Hertzog, Nair, Rogers \& Sharit, 2006; Morris \& Venkatesh, 2000) and surveys have found that younger respondents are likely to be more familiar with multitasking. To address this question, I conducted more fine-grained analyses with our data. Specifically, there were 54 older and 96 younger individuals (i.e., using age 40 as the cut point) in study three. The corresponding numbers were 42 and 59 in study four. In study three, multitasking ability had low correlations with multitasking performance and overall job performance (.01 and .05 , respectively) for the older respondents. The corresponding values were .06 and .15 for younger test takers. In study four, multitasking ability correlated .36 and .30 with multitasking performance and overall job performance for the older respondents. The corresponding values were .23 and .02 for younger test takers. Thus, at least in these two samples, age was not a consistent moderator of the predictive validity of multitasking ability-performance relations.

\section{Strengths and Limitations}

Some limitations with the data employed here need to be acknowledged. Although studies three and four utilize organizational data, study one administered multiple measures of polychronicity to a large sample of students as opposed to a working population. There may be differences in work preferences across students and 
employees. Additionally, there was no incentive for performance, and the setting was not representative of the high stakes environment of pre-employment testing.

A small number of studies met the inclusion criteria for study two. Although the results generally revealed the expected relationships, an analysis of potential moderators of the relationships between polychronicity and personality would be beneficial. However, the small number of studies did not allow for a robust test of possible moderators. Some variables that may moderate these relationships include sample (i.e., student versus working population) and the measures of polychronicity used. As more studies are published in this area, future research should investigate these potential moderating relationships.

In both studies three and four, only one measure of multitasking ability was collected. The multitasking simulation used was the same for each of the target jobs, and it is possible that multiple methods of measuring multitasking ability would have provided richer information about the hypothesized relationships. Additionally, in both studies three and four, the measure of multitasking performance was a single item measure. Supervisor ratings of multitasking performance may have been affected by halo bias, thus a more reliable multi-item measure of multitasking performance is desirable for future research. Moreover, assessments of multitasking performance and overall performance were obtained from the same rater (i.e., supervisor). Multi-rater assessments would have lowered the observed correlations of .74 and .77 found in the two studies (Viswesvaran et al., 2005) and resulted in stronger support for our meditational models. In studies 3 and 4, data were collected from an organizational sample of incumbents. In practice, multitasking assessments are used in a selection 
setting to predict future job performance. There may be important differences in applicants and incumbents that could result in a lower predictive validity coefficient when tested on incumbents than the assessments that are tested on actual applicants.

\section{Directions for Future Research}

Future research should further explore the measurement of polychronicity by further examining the factor structure and testing the fakability of measures of this construct in diverse samples including working populations. Information about the fakability of these measures will provide selection practitioners with meaningful information regarding the potential utility of polychronicity assessments in preemployment testing. Given the nature of polychronicity, which originated as a cultural variable, it would be beneficial to replicate the current studies on a heterogeneous, international sample, to determine whether the relationships identified in these studies hold across cultures. Although polychronicity is conceptualized as an individual difference variable in these studies, culture may still influence preferences for work behavior to some extent.

This series of studies examined the nomological networks of polychronicity and multitasking ability, and future research should extend this analysis to include additional variables. Suggestions for expanding the analysis of the nomological networks of polychronicity and multitasking ability include investigating relationships with emotional intelligence, proactivity, self-monitoring, and adaptability. Results of such a study are expected to further differentiate polychronicity and multitasking ability as distinct constructs, as well as provide valuable information about the nature of these constructs through their external correlates. 
Studies three and four assessed the predictive validity of multitasking ability across jobs varying in the requirements for multitasking, although multitasking was identified as a very important competency for successful performance of all jobs. Just as individual preference for multitasking is a moderator of the validity of multitasking, it is likely that job (and organizational) design will be a limiting factor in the predictive validity of multitasking measures. The $\mathrm{O}$ *Net database clearly documents differences across jobs in the speed with which information is to be processed. Required reaction times differ across tasks and organizational design will influence how work is handled (and the necessity for and importance of multitasking). Thus, multiple research studies of the validity of polychronicity and multitasking ability in different contexts will be required.

The dynamicity of the validity of multitasking ability as a predictor should also be considered. Theoretically, it is possible at the initial stages (e.g., transition stage) that individual differences in multitasking ability predict performance but as employees gain experience and learn on the job such performance differences vanish (i.e., the convergence hypothesis). On the contrary, one could also argue that individual differences in multitasking ability will facilitate individuals to gain proficiency in jobs requiring that skill and thereby amplify the performance differences over time (i.e., the divergence hypothesis). In the domain of cognitive ability, Schmidt, Hunter, Outerbridge and Goff (1988) tested these competing hypotheses and found that validities remained constant over five years (See also Schmidt, Hunter \& Outerbridge, 1986). Research is needed to assess individual differences in growth and learning curves over time where multitasking ability is involved. Similarly, an environment demanding multitasking 
behavior may cultivate a preference for engaging in more than one task at a time, such that individuals working in multitasking environments may become more polychronic over time.

\section{Conclusions}

In today's working environment, the ability to multitask is often essential for successful job performance, and time orientation is an important consideration for organizations. Researchers have modeled the dynamic processes involved in the pursuit of multiple goals and how it changes over time (e.g., Vancouver et al., 2010) but have not studied individual differences in the ability and preference for engaging in such multiple tasks (or the interaction between ability and motivation to engage in multiple tasks). This series of studies serves to clarify the factor structure of polychronicity, as well as the nomological networks of polychronicity and multitasking ability. Results converged to support a unidimensional model of polychronicity, with an overarching factor measured by four published polychronicity scales. Results of studies one and two converge to identify extraversion and openness to experience as consistent external correlates of polychronicity.

Data from two organizational samples provides evidence for the predictive validity of multitasking ability and showed that supervisor rating of multitasking performance mediates the relationship between multitasking ability and assessments of overall job performance. Further, the results demonstrated distinct correlational patterns for multitasking ability and polychronicity with cognitive ability and Big Five factors of personality. In fact, the relationship between multitasking and performance was 
moderated by polychronicity, thereby underscoring the need for more nuanced models of multitasking ability, preference for multitasking, and job performance. 


\section{References}

Ackerman, P. L., Schneider, W., \& Wickens, C. D. (1984). Deciding the existence of a time-sharing ability: A combined methodological and theoretical approach. Human Factors, 26, $71-82$.

Altmann, E. M., \& Gray, W. D. (2008). An integrated model of cognitive control in task switching. Psychological Review, 115, $602-639$.

Ancona, D. G., Okhuysen, G. A., \& Perlow, L. A. (2001). Taking time to integrate temporal research. Academy of Management Review, 26, 512 - 529.

Arndt, A., Arnold, T. J., \& Landry, T. D. (2006). The effects of polychromic-orientation upon retail employee satisfaction and turnover. Journal of Retailing, 82, 319-330.

Baron, R. M., \& Kenny, D. A. (1986). The moderator-mediator variable distinction in social psychological research: Conceptual, strategic, and statistical considerations. Journal of Personality and Social Psychology, 51, 1173-1182.

Barrick, M. R., \& Mount, M. K. (1991). The big five personality dimensions and job performance: A meta-analysis. Personnel Psychology, 44, 1 - 26.

Barrick, M. R., Mount, M. K., \& Judge, T. A. (2001). Personality and performance at the beginning of the new millennium: What do we know and where do we go next? International Journal of Selection and Assessment, 9, 9 - 29.

Bluedorn, A. C. \& Jaussi, K. S. (2007). Organizationally relevant dimensions of time across levels of analysis. Multi-Level Issues in Organizations and Time, 6, 187 223.

Bluedorn, A. C., Kalliath, T. J. Strube, M. J., \& Martin, G. D. (1999). Polychronicity and the Inventory of Polychronic Values (IPV): The development of an instrument to measure a fundamental dimension of organizational culture. Journal of Managerial Psychology, 14, 205 - 230.

Bluedorn, A. C., Kaufman, C. F., \& Lane, P. M. (1992). How many things do you like to do at once? An introduction to monochromic and polychromic time. Academy of Management Executive, 6, 17 - 26.

Bond, M. J., \& Feather, N. T. (1988). Some correlates of structure and purpose in the use of time. Journal of Personality and Social Psychology, 55, 321 - 329.

Branscome, T. A., \& Grynovicki, J. O. (2007). An investigation of factors affecting multi-task performance in an immersive. Aberdeen, MD: U.S. Army Research Laboratory. 
Brookings, J. B. (1990). A confirmatory factor analytic study of time haring performance and cognitive abilities. Intelligence, 14, $43-59$.

Brookings, J. B., \& Damos, D. L. (1991). Individual differences in multiple task performance. In D. Damos (Ed.), Multiple task performance (pp. 363 - 386), London: Taylor \& Francis.

Buhner, M., König, C., Pick, M., \& Krumm, S. (2006). Working memory dimensions as differential predictors of the speed and error aspect of multitasking performance. Human Performance, 19, $253-275$.

Calabresi, R., \& Cohen, J. (1968). Personality and time attitudes. Journal of Abnormal Psychology, 73, $431-439$.

Campbell, J. P., Gasser, M. B., \& Oswald, F.L. (1996). The substantive nature of job performance variability. In K. R. Murphy (Ed.), Individual differences and behavior in organizations (pp. 258 - 299). San Francisco: Jossey-Bass.

Chan, D., \& Schmitt, N., (1997). Video-based versus paper and pencil method of assessment in situational judgment tests: Subgroup differences in test performance and face validity perceptions. Journal of Applied Psychology, 82, $143-159$.

Chan, D., Schmitt, N., DeShon, R., Clause, C., \& Delbridge, K. (1997). Reactions to cognitive ability tests: The relationships between race, test performance, face validity perceptions, and test taking motivation. Journal of Applied Psychology, $82,300-310$.

Cohen, A. (2003). Multiple commitments in the workplace: An integrative approach. Mahwah, NJ: Lawrence Erlbaum Associates.

Conte, J. M., \& Gintoft, J. N. (2005). Polychronicity, Big Five Personality Dimensions, and Sales Performance. Human Performance, 18, 427 - 444.

Conte, J. M., \& Jacobs, R. R. (2003). Validity Evidence Linking Polychronicity and Big Five Personality Dimensions to Absence, Lateness, and Supervisory Performance Ratings. Human Performance, 16, $107-129$.

Conte, J. M., Mathieu, J. E., \& Landy, F. J. (1998). The nomological and predictive validity of time urgency. Journal of Organizational Behavior, 19, $1-13$.

Conte, J. M., Rizzuto, T. E., \& Steiner, D. D. (1999). A construct-oriented analysis of individual level polychronicity. Journal of Managerial Psychology, 14, 269 287. 
Czaja, S. J., \& Sharit, J. (1998). Age differences in attitudes towards computers. Journal of Gerontology, 53, 329 - 340.

Czaja, S. J., Charness, N., Fisk, A. D., Hertzog, C., Nair, S. N., Rogers, W. A., \& Sharit, J. (2006). Factors predicting the use of technology: Findings from the center for research and education on aging and technology enhancement (CREATE). Psychol Aging, 21, $333-352$.

Delbridge, K. A. (2000). Individual differences in multi-tasking ability: Exploring a nomological network. Unpublished Dissertation: Michigan State University.

Fogarty, G. (1987). Timesharing in relation to broad ability domains. Intelligence, 11, $207-231$.

Francis-Smythe, J., \& Robertson, I. (1999). Time-related individual differences. Time \& Society, 8, $273-292$.

Girgis, Z. M. (2010). Predicting multitasking performance and understanding the nomological network of polychronicity. Unpublished Thesis: San Diego State University.

Goldberg, L. R. (1990). An alternate "Description of Personality": The Big-Five Factor Structure. Journal of Personality and Social Psychology, 59, 1216-1229.

Goonetilleke, R. S., \& Luximon, Y. (2009). The relationship between monochronicity, polychronicity, and individual characteristics. Human performance Laboratory, Hong Kong University of Science \& Technology. Clear Water Bay: Hong Kong. (http://repository.ust.hk/dspace/bitstream/1783.1/6994/1/ manuscript unmarked.pdf) Internet Web Site.

Gopher, D. (1982). A selective attention test as a predictor of success in flight training. Human Factors, 24, 173 - 183.

Gopher, D., \& Kahneman, D. (1971). Individual differences in attention and the prediction of flight criteria. Perceptual and Motor Skills, 33, 1335 - 1342.

Hall, E.T. (1959), The Silent Language, Anchor Books, New York, NY.

Hall, E.T. (1983), The Dance of Life: The Other Dimension of Time, Anchor Press/Doubleday, Garden City, NY.

Hall, E. T., \& Hall, M. R. (1990). Understanding Cultural Differences, Intercultural Press, Yarmouth, ME. 
Hambrick, D. Z., Oswald, F. L., Darowski, E. S., Rench, T. A., \& Brou, R. (2010). Predictors of multitasking performance in a synthetic work paradigm. Applied Cognitive Psychology, 8, 1149 - 1167.

Hambrick, D. Z., Rench, T. A., Jones, L. A., Oswald, F. L., \& Moon, N. (2007) Relations of Cognitive and Non-Cognitive Variables to Strategy Use in Multitasking. Paper presented at the 22nd annual conference for the Society of Industrial and Organizational Psychology. New York, NY.

Hambrick, D. Z., Rench, T. A, Poposki, E., Darowski, E. S., Roland, D., Bearden, R. M., Oswald, F. L., \& Brou, R. (in press). The relationship between the ASVAB and multitasking: A process specific approach. Military Psychology.

Haase, R. F., Lee, D. Y., \& Banks, D. L. (1979). Cognitive correlates of polychronicity. Perceptual and Motor Skills, 49, 271 - 282.

Hausknecht, J. P., Day, D. V., \& Thomas, S. C. (2004). Applicant reactions to selection procedures: An updated model and meta-analysis. Personnel Psychology, 57, 639 -683 .

Hecht, T. D., \& Allen, N. J. (2005). Exploring links between polychronicity and wellbeing from the perspective of person-job fit: Does it matter if you prefer to do only one thing at a time? Organizational Behavior and Human Decision Processes, 98, $155-178$.

Howard, A. (1996). The changing nature of work. San Francisco: Jossey-Bass.

Hunter, J. E. \& Hunter, R. F. (1984). Validity and utility of alternative predictors of job performance. Psychological Bulletin, 96, 72 - 98.

Hunter, J. E., \& Schmidt, F. L. (2004). Methods of Meta-Analysis: Correcting Error and Bias in Research Synthesis (2nd ed.). Sage.

Hyde, J. S. (2005). The gender similarities hypothesis. American Psychologist, 60, 581 592.

Ilgen, D. R., \& Pulakos, E. D. (1999). Employee performance in today's organizations. In D. R. Ilgen and E. D. Pulakos (Eds.), The changing nature of work performance: Implications for staffing, motivation, and development. San Francisco: JosseyBass.

International Personality Item Pool: A scientific collaboratory for the development of advanced measures of personality traits and other individual differences (http://ipip.ori.org/). Internet Web Site. 
Ishizaka, K., Marshall, S.P., \& Conte, J.M. (2001). Individual differences in attentional strategies in multitasking situations. Human Performance, 14, 339-358.

Jenings, A. E., \& Chiles, W. D. (1977). An investigation of time-sharing ability as a factor in complex performance. Human Factors, 19, 535 - 547.

Judge, T. A., Heller, D., \& Mount, M. K. (2002). Five-Factor Model of Personality and Job Satisfaction: A Meta-Analysis. Journal of Applied Psychology, 87, 530 - 541.

Kantrowitz, T., \& Kinney, T. B. (2009). It's about time: Investigating multitasking and polychronicity in the workplace. Presentation to the Personnel Testing Council of Metropolitan, Washington, D.C.

Kantrowitz, T. M., Grelle, D. M., Beaty, J. C., \& Wolf, M. B. (2012). Time is Money: Polychronicity as a predictor of performance across job levels. Human Performance, 25, $1-24$.

Kaufman, C. F., Lane, P. M., \& Lindquist, J. D. (1991). Exploring more than 24 hours a day: A preliminary investigation of polychronic time use. Journal of Consumer Research, 18, $392-401$.

Kenny, D. A. (2011). Measuring model fit. Retrieved from: http://davidakenny.net/cm/fit.htm.

Kinney, T. B. (2007). Task and individual characteristics as predictors of performance in a job-relevant multi-tasking environment. Unpublished Dissertation: The Pennsylvania State University.

Kinney, T. B., Kung, M., Walvoord, A. G., \& Shoemaker, A. (2010). So much to do, so little time: Multitasking and performance. Paper presented at the 25th Annual Conference for the Society of Industrial and Organizational Psychologists. Atlanta, GA.

Kinney, T. B., Reeder, M., \& O’Connell, M. (2008). Cognitive predictors of performance in an applied multitasking environment. Paper presented at the 23rd Annual Conference for the Society of Industrial and Organizational Psychologists. San Francisco, CA.

Kinney, T. B., Reeder, M., \& O’Connell, M. (2009). Comparing Multitasking and cognitive ability as predictors of job performance. Paper presented at the 24th Annual Conference for the Society of Industrial and Organizational Psychologists. New Orleans, LA. 
Kirnan, J. P., Farley, J. A., \& Geisinger, K. F. (1989). The relationship between recruiting source, applicant quality and hire performance: An analysis by sex, ethnicity, and age. Personnel Psychology, 42, 293 - 308.

König, C. J., Buhner, M., \& Murling, G. (2005). Working memory, fluid intelligence, and attention are predictors of multitasking performance, but polychronicity and extraversion are not. Human Performance, 18, 241 - 266.

König, C. J., Oberlarcher, L., \& Kleinmann, M. (2010). Personal and situational determinants of multitasking at work. Journal of Personnel Psychology, 9, 9 103.

König, C. J., \& Waller, M. J. (2010). Time for reflection: A critical examination of polychronicity. Human Performance, 23, $173-190$.

Landy, F. J. (2005). Some historical and scientific issues related to research on emotional intelligence. Journal of Organizational Behavior, 26, 411 - 424.

Landy, F.J., Rastegary, H., Thayer, J., \& Colvin, C. (1991), Time urgency: the construct and its measurement. Journal of Applied Psychology, 76, 644 - 657.

Lawler, E. E. (1967). The multitrait-multirater approach to measuring managerial job performance. Journal of Applied Psychology, 51, 369 - 381.

Lieberman, M. D., \& Rosenthal, R. (2001). Why Introverts Can't Always Tell Who Likes Them: Multitasking and Nonverbal Decoding. Journal of Personality and Social Psychology, 80, 294-310.

Lindbeck, A., \& Snower, D.J., 2000. Multi-task learning and the reorganization of work. Journal of Labor Economics, 18, 353 - 376.

Lindquist, J. D., \& Kaufman-Scarborough, C. (2007). The Polychronic-Monochronic Tendency Model: PMTS scale development and validation. Time \& Society, 16, $253-285$.

Locke, E. A. (2005). Why emotional intelligence is an invalid concept. Journal of Organizational Behavior, 26, 425 - 431.

Madjar, N. \& Oldham, G. R. (2006). Task rotation and polychronicity: Effects on individuals' creativity. Human Performance, 19, $117-131$.

Maier, N. (1955). Psychology in Industry. (2 ${ }^{\text {nd }}$ edition). Oxford, England: Houghton Mifflin. 
McCrae, R. R., \& Costa, P. T. Jr. (1987). Validation of the Five Factor Model of personality across instruments and observers. Journal of Personality and Social Psychology, 52, $81-90$.

McQueen, E. N. (1917). The distribution of attention. British Journal of Psychology, 11, $207-231$.

Miyake, A., Witzki, A. H., \& Emerson, M. J. (2001). Field dependence-independence from a working memory perspective: A dual-task investigation of the Hidden Figures Test. Memory, 9, $445-457$.

Morgeson F. P., Campion, M. A., Dipboye, R. L., Hollenbeck, J. R., Murphy, K., \& Schmitt, N. (2007). Reconsidering the use of personality tests in personnel selection contexts. Personnel Psychology, 60, 683 - 729.

Morris, M. G., \& Venkatesh, V. (2000). Age differences in technology adoption decisions: Implications for a changing work force. Personnel Psychology, 53, 375 -403 .

Oberlander, E. M. (2008). Understanding and predicting multitasking performance using non-cognitive variables: Addressing issues in past research and developing a new measure of individual polychronicity. Unpublished Thesis: Michigan State University.

Onken, M. H. (1999). Temporal elements of organizational culture and impact on firm performance. Journal of Managerial Psychology, 14, 231 - 243.

Oswald, F. L., Hambrick, D. Z., \& Jones, L. A. (2007). Keeping all the plates spinning: Understanding and predicting multitasking performance. In D. H. Jonassen (Ed.), Learning to solve complex scientific problems.

Palmer, D. K.. \& Schoorman, F. D. (1999). Unpackaging the multiple aspects of time in polychronicity. Journal of Managerial Psychology, 14, 323 - 345.

Persing, D. L. (1999). Managing in polychronic times: Exploring individual creativity performance in intellectually intensive venues. Journal of Managerial Psychology, 14, $358-373$.

Poposki, E. M., \& Oswald, F. L. (2010). The Multitasking Preference Inventory: Toward an improved measure of individual differences in polychronicity. Human Performance, 23, $247-264$.

Poposki, E. M., Oswald, F. L., \& Brou, R. J. (2009a). Development of a new measure of polychronicity. Report No. NPRST-TN-09-5. Navy Personnel Research, Studies, and Technology: Millington, TN. 
Poposki, E. M., Oswald, F. L., \& Chen, H. T. (2009b). Neuroticism negatively affects multitasking performance through state anxiety. Report No. NPRST-TN-09-3. Navy Personnel Research, Studies and Technology: Millington, TN.

Rotundo, M., \& Sackett, P. R. (2002). The relative importance of task, citizenship, and counterproductive performance to global ratings of job performance: A policycapturing approach. Journal of Applied Psychology, 87, 66-80.

Salvucci, D. D., \& Taatgen, N. A. (2008). Threaded Cognition: An integrated theory of concurrent multitasking. Psychological Review, 115, $101-130$.

Salvucci, D. D., \& Taatgen, N. A. (2011). The Multitasking Mind. New York: Oxford University Press.

Schein, E. (1990). Organizational Culture. American Psychologist, 45, 109 - 119.

Schell, K. L., \& Conte, J. M. (2008). Associations among polychronicity, goal orientation, and error orientation. Personality and Individual Differences, 44, 288 $-298$.

Schmidt, F. L., \& Hunter, J. E. (1998). The validity and utility of selection methods in personnel psychology: Practical and theoretical implications of 85 years of research findings. Psychological Bulletin, 124, $262-274$.

Schmidt, F. L., Hunter, J. E., Outerbridge, A. N., \& Goff, S. (1988). Joint relation of experience and ability to job performance: Test of three hypotheses. Journal of Applied Psychology, 73, 46 - 57.

Schmidt, F. L., Hunter, J. E., Outerbridge, A. M., \& Tratrner, M. H. (1986). The economic impact of job selection methods on the size, productivity, and payroll costs of the federal workforce: An empirical demonstration. Personnel Psychology, 39, 1 - 29.

Schriber, J. B., \& Gutek, B. A. (1987). Some time dimensions of work: Measurement of an underlying aspect of organization culture. Journal of Applied Psychology, 72, $642-650$.

Sharp, S. (1899). Individual Psychology: A study in psychological method. The American Journal of Psychology, 10, 329 - 391.

Slocombe, T. E., \& Bluedorn, A. C. (1999). Organizational behavior implications of the congruence between preferred polychronic and experienced work-unit polychronicity. Journal of Organizational Behavior, 20, 75 - 99. 
Souitaris, V., \& Mastero, B. M. (2010). Polychronicity in top management teams: The impact on strategic decision processes and performance of new technology ventures. Strategic Management Journal, 31, 652 - 678.

Stachowski, A. A. (2011). A model of time use at work: Individual differences, time use, and performance. Unpublished Dissertation: George Mason University.

Sverko, B. Jeneic, Z., \& Kulenovic, A. (1983). A contribution to the investigation of time-sharing ability. Ergonomics, 26, 151- 160.

Szymura, B. \& Necka, E. (1998). Visual Selective Attention and Personality: An Experimental Verification of Three Models of Extraversion. Personality and Individual Differences, 24, 713-729.

Taylor, M.S., Locke, E.A., Lee, C., \& Gist, M.E. (1984). Type A behavior and faculty research productivity: what are the mechanisms? Organizational Behavior and Human Performance, 34, $402-418$.

Vancouver, J. B., Weinhardt, J. M., \& Schmidt, A. M. (2010). A formal, computational theory of multi-goal pursuit: Integrating goal-choice and goal striving processes. Journal of Applied Psychology, 95, 985 - 1008.

Van Rooy, D., \& Viswesvaran, C. (2004). Emotional intelligence: A meta-analytic investigation of predictive validity and nomological net. Journal of Vocational Behavior, 65, 71-95.

Viswesvaran, C. (1993). Modeling job performance: Is there a general factor? Unpublished doctoral dissertation, University of Iowa.

Viswesvaran, C., \& Ones, D. S. (2000). Perspectives on models of job performance. International Journal of Selection and Assessment, 8, 216-227.

Viswesvaran, C., Schmidt, F. L., \& Ones, D. S. (2005). Is there a general factor in ratings of job performance? A meta-analytic framework for disentangling substantive and error influences. Journal of Applied Psychology, 90, 108-131.

Vroom, V. H. (1964). Work and motivation. New York: Wiley.

Wickens, C. D. (1991). Processing resources and attention. In D. Damos (Ed.), Multiple task performance (pp. 3 - 33), London: Taylor \& Francis.

Wickens, C. D., Mountford, S. J., \& Schreiner, W. (1981). Multiple resources, taskhemapspheric integrity and individual differences in time sharing. Human Factors, 23, $211-229$. 
Witkin, H. A., \& Goodenough, D. R. (1977). Field dependence and interpersonal behavior. Psychological Bulletin, 84, $661-689$.

Zeigarnik, B. (1927). On finished and unfinished tasks. Psychologische Forschung, 9, 1 15. 


\section{APPENDICES}

\section{Appendix 1}

\section{Incremental Validity}

A series of multiple regressions were conducted to build a model for predicting each of the Big Five from measures of polychronicity, presented in Tables $14-18$. The incremental validity of each scale above and beyond the others was assessed to see if any of the measures offer unique variance in the prediction of personality.

Incremental Validity of IPV. The IPV offered unique incremental validity in predicting only one of the Big Five, agreeableness, $\Delta R^{2}=.011, \mathrm{p}<.01$, whereas the others analyses of incremental validity fell short of statistical significance. Detailed results of additional analyses of the incremental validity of the IPV are provided below.

To test the incremental validity of the IPV in predicting extraversion, demographic controls (age and gender) were entered along with PAI, MPI, and PMTS scale scores in Step 1, $F(5,720)=4,69, p<.01, R^{2}=.032$. As shown in Table 14, none of these variables had significant unique effects, $p<.05$. The IPV was entered in the second step. This predictor did not significantly increase the fit of the model to the data, $F(1,719)=4.47, p>.05, \Delta R^{2}=.004$. In the second step, the MPI was the only significant predictor, $p<.05$.

To test the incremental validity of the IPV in predicting agreeableness, demographic controls (age and gender) were entered along with PAI, MPI, and PMTS scale scores in Step $1, F(5,720)=6.51, p<.01, R^{2}=.043$. As shown in Table 14, only gender had a significant unique effect, $p<.05$. The IPV was entered in the second step. This predictor significantly increased the fit of the model to the data, $F(1,719)=8.04, p$ 
$<.01, \Delta R^{2}=.011$. In the second step, the gender, PMTS, and IPV had significant unique effects, $p<.05$.

To test the incremental validity of the IPV in predicting conscientiousness, demographic controls (age and gender) were entered along with PAI, MPI, and PMTS scale scores in Step $1, F(5,720)=2.90, p<.05, R^{2}=.020$. As shown in Table 14, age and the MPI had significant unique effects, $p<.05$. The IPV was entered in the second step. This predictor did not significantly increase the fit of the model to the data, $F(1$, 719) $=.00, \Delta R^{2}=.000$. In the second step, age and MPI had significant unique effects, $p$ $<.05$.

To test the incremental validity of the IPV in predicting neuroticism, demographic controls (age and gender) were entered along with PAI, MPI, and PMTS scale scores in Step $1, F(5,720)=15.29, p<.01, R^{2}=.090$. As shown in Table 14, age and the MPI had significant unique effects, $p<.05$. The IPV was entered in the second step. This predictor did not significantly increase the fit of the model to the data, $F(1,719)=0.34$, $\Delta R^{2}=.000$. In the second step, age and gender had significant unique effects, $p<.01$.

To test the incremental validity of the IPV in predicting openness to experience, demographic controls (age and gender) were entered along with PAI, MPI, and PMTS scale scores in Step $1, F(5,720)=8.33, p<.01, R^{2}=.055$. As shown in Table 14, gender and PMTS had significant unique effects, $p<.05$. The IPV was entered in the second step. This predictor did not significantly increase the fit of the model to the data, $F(1$, $719)=1.52, \Delta R^{2}=.002$. In the second step, gender, PAI and PMTS had significant unique effects, $p<.05$. 
Table 14. Incremental Validity of IPV

\begin{tabular}{llccccc}
\hline & & Extraversion & Agreeableness & Conscientiousness & Neuroticism & Openness \\
Step & Predictors & $\beta$ & $\beta$ & $\beta$ & $\beta$ & $\beta$ \\
\hline 1 & Age & .00 & .04 & .07 & $-.12^{* *}$ & .02 \\
& Gender & .02 & $.16^{* *}$ & .01 & $.27^{* *}$ & $-.10^{* *}$ \\
& PAI & .01 & .05 & .05 & -.07 & .11 \\
& MPI & .11 & -.05 & -.18 & .02 & -.05 \\
& PMTS & .08 & .11 & .11 & -.01 & $.16^{* *}$ \\
& $R^{2}$ & $.032^{* *}$ & $.043^{* *}$ & $.020^{*}$ & $.096^{* *}$ & \\
& & & & & $.055^{* *}$ \\
\hline 2 & Age & -.01 & .03 & $.07^{*}$ & $-.13^{* *}$ & .01 \\
& Gender & .02 & $.16^{* *}$ & .01 & $.27^{* *}$ & $-.11^{* *}$ \\
& PAI & .04 & .09 & .05 & -.06 & $.12^{*}$ \\
& MPI & $.18^{*}$ & .07 & $-.18^{*}$ & .05 & .00 \\
& PMTS & .10 & $.15^{*}$ & .11 & -.01 & $.18^{* *}$ \\
& IPV & -.13 & $-.21^{* *}$ & .00 & -.04 & -.09 \\
$R^{2}$ & .036 & .054 & .020 & .096 & .057 \\
\hline & & & & & .00 \\
\hline$R^{2}$ & .004 & $.011^{* *}$ & .000 & .000 & .002 \\
\hline
\end{tabular}

Notes. $\mathrm{N}=727-732 . * \mathrm{p}<.05, * * \mathrm{p}<.01$

Incremental Validity of PAI. The PAI offered unique incremental validity in predicting only one of the Big Five, openness to experience, $\Delta \mathrm{R} 2=.005, \mathrm{p}<.05$, whereas the others analyses of incremental validity fell short of statistical significance. Detailed results of additional analyses of the incremental validity of the PAI are provided below.

To test the incremental validity of the PAI in predicting extraversion, demographic controls (age and gender) were entered along with IPV, MPI, and PMTS scale scores in Step 1, $F(5,720)=5.30, p<.01, R^{2}=.051$. As shown in Table 15, gender, IPV and PMTS had significant unique effects, $p<.05$. The PAI was entered in the second step. This predictor did not significantly increase the fit of the model to the data, $F(1,719)=0.39, \Delta R^{2}=.000$. In the second step, MPI had a significant unique effect, $p<.05$. 
To test the incremental validity of the PAI in predicting agreeableness, demographic controls (age and gender) were entered along with IPV, MPI, and PMTS scale scores in Step $1, F(5,720)=7.73, p<.01, R^{2}=.051$. As shown in Table 15, gender, IPV, and PMTS had significant unique effects, $p<.05$. The PAI was entered in the second step. This predictor did not significantly increase the fit of the model to the data, $F(1,719)=2.20, \Delta R^{2}=.003$. In the second step, gender, MPI and PMTS had a significant unique effect, $p<.05$.

To test the incremental validity of the PAI in predicting conscientiousness, demographic controls (age and gender) were entered along with IPV, MPI, and PMTS scale scores in Step $1, F(5,720)=2.77, p<.05, R^{2}=.019$. As shown in Table 15, age, MPI and PMTS had significant unique effects, $p<.05$. The PAI was entered in the second step. This predictor did not significantly increase the fit of the model to the data, $F(1,719)=0.66, \Delta R^{2}=.001$. In the second step, age and MPI had significant unique effects, $p<.05$.

To test the incremental validity of the PAI in predicting neuroticism, demographic controls (age and gender) were entered along with IPV, MPI, and PMTS scale scores in Step $1, F(5,720)=15.16, p<.01, R^{2}=.095$. As shown in Table 15, age, age and gender had significant unique effects, $p<.01$. The PAI was entered in the second step. This predictor did not significantly increase the fit of the model to the data, $F(1,719)=0.05$, $\Delta R^{2}=.001$. In the second step, age and gender had significant unique effects, $p<.01$.

To test the incremental validity of the PAI in predicting openness to experience, demographic controls (age and gender) were entered along with IPV, MPI, and PMTS scale scores in Step 1, $F(5,720)=7.79, p<.01, R^{2}=.051$. As shown in Table 15, gender 
and PMTS had significant unique effects, $p<.01$. The PAI was entered in the second step. This predictor significantly increased the fit of the model to the data, $F(1,719)=$ 4.09, $\Delta R^{2}=.005, \mathrm{p}<.05$. In the second step, gender, PMTS, and PAI had significant unique effects, $p<.05$.

Table 15. Incremental Validity of PAI

\begin{tabular}{llccccc}
\hline & & Extraversion & Agreeableness & Conscientiousness & Neuroticism & Openness \\
Step & Predictors & $\beta$ & $\beta$ & $\beta$ & $\beta$ & $\beta$ \\
\hline 1 & Age & -.01 & .03 & $.08^{*}$ & $-.13^{* *}$ & .01 \\
& Gender & .02 & $.16^{* *}$ & .01 & $.27^{* *}$ & $-.11^{* *}$ \\
& IPV & -.12 & $-.18^{*}$ & .01 & -.06 & -.05 \\
& MPI & $.19^{* *}$ & .09 & $-.17^{* *}$ & .03 & .02 \\
& PMTS & $.11^{*}$ & $.18^{* *}$ & $.12^{*}$ & -.03 & .23 \\
& $R^{2}$ & $.035^{* *}$ & $.051^{* *}$ & $.019^{*}$ & $.089^{* *}$ & $.051^{* *}$ \\
\hline 2 & & & & & .01 \\
& Age & -.01 & .03 & $.07^{*}$ & $-.13^{* *}$ & $.011^{* *}$ \\
& Gender & .02 & $.16^{* *}$ & .01 & $.27^{* *}$ & -.09 \\
& IPV & -.13 & $-.21^{*}$ & .00 & -.04 & .00 \\
& MPI & $.18^{*}$ & .07 & $-.18^{*}$ & .05 & $.18^{* *}$ \\
& PMTS & .10 & $.15^{*}$ & .11 & -.01 & $.12^{*}$ \\
& PAI & .04 & .09 & .05 & -.06 & .057 \\
& $R^{2}$ & .036 & .054 & .020 & .089 & $.005^{*}$ \\
\hline
\end{tabular}

Notes. $\mathrm{N}=727-732 . * \mathrm{p}<.05, * * \mathrm{p}<.01$ 
Incremental Validity of MPI. The MPI offered unique incremental validity in predicting two of the Big Five, extraversion, $\Delta R^{2}=.009, \mathrm{p}<.05$, and conscientiousness, $\Delta R^{2}=.009, \mathrm{p}<.05$, whereas the others analyses of incremental validity fell short of statistical significance. Detailed results of additional analyses of the incremental validity of the MPI are provided below.

To test the incremental validity of the MPI in predicting extraversion, demographic controls (age and gender) were entered along with IPV, PAI, and PMTS scale scores in Step $1, F(5,720)=4.05, p<.01, R^{2}=.027$. As shown in Table 5, PMTS had a significant unique effect, $p<.01$. The MPI was entered in the second step. This predictor significantly increased the fit of the model to the data, $F(1,719)=6.39, \Delta R^{2}=$ $.009, \mathrm{p}<.05$. In the second step, gender, only the MPI had a significant unique effect, $p<$ .05 .

To test the incremental validity of the MPI in predicting agreeableness, demographic controls (age and gender) were entered along with IPV, PAI, and PMTS scale scores in Step $1, F(5,725)=8.00, p<.01, R^{2}=.053$. As shown in Table 16, gender, IPV, and PMTS had a significant unique effect, $p<.01$. The MPI was entered in the second step. This predictor did not significantly increase the fit of the model to the data, $F(1,719)=0.89, \Delta R^{2}=.001, \mathrm{p}>.05$. In the second step, gender, IPV, and PMTS had significant unique effects, $p<.05$.

To test the incremental validity of the MPI in predicting conscientiousness, demographic controls (age and gender) were entered along with IPV, PAI, and PMTS scale scores in Step $1, F(5,720)=1.60, p>.05, R^{2}=.011$. As shown in Table 16, none of the variables had significant unique effects. The MPI was entered in the second step. 
This predictor significantly increased the fit of the model to the data, $F(1,719)=6.45$, $\Delta R^{2}=.009, \mathrm{p}<.05$. In the second step, age and MPI had significant unique effects, $p<$ .05 .

To test the incremental validity of the MPI in predicting neuroticism, demographic controls (age and gender) were entered along with IPV, PAI, and PMTS scale scores in Step $1, F(5,720)=15.27, p<.01, R^{2}=.096$. As shown in Table 16, gender, none of the variables had significant unique effects. The MPI was entered in the second step. This predictor did not significantly increase the fit of the model to the data, $F(1,719)=0.43, \Delta R^{2}=.001$. In the second step, age and gender had significant unique effects, $p<.01$.

To test the incremental validity of the MPI in predicting openness to experience, demographic controls (age and gender) were entered along with IPV, PAI, and PMTS scale scores in Step $1, F(5,720)=8.65, p<.01, R^{2}=.057$. As shown in Table 16, gender, PAI and PMTS had significant unique effects. The MPI was entered in the second step. This predictor did not significantly increase the fit of the model to the data, $F(1,719)=0.003, \Delta R^{2}=.000$. In the second step, gender, PAI and PMTS had significant unique effects, $p<.05$. 
Table 16. Incremental Validity of MPI

\begin{tabular}{llccccc}
\hline & & Extraversion & Agreeableness & Conscientiousness & Neuroticism & Openness \\
Step & Predictors & $\beta$ & $\beta$ & $\beta$ & $\beta$ & $\beta$ \\
\hline 1 & Age & .00 & .03 & .07 & $-.13^{* *}$ & .01 \\
& Gender & .02 & $.16^{* *}$ & .00 & $.27^{* *}$ & $-.11^{* *}$ \\
& IPV & -.03 & $-.17^{* *}$ & -.11 & -.02 & -.09 \\
& PAI & .06 & .10 & .02 & -.05 & $.12^{*}$ \\
& PMTS & $.13^{*}$ & $.16^{* *}$ & .07 & .00 & $.18^{*}$ \\
& $R^{2}$ & $.027^{* *}$ & $.053^{* *}$ & .011 & $.090^{* *}$ & \\
& & & & & $.057^{* *}$ \\
\hline 2 & Age & -.01 & .03 & $.07^{*}$ & $-.13^{* *}$ & .01 \\
& Gender & .02 & $.16^{* *}$ & .01 & $.27^{* *}$ & $-.11^{*}$ \\
& IPV & -.13 & $-.21^{* *}$ & .00 & -.04 & -.09 \\
& PAI & .04 & .09 & .05 & .06 & $.12^{*}$ \\
& PMTS & .10 & $.15^{*}$ & .11 & -.01 & $.18^{*}$ \\
& MPI & $.18^{*}$ & .07 & $-.18^{*}$ & .05 & .00 \\
$R^{2}$ & .036 & .054 & .020 & .089 & .057 \\
\hline & & & .001 & $.009^{*}$ & .001 & .000
\end{tabular}

Notes. $\mathrm{N}=727-732 . * \mathrm{p}<.05, * * \mathrm{p}<.01$

Incremental Validity of PMTS. The PMTS offered unique incremental validity in predicting two of the Big Five, agreeableness, $\Delta R^{2}=.007, \mathrm{p}<.05$, and conscientiousness, $\Delta R^{2}=.012, \mathrm{p}<.05$, whereas the others analyses of incremental validity fell short of statistical significance. Detailed results of additional analyses of the incremental validity of the PMTS are provided below.

To test the incremental validity of the PMTS in predicting extraversion, demographic controls (age and gender) were entered along with IPV, PAI, and MPI scale scores in Step $1, F(5,720)=4.82, p<.01, R^{2}=.032$. As shown in Table 17, gender, MPI had a significant unique effect. The PMTS was entered in the second step. This predictor 
did not significantly increase the fit of the model to the data, $F(1,719)=2.65, \Delta R^{2}=$ .004. In the second step MPI had a significant unique effect, $p<.05$.

To test the incremental validity of the PMTS in predicting agreeableness, demographic controls (age and gender) were entered along with IPV, PAI, and MPI scale scores in Step $1, F(5,720)=6.99, p<.01, R^{2}=.046$. As shown in Table 17, gender, , IPV, and PAI had a significant unique effect. The PMTS was entered in the second step. This predictor did not significantly increase the fit of the model to the data, $F(1,719)=$ $5.68, \Delta R^{2}=.007$. In the second step, gender, IPV, and PMTS had significant unique effects, $p<.05$.

To test the incremental validity of the PMTS in predicting conscientiousness, demographic controls (age and gender) were entered along with IPV, PAI, and MPI scale scores in Step 1, $F(5,720)=2.31, p<.05, R^{2}=.016$. As shown in Table 17, gender, age and MPI had significant unique effects. The PMTS was entered in the second step. This predictor did not significantly increase the fit of the model to the data, $F(1,719)=2.89$, $\Delta R^{2}=.004$. In the second step, age and MPI had significant unique effects, $p<.05$.

To test the incremental validity of the PMTS in predicting neuroticism, demographic controls (age and gender) were entered along with IPV, PAI, and MPI scale scores in Step $1, F(5,720)=15.63, p<.01, R^{2}=.096$. As shown in Table 17, age and gender had significant unique effects. The PMTS was entered in the second step. This predictor did not significantly increase the fit of the model to the data, $F(1,719)=0.01$, $\Delta R^{2}=.000$. In the second step, age and gender had significant unique effects, $p<.01$.

To test the incremental validity of the PMTS in predicting openness to experience, demographic controls (age and gender) were entered along with IPV, PAI, 
and MPI scale scores in Step $1, F(5,720)=6.81, p<.01, R^{2}=.045$. As shown in Table 17, gender and PAI had significant unique effects. The PMTS was entered in the second step. This predictor significantly increased the fit of the model to the data, $F(1,719)=$ 8.77, $\Delta R^{2}=.012$. In the second step, gender, PAI and PMTS had significant unique effects, $p<.05$.

Table 17. Incremental Validity of PMTS

\begin{tabular}{llccccc}
\hline & & Extraversion & Agreeableness & Conscientiousness & Neuroticism & Openness \\
Step & Predictors & $\beta$ & $\beta$ & $\beta$ & $\beta$ & $\beta$ \\
\hline 1 & Age & .00 & .04 & $.08^{*}$ & $-.13^{* *}$ & .02 \\
& Gender & .02 & $.16^{* *}$ & .01 & $.27^{* *}$ & $-.11^{* *}$ \\
& IPV & -.11 & $-.17^{*}$ & .03 & -.04 & -.04 \\
& PAI & .07 & $.15^{*}$ & .09 & -.06 & $.19^{* *}$ \\
& MPI & $.20^{* *}$ & .10 & $-.16^{*}$ & .04 & .04 \\
& $R^{2}$ & $.032^{* *}$ & $.046^{* *}$ & $.016^{*}$ & $.096^{* *}$ & \\
& & & & & $.045^{* *}$ \\
\hline 2 & Age & -.01 & .03 & $.07^{*}$ & $-.13^{* *}$ & .01 \\
& Gender & .02 & $.16^{* *}$ & .01 & $.27^{* *}$ & $-.11^{* *}$ \\
& IPV & -.13 & $-.21^{* *}$ & .00 & -.04 & -.09 \\
& PAI & .04 & .09 & .05 & -.06 & $.12^{*}$ \\
& MPI & $.18^{*}$ & .07 & $-.18^{*}$ & .05 & .00 \\
& PMTS & .10 & $.15^{*}$ & .11 & -.01 & $.18^{* *}$ \\
$R^{2}$ & .036 & .054 & .020 & .096 & .057 \\
\hline$R^{2}$ & .004 & $.007^{*}$ & .004 & .000 & $.012^{* *}$
\end{tabular}

Notes. $\mathrm{N}=727-732 .{ }^{*} \mathrm{p}<.05, * * \mathrm{p}<.01$ 
Incremental Validity of the IPV, PAI and PMTS over MPI. Because the IPV, PAI, and MPI focus on the measurement of two factors of polychronicity (the preference for engaging in multiple tasks at the same time and the belief that it is the best way to get things done) whereas the MPI is based on the definition of polychronicity as only the a single factor (preference), it is expected that the IPV, PAI, and PMTS will together contribute significant incremental validity in the prediction of each of the Big Five above and beyond the effects of the MPI alone. The IPV, PAI, and PMTS offered unique incremental validity in predicting two of the Big Five, agreeableness, $\Delta R^{2}=.019, \mathrm{p}<.01$, and openness to experience, $\Delta R^{2}=.027, \mathrm{p}<.01$, whereas the others analyses of incremental validity fell short of statistical significance. Detailed results of additional analyses of the incremental validity of the IPV, PAI, and PMTS over the MPI are provided below.

To test the incremental validity of these three scales (IPV, PAI and PMTS) in predicting extraversion, demographic controls (age and gender) were entered along with MPI scale scores in Step $1, F(3,722)=7.07, p<.01, R^{2}=.029$. As shown in Table 18, MPI had a significant unique effect. The IPV, PAI and PMTS were entered in the second step. These predictors did not significantly increase the fit of the model to the data, $F(3$, $719)=1.83, \Delta R^{2}=.007$. In the second step, gender, only the MPI had a significant unique effect, $p<.05$.

To test the incremental validity of these three scales (IPV, PAI and PMTS) in predicting agreeableness, demographic controls (age and gender) were entered along with MPI scale scores in Step $1, F(3,722)=8.61, p<.01, R^{2}=.035$. As shown in Table 18 , gender had a significant unique effect. The IPV, PAI and PMTS were entered in the 
second step. These predictors significantly increased the fit of the model to the data, $F(3$, $719)=4.88, \Delta R^{2}=.019, p<.01$. In the second step, gender, IPV and PMTS had significant unique effects, $p<.05$.

To test the incremental validity of these three scales (IPV, PAI and PMTS) in predicting conscientiousness, demographic controls (age and gender) were entered along with MPI scale scores in Step $1, F(3,722)=2.70, p<.05, R^{2}=.011$. As shown in Table 18, age had a significant unique effect. The IPV, PAI and PMTS were entered in the second step. These predictors did not significantly increase the fit of the model to the data, $F(3,719)=2.12, \Delta R^{2}=.009$. In the second step, age and MPI had significant unique effects, $p<.05$.

To test the incremental validity of these three scales (IPV, PAI and PMTS) in predicting neuroticism, demographic controls (age and gender) were entered along with MPI scale scores in Step $1, F(3,722)=24.78, p<.01, R^{2}=.093$. As shown in Table 18, age and gender had significant unique effects. The IPV, PAI and PMTS were entered in the second step. These predictors did not significantly increase the fit of the model to the data, $F(3,719)=0.81, \Delta R^{2}=.003$. In the second step, age and gender had significant unique effects, $p<.05$.

To test the incremental validity of these three scales (IPV, PAI and PMTS) in predicting openness to experience, demographic controls (age and gender) were entered along with MPI scale scores in Step $1, F(3,722)=7.30, p<.01, R^{2}=.029$. As shown in Table 18, gender and MPI had significant unique effects. The IPV, PAI and PMTS were entered in the second step. These predictors significantly increased the fit of the model to 
the data, $F(3,719)=6.92, \Delta R^{2}=.027, p<.01$. In the second step, gender, PAI and PMTS had significant unique effects, $p<.05$.

Table 18. Incremental Validity of IPV, PAI and PMTS over MPI

\begin{tabular}{|c|c|c|c|c|c|c|}
\hline & & Extraversion & Agreeableness & Conscientiousness & Neuroticism & Openness \\
\hline Step & Predictors & $\beta$ & $\beta$ & $\beta$ & $\beta$ & $\beta$ \\
\hline \multirow[t]{4}{*}{1} & Age & .01 & .05 & $.08 *$ & $-.13 * *$ & .03 \\
\hline & Gender & .02 & $.16^{* *}$ & .01 & $.27 * *$ & $-.11 * *$ \\
\hline & MPI & $.17 * *$ & .06 & -.07 & -.04 & $.14 * *$ \\
\hline & $R^{2}$ & $.029 * *$ & $.035 * *$ & $.011 *$ & $.093 * *$ & $.029 * *$ \\
\hline \multirow[t]{7}{*}{2} & Age & -.01 & .03 & $.07 *$ & $-.13 * *$ & .01 \\
\hline & Gender & .02 & $.16^{* *}$ & .01 & $.27 * *$ & $-.11 * *$ \\
\hline & MPI & $.18^{*}$ & .07 & $-.18 *$ & .05 & .00 \\
\hline & IPV & -.13 & $-.21 * *$ & .00 & -.04 & -.09 \\
\hline & PAI & .04 & .09 & .05 & -.06 & $.12 *$ \\
\hline & PMTS & .10 & $.15^{*}$ & .11 & -.01 & $.18 * *$ \\
\hline & $R^{2}$ & .036 & .054 & .020 & .096 & .057 \\
\hline & $\Delta R^{2}$ & .007 & $.019 * *$ & .009 & .003 & $.027 * *$ \\
\hline
\end{tabular}

Notes. $\mathrm{N}=727-732 . * \mathrm{p}<.05, * * \mathrm{p}<.01$

In summary, each of the measures are highly correlated with each other, and predict little unique incremental variance in the prediction of personality. 


\section{Appendix 2}

\section{IPV Preference}

\begin{tabular}{cl}
\hline Item \# & Item \\
\hline 1 & $\begin{array}{l}\text { I like to juggle several activities at the same time. } \\
2\end{array}$ \\
$\begin{array}{l}\text { I would rather complete an entire project every day than complete } \\
\text { parts of several projects. }\end{array}$ \\
4 & $\begin{array}{l}\text { When I work by myself, I usually work on one project at a time. } \\
5\end{array}$ \\
9 & $\begin{array}{l}\text { I prefer to do one thing at a time. } \\
\text { Ihe same time. }\end{array}$ \\
10 & $\begin{array}{l}\text { I would rather complete parts of several projects every day than } \\
\text { complete an entire project. }\end{array}$
\end{tabular}

IPV Belief

Item \# Item

$3 \quad$ I believe people should try to do many things at once.

$6 \quad$ I believe people do their best work when they have many tasks to complete.

$7 \quad$ I believe it is best to complete one task before beginning another.

8 I believe it is best for people to be given several tasks and assignments to perform.

\section{PAI Preference}

Item \# Item

$1 \quad$ I do not like to juggle several activities at the same time.

3 When I sit down at my desk, I work on one project at a time.

4 I am comfortable doing several things at the same time.

PAI Belief

\begin{tabular}{cl}
\hline Item \# & Item \\
\hline 2 & People should not try to do many things at once.
\end{tabular}

PMTS Preference

\begin{tabular}{ll}
\hline Item \# & Item \\
\hline 1 & I prefer to do two or more activities at the same time. \\
2 & I typically do two or more activities at the same time. \\
4 & I am comfortable doing more than one activity at the same time. \\
5 & I like to juggle two or more activities at the same time. \\
PMTS Belief \\
\hline Item \# & Item \\
\hline 3 & $\begin{array}{l}\text { Doing two or more activities at the same time is the most efficient } \\
\text { way to use my time. }\end{array}$
\end{tabular}


VITA

\section{KRISTIN RUTH SANDERSON}

Born, Hollywood, Florida

M.A. $\quad$ East Carolina University, 2007 - 2009

Greenville, NC

B.S. $\quad$ Furman University, 2000 - 2004

Greenville, SC

\section{PUBLICATIONS AND PRESENTATIONS}

Sanderson, K. R., Drew, E. N., Bruk-Lee, V., Levine, P., \& Wrenn, K. (2012). For your eyes only? Reactions to Internet based multimedia SJTs. Presented at the $27^{\text {th }}$ Annual Conference of the Society for Industrial and Organizational Psychology, San Diego, CA.

Sanderson, K. R., Bruk-Lee, V., Viswesvaran, C., Kantrowitz, T., \& Gutierrez, S. (2012). Multitasking and job performance: Investigating incremental validity over traditional predictors. Presented at the $27^{\text {th }}$ Annual Conference of the Society for Industrial and Organizational Psychology, San Diego, CA.

Sanderson, K. R., Viswesvaran, C., \& Pace, V. L. (2011). Unproctored Internet Testing (UIT) practices: Fair and effective? The Industrial-Organizational Psychologist, 48, 29 38.

Sanderson, K. R., Viswesvaran, C., \& Pace, V. L. (2011). Catch me if you can! Cheating in unproctored Internet testing. Presented at the $26^{\text {th }}$ Annual Conference of the Society for Industrial and Organizational Psychology, Chicago, IL.

Sanderson, K. R., Viswesvaran, C., \& Pace, V. L. (2011). Test me once, I'm ok; Test me again, I'm gone? Presented at the $119^{\text {th }}$ Annual Conference of the American Psychological Association, Washington, DC.

Drew, E. N., Reaves, A., \& Sanderson, K. R. (2011). Graduate program retention: Do we practice what we preach? Presented at the $26^{\text {th }}$ Annual Conference of the Society for Industrial and Organizational Psychology, Chicago, IL.

Sanderson, K. R., \& Aziz, S. (2010). Exploring the relationship between burnout and affective personality. Presented at the $25^{\text {th }}$ Annual Conference of the Society for Industrial and Organizational Psychology, Atlanta, GA. 


\section{HONORS AND AWARDS}

\section{SIOP Scholar}

Society for Industrial and Organizational Psychology, 2012

Mary L. Tenopyr Graduate Student Scholarship

Society for Industrial and Organizational Psychology, 2012

Fraser Industrial/Organizational Psychology Graduate Student Award

Florida International University, 2011

Willis Industrial/Organizational Psychology Graduate Student Fellowship

East Carolina University, 2008 